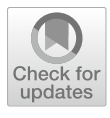

Cite as

Nano-Micro Lett.

(2021) 13:129

Received: 31 January 2021

Accepted: 21 March 2021

Published online: 17 May 2021

(C) The Author(s) 2021

\section{Recent Developments of Transition Metal Compounds-Carbon Hybrid Electrodes for High Energy/Power Supercapacitors}

\author{
Kang Ren ${ }^{1}$, Zheng Liu ${ }^{1}{ }^{凶}$, Tong Wei ${ }^{1}$, Zhuangjun Fan ${ }^{1} \bowtie$
}

\title{
HIGHLIGHTS
}

- The development of transition metal compounds-carbon hybrid electrodes for high energy/power supercapacitors is summarized.

- Effects of the conductive carbon skeleton, interfacial engineering, and electronic structure for transition metal compounds-carbon hybrid are discussed.

- Some perspectives and issues in the future are provided.

ABSTRACT Due to their rapid power delivery, fast charging, and long cycle life, supercapacitors have become an important energy storage technology recently. However, to meet the continuously increasing demands in the fields of portable electronics, transportation, and future robotic technologies, supercapacitors with higher energy densities without sacrificing high power densities and cycle stabilities are still challenged. Transition metal compounds (TMCs) possessing high theoretical capacitance are always used as electrode materials to improve the energy densities of supercapacitors. However, the power densities and cycle lives of such TMCs-based electrodes are still inferior due to their low intrinsic conductivity and large volume expansion during the charge/discharge process, which greatly impede their large-scale applications. Most recently, the ideal integrating of TMCs and conductive carbon skeletons is considered as an effective solution to solve the above challenges. Herein, we summarize the recent developments of TMCs/carbon hybrid electrodes which exhibit both high energy/power densities from the aspects of structural design strategies, including conductive carbon skel-

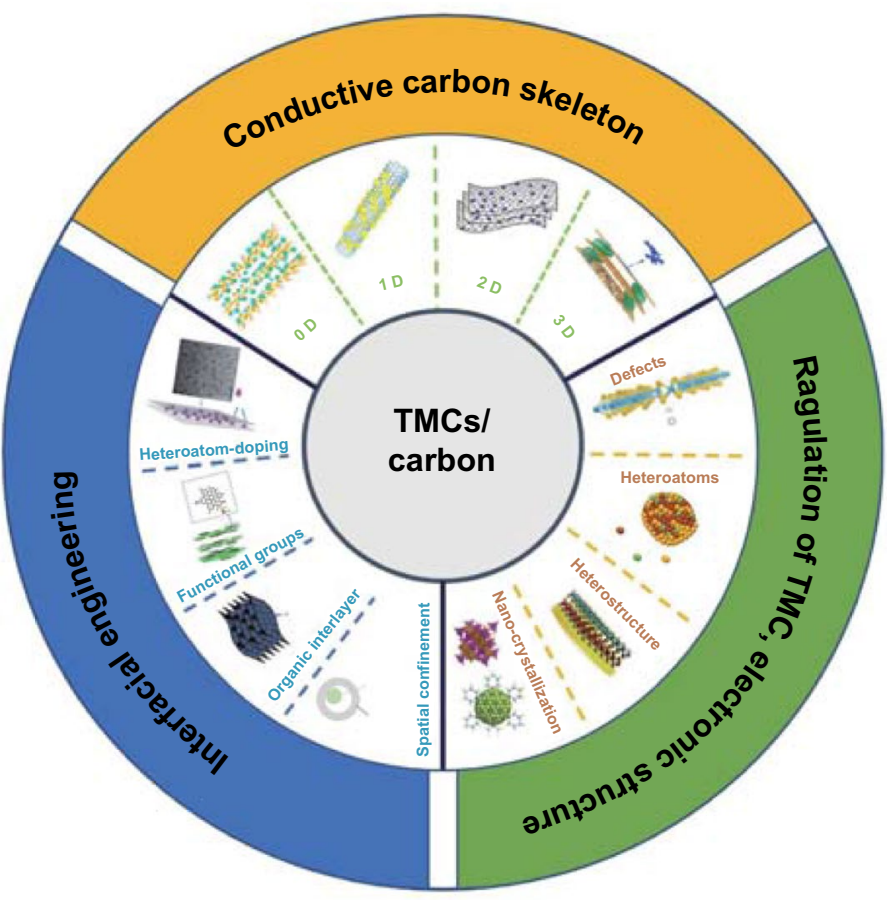
eton, interface engineering, and electronic structure. Furthermore, the remaining challenges and future perspectives are also highlighted so as to provide strategies for the high energy/power TMCs/ carbon-based supercapacitors.

Zheng Liu, liuzhengbeyond@163.com; Zhuangjun Fan, fanzhj666@163.com

1 State Key Laboratory of Heavy Oil Processing, School of Materials Science and Engineering, China University of Petroleum (East China),

Qingdao 266580, People's Republic of China 
KEYWORDS TMCs/carbon hybrid; Supercapacitors; High power density; Carbon skeleton; Interfacial engineering; Transition metal electronic structure

\section{Introduction}

In recent years, the intense consumption of fossil energy and environmental pollution has brought great challenges to the survival and development of human beings. Therefore, searching for clean and sustainable energy sources has become one of the most important topics [1-4]. Especially for intermittent energy storage, such as wind energy, tidal energy, and solar energy, new technologies suited for both high energy density and power density are urgently needed [4-6]. Electrochemical capacitors commonly refer to as supercapacitors, which offer high power density, superior rate performance, and excellent cycle stability [7], have become a prime candidate for the high power applications that require fast on-off response such as hybrid electric vehicles, grid stabilization systems, forklifts, load cranes, aerospace equipment, and military weapons [6, 8]. Current commercial supercapacitors are mainly based on carbon materials, which store/release electrical charges through the physical adsorption/desorption of charges or electrolyte ions on the electrode surface, also called electrochemical double layer capacitors (EDLCs) [9]. Compared with commercial batteries $\left(>100 \mathrm{Wh} \mathrm{kg}^{-1}\right)$, the energy densities of EDLCs (less than $10 \mathrm{Wh} \mathrm{kg}^{-1}$ ) are still low, which have become a great challenge for the large-scale application and further popularization of supercapacitors $[10,11]$. To address the issue, the development of alternative electrode materials with higher specific capacitance is extremely urgent.

Transition metal compounds (TMCs), such as metal oxides, hydroxides, sulfides, and phosphides, have attracted great attention due to their high theoretical capacitance [12, 13], abundant sources, and low cost, etc. [14-16]. In this case, the studies of TMC-based supercapacitors are rising up due to their obviously enlarged energy densities (approaching $10^{2} \mathrm{Wh} \mathrm{kg}^{-1}$ ) [3]. The energy storage mechanisms of TMC-based electrodes primarily involve the electron transfer in the process of redox reactions and valence state changes of transition metal ions, indicating that the ion diffusion rate and phase transformation due to the change of valence state are important for electrochemical properties. Such transformation generally leads to the sluggish bulk phase reaction and dramatic volumetric expansion/shrinkage during the energy storage process and finally resulting in the low chemical reaction kinetics and inferior cycle stabilities of TMC-based supercapacitors. Since rapid charge/ discharge capability and long cycling stability of minimum 10,000 cycles are key criteria for supercapacitors, the poor electrical conductivity, low power density, unsatisfactory mechanical/electrochemical stability, and some other problems, still limit their prospects of TMCs for large-scaled applications [17].

Due to the superior electric conductivity, large specific surface area, low cost, and structural controllability, carbon materials, such as graphene quantum dots, carbon nanotubes, graphene, porous carbon, etc., have been widely researched for energy storage and conversion [7, 18, 19]. Therefore, combining with various dimensional carbon skeletons can not only improve the intrinsic low conductivity, but also modify the morphology of transition metal crystals, which is beneficial for the enhancement of reaction kinetics, fast charging/discharging rate, and cycling stability of TMCs/ carbon composites [20]. Although a large number of studies have been done for TMCs/carbon composites, the physical mixture or simple combination of transition metal derivative particles with carbon skeletons still faces some inevitable challenges, such as huge volume expansion/shrinkage during ultra-long charge/discharge process, or even breaking down of electrochemically active materials from carbon surface due to the vulnerable TMCs/carbon interfaces.

Recently, TMCs with nanoscale dimensions, especially quantum dot morphology, have aroused enormous attention in various applications because of their attractive intrinsic characteristics, such as small size effect, quantum tunneling effect, coulomb blockade effect, and surface effect [21-23]. Compared with bulk materials, the combination of nanoscale TMCs and carbon skeletons can provide improved electrochemical performance, which is beneficial for the construction of fast ions transport [24, 25]. In addition to nano-crystallization, the rational modification of TMCs crystals, such as the introduction of lattice defects, heterostructure, metal heteroatoms, etc., can also certainly enhance the redox reaction kinetics through decreasing reaction energy or shortening the ions diffusion paths [16]. However, nanoscale TMCs, which show high surface area/energy and large amounts of surface 
electrons, unavoidably aggregate during the long-times charge/ discharge process. Therefore, how to keep the uniform dispersion and stable presence of nanoscale TMCs is another vital challenge that needs to be urgently solved. The construction of interfacial adhesion between TMCs and carbon skeletons may be an effective strategy to promote the uniform and stable dispersion of nanoscale-TMCs on the carbon surface. While it is crucial to systematically understand the design principles from the aspects of carbon skeletons, TMC's electronic structure, and interfaces for TMCs/carbon composites, there is a lack of review that dedicates to the up-to-date reports for boosting the power/energy densities and cycling stabilities of TMCs/carbon-based supercapacitors.

Though TMCs/carbon composites have drawn tremendous attention for supercapacitors, the deeper research about the energy storage process and attenuation mechanisms has not yet been clearly understood. In addition, the systematic discussion about the relationship between structural design strategies, high power/energy densities, and fast pseudocapacitive reaction kinetics is critical for the practical and large-scale application of TMCs/carbon hybrid electrodes. In this review, we mainly focus on the latest advances in the field of TMCs/ carbon hybrid electrodes for supercapacitors, including the construction of conductive carbon skeletons, modification of TMCs/carbon interface engineering, and regulation of electronic structures of TMCs (Fig. 1). More importantly, we propose the challenges and perspectives of developing such TMCs/carbon composites, along with the possible strategies and research directions in the future.

\section{Conductive Carbon Skeletons}

The high power densities of TMC-based electrodes are commonly restricted due to their poor intrinsic conductivity and sluggish redox reaction kinetics. To solve these challenges, TMCs are usually composited with carbon skeletons, which can not only construct effective electrons/ions transfer channels, but also sustain the structural stability of the entire electrode. In recent years, carbon skeletons with various dimensions $(0,1,2$, or $3 \mathrm{D})$ have been successfully designed and introduced into the TMCs composite [23, 26-28] (Fig. 2). In this section, we will discuss the application of carbon materials as conductive skeletons in designing and fabricating TMCs/carbon hybrid electrodes from the aspect of carbon structures with different dimensions. Table 1 summarizes the

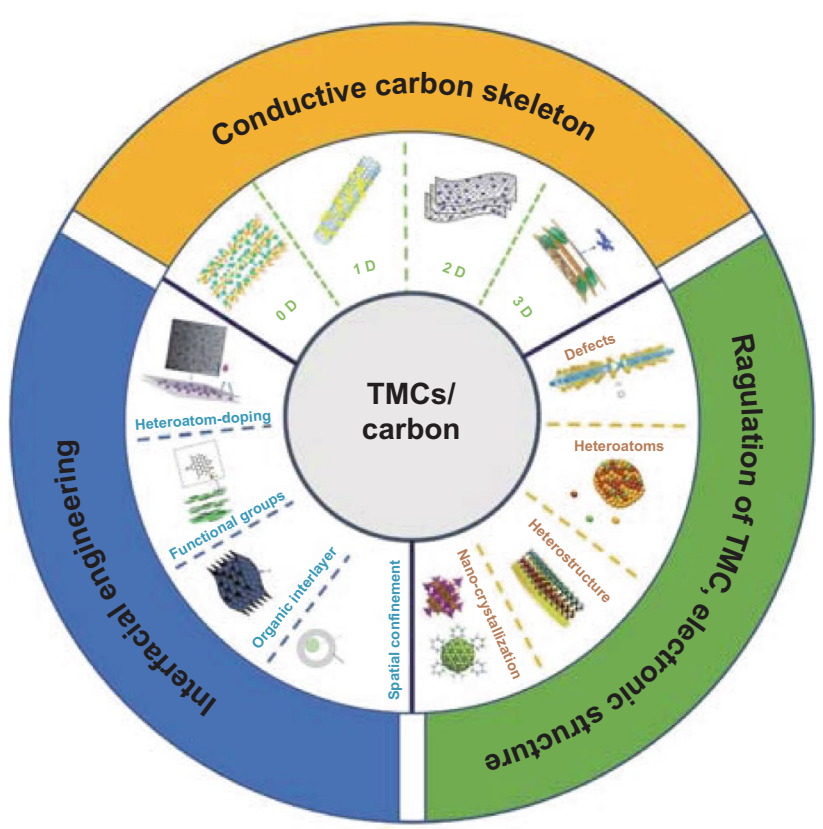

Fig. 1 Schematic illustration of strategies of TMCs/carbon hybrid electrodes

electrochemical performance of TMCs/carbon hybrid electrodes for supercapacitors in recent years.

\subsection{D Carbons (Carbon or Graphene Quantum Dots)}

OD carbon materials, such as carbon quantum dots (CQDs) or graphene quantum dots (GQDs), have been diffusely studied in supercapacitors due to their small size effect, quantum tunneling effect, coulomb blockade effect, and surface effect, endowing such carbons with high electrons mobility, huge specific surface area, etc. [26, 46, 47]. In this case, TMCs combined with OD carbon materials have emerged as promising materials for supercapacitors. For example, the reduced carbon quantum dots (RCQDs) were successfully embedded into the $\mathrm{RuO}_{2}$ nanoparticles $\left(\mathrm{RCQDs} / \mathrm{RuO}_{2}\right.$ ) through a facile impregnation method (As shown in Fig. 3a) [48]. The hybrid network constructed by $\mathrm{RCQDs} / \mathrm{RuO}_{2}$ can provide rapid electronic transport and ionic migration paths. The RCQDs incorporated into the integral structure can effectively prevent the further agglomeration of $\mathrm{RuO}_{2}$ nanoparticles and vastly facilitate the fast ions/electrons transfer during charge-discharge processes (Fig. 3a), and keep the structural stability. As a result, the RCQDs $/ \mathrm{RuO}_{2}$ electrode exhibited high specific 

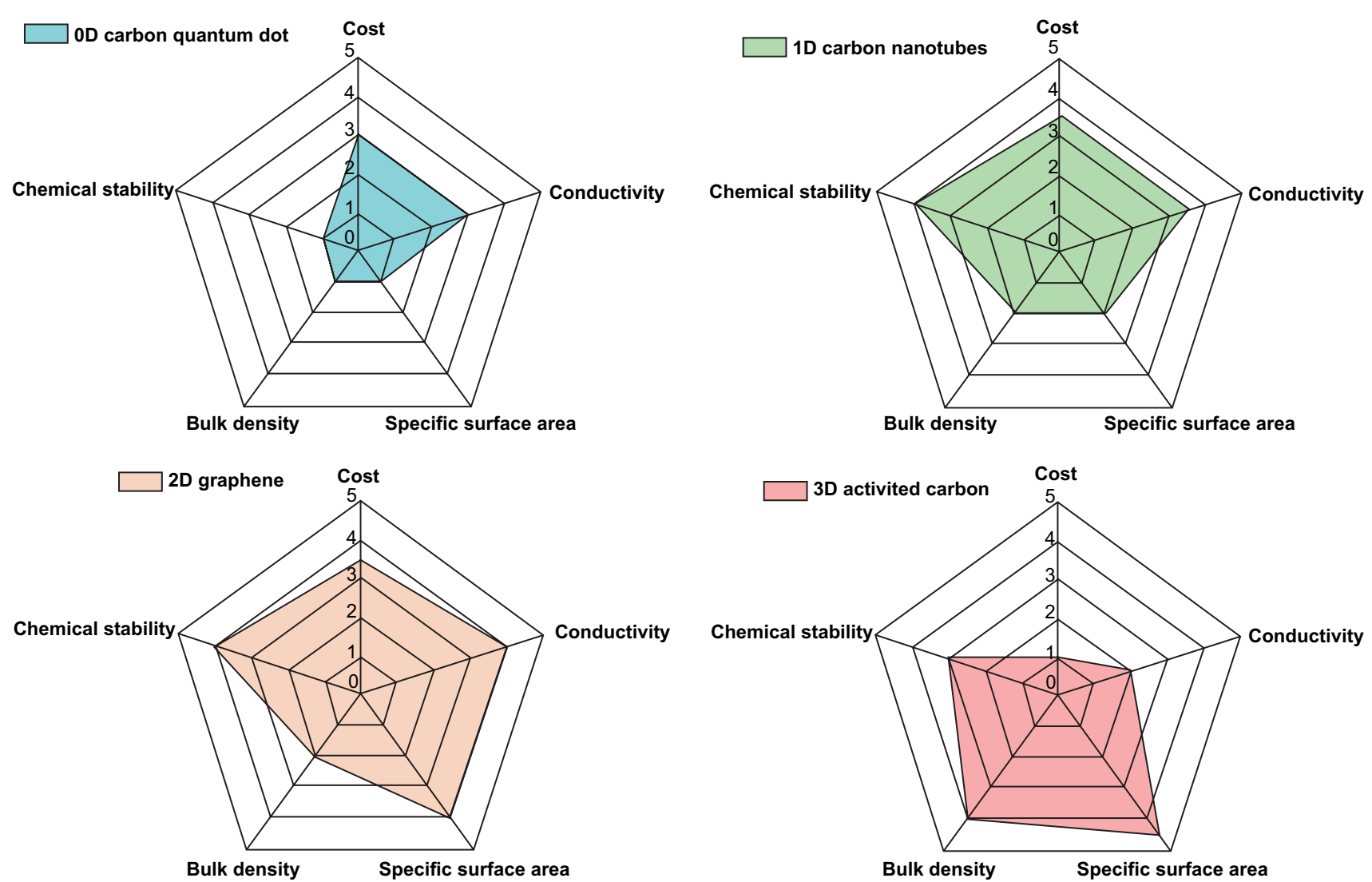

Fig. 2 Comparison of the physicochemical properties of different dimensions carbon

capacitance $\left(594 \mathrm{~F} \mathrm{~g}^{-1}\right.$ ) and superior rate capability (77.4\% capacity retention at $50 \mathrm{~A} \mathrm{~g}^{-1}$ compared to that at $1 \mathrm{~A} \mathrm{~g}^{-1}$ ). Moreover, the capacitance of RCQDs/RuO 2 remained $96.9 \%$ after 5000 cycles at $5 \mathrm{~A} \mathrm{~g}^{-1}$, which was much higher than the $\mathrm{RuO}_{2}$ electrode (the rate capability and capacity retention of corresponding was only $58.3 \%$ and $73.9 \%$, respectively).

GQDs were also introduced into the $\mathrm{MnO}_{2}$ nanoparticles $\left(\mathrm{GQDs} / \mathrm{MnO}_{2}\right)$ through the hydrothermal and plasma-enhanced chemical vapor deposition process [32]. By controlling the deposition time, a series of GQDs/ $\mathrm{MnO}_{2}$ composites were obtained, and the GQDs (the size of 2-3 nm) were well dispersed on the surfaces of $\mathrm{MnO}_{2}$ sheets. Benefiting from the high conductivity and rich active sites of GQDs (Fig. 3b), the maximum specific capacitance of GQDs/ $\mathrm{MnO}_{2}-3$ (3 represents the mass ratio of $\mathrm{MnO}_{2} /$ GQDs) can reach to $1170 \mathrm{~F} \mathrm{~g}^{-1}$ at $5 \mathrm{mV} \mathrm{s}^{-1}$ and excellent cycle performance can be achieved $(92.7 \%$ retention after 10,000 cycles). More importantly, as demonstrated in asymmetric supercapacitors (ASCs) using GQDs/ $\mathrm{MnO}_{2}-3$ and nitrogen-doped graphene as anode and cathode, respectively, the superior energy density of $79 \mathrm{Wh} \mathrm{kg}^{-1}$ at an ultrahigh power density of $12,351 \mathrm{~W} \mathrm{~kg}^{-1}$ can be obtained in an aqueous electrolyte with ultrawide voltage window $(2.3 \mathrm{~V})$. In addition, the GQDs embed to $\mathrm{V}_{2} \mathrm{O}_{5}$ interlayer, constructing VNS-GQDs positive electrode composite material was recently reported by Ganganboina and co-workers via a solvothermal treatment process [33]. Due to the high conductivity of graphene quantum dots, the VNS-GQDs exhibited an ultra-high specific capacitance of $572 \mathrm{~F} \mathrm{~g}^{-1}$ at $1 \mathrm{~A} \mathrm{~g}^{-1}$, which could keep $92 \%$ retention after 10,000 charge-discharge cycles, much higher than that of VNS $\left(227 \mathrm{~F} \mathrm{~g}^{-1}\right)$. Due to the synergistic effect of GQDs and VNS nanosheets, the assembled asymmetric device (VNS-GQDs//MCS) demonstrated a superior energy density of $20.62 \mathrm{Wh} \mathrm{kg}^{-1}$ at the superhigh power density of $14.86 \mathrm{~kW} \mathrm{~kg}^{-1}$.

In addition to the metal oxides, other transition metal derivatives, such as metal hydroxides/sulfides, can also be decorated by GQDs. For example, the CQDs/Ni $(\mathrm{OH})_{2}$ with a lamellar structure was prepared by Wei and co-workers 
Table 1 Different dimensional carbon based electrode materials

\begin{tabular}{|c|c|c|c|c|c|c|c|}
\hline $\begin{array}{l}\text { Electrode mate- } \\
\text { rial }\end{array}$ & $\begin{array}{l}\text { Conductive } \\
\text { skeleton }\end{array}$ & Electrolyte & $\begin{array}{l}\text { Specific/volumet- } \\
\text { ric capacity }\end{array}$ & $\begin{array}{l}\text { Theoretical } \\
\text { capacity of } \\
\text { TMCs }\end{array}$ & Rate performance & Cycling life & References \\
\hline $\mathrm{NiCo}_{2} \mathrm{O}_{4} / \mathrm{CQDs}$ & CQDs (0D) & $2 \mathrm{M} \mathrm{KOH}$ & $\begin{array}{l}856 \mathrm{~F} \mathrm{~g}^{-1} \text { at } \\
1 \mathrm{~A} \mathrm{~g}^{-1}\end{array}$ & $>3000 \mathrm{~F} \mathrm{~g}^{-1}$ & $\begin{array}{l}520 \mathrm{~F} \mathrm{~g}^{-1} \text { at } \\
100 \mathrm{~A} \mathrm{~g}^{-1}\end{array}$ & $\begin{array}{l}98.75 \% \text { after } \\
10,000 \text { cycles at } \\
5 \mathrm{~A} \mathrm{~g}^{-1}\end{array}$ & [29] \\
\hline $\mathrm{MnO}_{2} / \mathrm{CQDs}$ & CQDs (0D) & $1 \mathrm{M} \mathrm{Na}_{2} \mathrm{SO}_{4}$ & $\begin{array}{c}340 \mathrm{~F} \mathrm{~g}^{-1} \text { at } \\
1 \mathrm{~A} \mathrm{~g}^{-1}\end{array}$ & $1100 \mathrm{Fg}^{-1}$ & $\begin{array}{l}260 \mathrm{Fg}^{-1} \text { at } \\
20 \mathrm{Ag}^{-1}\end{array}$ & $\begin{array}{l}80.1 \% \text { after } \\
10,000 \text { cycles at } \\
1 \mathrm{~A} \mathrm{~g}^{-1}\end{array}$ & {$[30]$} \\
\hline $\mathrm{Ni}(\mathrm{OH})_{2} / \mathrm{CQDs}$ & CQDs (0D) & $2 \mathrm{M} \mathrm{KOH}$ & $\begin{array}{c}2900 \mathrm{~F} \mathrm{~g} \mathrm{~g}^{-1} \text { at } \\
1 \mathrm{~A} \mathrm{~g}^{-1}\end{array}$ & $2082 \mathrm{~F} \mathrm{~g}^{-1}$ & $\begin{array}{l}2051 \mathrm{~F} \mathrm{~g}^{-1} \text { at } \\
10 \mathrm{~A} \mathrm{~g}^{-1}\end{array}$ & - & {$[31]$} \\
\hline $\mathrm{MnO}_{2} / \mathrm{GQDs}$ & GQDs (0D) & $1 \mathrm{M} \mathrm{Na}_{2} \mathrm{SO}_{4}$ & $\begin{array}{l}1170 \mathrm{~F} \mathrm{~g} \mathrm{~g}^{-1} \text { at } \\
5 \mathrm{mV} \mathrm{s}^{-1}\end{array}$ & $1100 \mathrm{Fg}^{-1}$ & - & $\begin{array}{l}92.7 \% \text { after } 10,000 \\
\text { cycles }\end{array}$ & {$[32]$} \\
\hline $\mathrm{V}_{2} \mathrm{O}_{5} / \mathrm{GQDs}$ & GQDs (0D) & $0.1 \mathrm{M} \mathrm{H}_{2} \mathrm{SO}_{4}$ & $\begin{array}{c}572 \mathrm{~F} \mathrm{~g}^{-1} \text { at } \\
1 \mathrm{~A} \mathrm{~g}^{-1}\end{array}$ & $2122 \mathrm{~F} \mathrm{~g}^{-1}$ & $\begin{array}{c}346 \mathrm{~F} \mathrm{~g}^{-1} \text { at } \\
20 \mathrm{~A} \mathrm{~g}^{-1}\end{array}$ & $\begin{array}{l}92 \% \text { after } 10,000 \\
\text { cycles }\end{array}$ & {$[33]$} \\
\hline $\mathrm{MnO}_{2} / \mathrm{CNT}$ & CNT (1D) & $0.5 \mathrm{M} \mathrm{Na}_{2} \mathrm{SO}_{4}$ & $\begin{array}{l}410 \mathrm{~F} \mathrm{~g}^{-1} \text { at } \\
0.05 \mathrm{mV} \mathrm{s}^{-1}\end{array}$ & $1370 \mathrm{~F} \mathrm{~g}^{-1}$ & - & - & [34] \\
\hline $\mathrm{Ni}(\mathrm{OH})_{2} / \mathrm{CNT}$ & CNT(1D) & $6 \mathrm{M} \mathrm{KOH}$ & $\begin{array}{l}3100 \mathrm{~F} \mathrm{~g}^{-1} \text { at } \\
2.5 \mathrm{~mA} \mathrm{~cm}^{-2}\end{array}$ & $2082 \mathrm{~F} \mathrm{~g}^{-1}$ & $\begin{array}{l}2077 \mathrm{~F} \mathrm{~g}^{-1} \text { at } \\
50 \mathrm{~mA} \mathrm{~cm}^{-2}\end{array}$ & - & {$[35]$} \\
\hline $\mathrm{NiO} / \mathrm{PCNF}$ & PCNF (1D) & $6 \mathrm{M} \mathrm{KOH}$ & $\begin{array}{l}850 \mathrm{~F} \mathrm{~g}^{-1} \text { at } \\
1 \mathrm{~A} \mathrm{~g}^{-1}\end{array}$ & $2584 \mathrm{~F} \mathrm{~g}^{-1}$ & $\begin{array}{l}748 \mathrm{~F} \mathrm{~g}^{-1} \text { at } \\
10 \mathrm{~A} \mathrm{~g}^{-1}\end{array}$ & $\begin{array}{l}96.7 \% \text { after } \\
10,000 \text { cycles }\end{array}$ & {$[36]$} \\
\hline N-GNTs@NSNs & N-GNTs (1D) & $3 \mathrm{M} \mathrm{KOH}$ & $\begin{array}{l}2160 \mathrm{~F} \mathrm{~g}^{-1} \text { at } \\
6 \mathrm{~A} \mathrm{~g}^{-1}\end{array}$ & $703 \mathrm{mAh} \mathrm{g}^{-1}$ & $\begin{array}{l}1650 \mathrm{~F} \mathrm{~g}^{-1} \text { at } \\
40 \mathrm{~A} \mathrm{~g}^{-1}\end{array}$ & $\begin{array}{l}95.8 \% \text { after } \\
12,000 \text { cycles }\end{array}$ & {$[37]$} \\
\hline $\begin{array}{l}\mathrm{Ni}(\mathrm{OH})_{2} / \text { gra- } \\
\text { phene }\end{array}$ & graphene (2D) & $6 \mathrm{M} \mathrm{KOH}$ & $\begin{array}{c}1735 \mathrm{~F} \mathrm{~g} \mathrm{~g}^{-1} \text { at } \\
1 \mathrm{mV} \mathrm{s}^{-1}\end{array}$ & $2082 \mathrm{~F} \mathrm{~g}^{-1}$ & $\begin{array}{r}523 \mathrm{~F} \mathrm{~g}^{-1} \text { at } \\
50 \mathrm{mV} \mathrm{s}^{-1}\end{array}$ & - & {$[38]$} \\
\hline $\mathrm{Fe}_{2} \mathrm{O}_{3} / \mathrm{rGO}$ & rGO (2D) & $3 \mathrm{M} \mathrm{KOH}$ & $\begin{array}{c}178.3 \mathrm{~F} \mathrm{~cm}^{-3} \text { at } \\
1 \mathrm{mV} \mathrm{s}^{-1}\end{array}$ & $3625 \mathrm{~F} \mathrm{~g}^{-1}$ & $\begin{array}{c}123.7 \mathrm{~F} \mathrm{~cm}^{-3} \text { at } \\
50 \mathrm{mV} \mathrm{s}^{-1}\end{array}$ & $\begin{array}{l}83.1 \% \text { after } \\
10,000 \text { cycles }\end{array}$ & [39] \\
\hline $\mathrm{Mn}_{3} \mathrm{O}_{4} / \mathrm{rGO}$ & rGO (2D) & $1 \mathrm{M} \mathrm{Na}_{2} \mathrm{SO}_{4}$ & $\begin{array}{l}109 \mathrm{~F} \mathrm{~cm}^{-3} \text { at } \\
0.2 \mathrm{~A} \mathrm{~cm}^{-3}\end{array}$ & $\sim 1400 \mathrm{~F} \mathrm{~g}^{-1}$ & $\begin{array}{l}20 \mathrm{~F} \mathrm{~cm}^{-3} \text { at } 20 \mathrm{~A} \\
\mathrm{~cm}^{-3}\end{array}$ & $\begin{array}{l}100 \% \text { after } 10,000 \\
\text { cycles }\end{array}$ & {$[40]$} \\
\hline Graphene $/ \mathrm{Co}_{3} \mathrm{O}_{4}$ & Graphene (2D) & $6 \mathrm{M} \mathrm{KOH}$ & $\begin{array}{l}570 \mathrm{~F} \mathrm{~g}^{-1} \text { at } \\
1 \mathrm{~A} \mathrm{~g}^{-1}\end{array}$ & $3560 \mathrm{Fg}^{-1}$ & $\begin{array}{l}530 \mathrm{~F} \mathrm{~g}^{-1} \text { at } \\
20 \mathrm{~A} \mathrm{~g}^{-1}\end{array}$ & $\begin{array}{l}93 \% \text { after } 5000 \\
\text { cycles at } \\
10 \mathrm{~A} \mathrm{~g}^{-1}\end{array}$ & [41] \\
\hline $3 \mathrm{D} \mathrm{rGO} / \mathrm{Co}_{3} \mathrm{O}_{4}$ & $3 \mathrm{D}$ rGO (3D) & $6 \mathrm{M} \mathrm{KOH}$ & $\begin{array}{c}1765 \mathrm{Fg}^{-1} \text { at } \\
1 \mathrm{~A} \mathrm{~g}^{-1}\end{array}$ & $3560 \mathrm{~F} \mathrm{~g}^{-1}$ & $\begin{array}{c}1266 \mathrm{~F} \mathrm{~g}^{-1} \text { at } \\
20 \mathrm{~A} \mathrm{~g}^{-1}\end{array}$ & $\begin{array}{l}93 \% \text { after } 5000 \\
\text { cycles at } \\
10 \mathrm{~A} \mathrm{~g}^{-1}\end{array}$ & {$[42]$} \\
\hline $\mathrm{VN} / \mathrm{C}$ & $C(3 D)$ & $6 \mathrm{M} \mathrm{KOH}$ & $\begin{array}{c}392.0 \mathrm{~F} \mathrm{~g}^{-1} \text { at } \\
0.5 \mathrm{~A} \mathrm{~g}^{-1}\end{array}$ & $1340 \mathrm{~F} \mathrm{~g}^{-1}$ & $\begin{array}{c}197.9 \mathrm{~F} \mathrm{~g}^{-1} \text { at } \\
30 \mathrm{~A} \mathrm{~g}^{-1}\end{array}$ & $\begin{array}{l}82.9 \% \text { after } 8000 \\
\text { cycles }\end{array}$ & [43] \\
\hline $3 \mathrm{DPC} / \mathrm{Co}_{3} \mathrm{O}_{4}$ & 3DPC (3D) & $3 \mathrm{M} \mathrm{KOH}$ & $\begin{array}{l}423 \mathrm{~F} \mathrm{~g}^{-1} \text { at } \\
1 \mathrm{~A} \mathrm{~g}^{-1}\end{array}$ & $3560 \mathrm{~F} \mathrm{~g}^{-1}$ & $\begin{array}{c}362.5 \mathrm{~F} \mathrm{~g}^{-1} \text { at } \\
10 \mathrm{~A} \mathrm{~g}^{-1}\end{array}$ & $\begin{array}{l}83 \% \text { after } 2000 \\
\text { cycles at } \\
3 \mathrm{~A} \mathrm{~g}^{-1}\end{array}$ & [44] \\
\hline $\begin{array}{l}\mathrm{CoZnNiS/CNTs/} \\
\text { rGO }\end{array}$ & $\mathrm{CNTs} / \mathrm{rGO}(3 \mathrm{D})$ & $6 \mathrm{M} \mathrm{KOH}$ & $\begin{array}{l}1727.0 \mathrm{~F} \mathrm{~cm}^{-3} \text { at } \\
1 \mathrm{~A} \mathrm{~g}^{-1}\end{array}$ & - & $\begin{array}{l}972.8 \mathrm{~F} \mathrm{~cm}^{-3} \text { at } \\
10 \mathrm{~A} \mathrm{~g}^{-1}\end{array}$ & $\begin{array}{l}90.6 \% \text { after } \\
10,000 \text { cycles }\end{array}$ & {$[45]$} \\
\hline
\end{tabular}

through a facile hydrothermal method [31]. The introduction of CQDs greatly improved the rate performance and specific capacitance of the overall electrode. As a result, the CQDs/ $\mathrm{Ni}(\mathrm{OH})_{2}$ electrode exhibited a high specific capacitance of $2900 \mathrm{~F} \mathrm{~g}^{-1}$ at $1 \mathrm{~A} \mathrm{~g}^{-1}$, and the capacitance still remained at $2051 \mathrm{~F} \mathrm{~g}^{-1}$ even at a high current density of $10 \mathrm{~A} \mathrm{~g}^{-1}$. Furthermore, Huang et al. fabricated GQDs/ $\mathrm{NiCo}_{2} \mathrm{~S}_{4}$ composite that GQDs decorated hierarchical-like hollow $\mathrm{NiCo}_{2} \mathrm{~S}_{4}$ nanostructures by simple two-step hydrothermal reactions
[49]. The introduction of the GQDs can change the surface morphology and internal structure of $\mathrm{NiCo}_{2} \mathrm{~S}_{4}$ nanowires, indicating the unique nanostructures result in low impedance, large specific surface area, and more redox active sites, more interspaces and pathways for ion diffusion. As a result, the prepared GQDs/NiCo $\mathrm{S}_{4}$ electrode exhibited high specific capacitance $\left(678.22 \mathrm{~F} \mathrm{~g}^{-1}\right.$ at $\left.0.2 \mathrm{~A} \mathrm{~g}^{-1}\right)$ and superior cycling stability (94\% retention after 5000 cycles). 

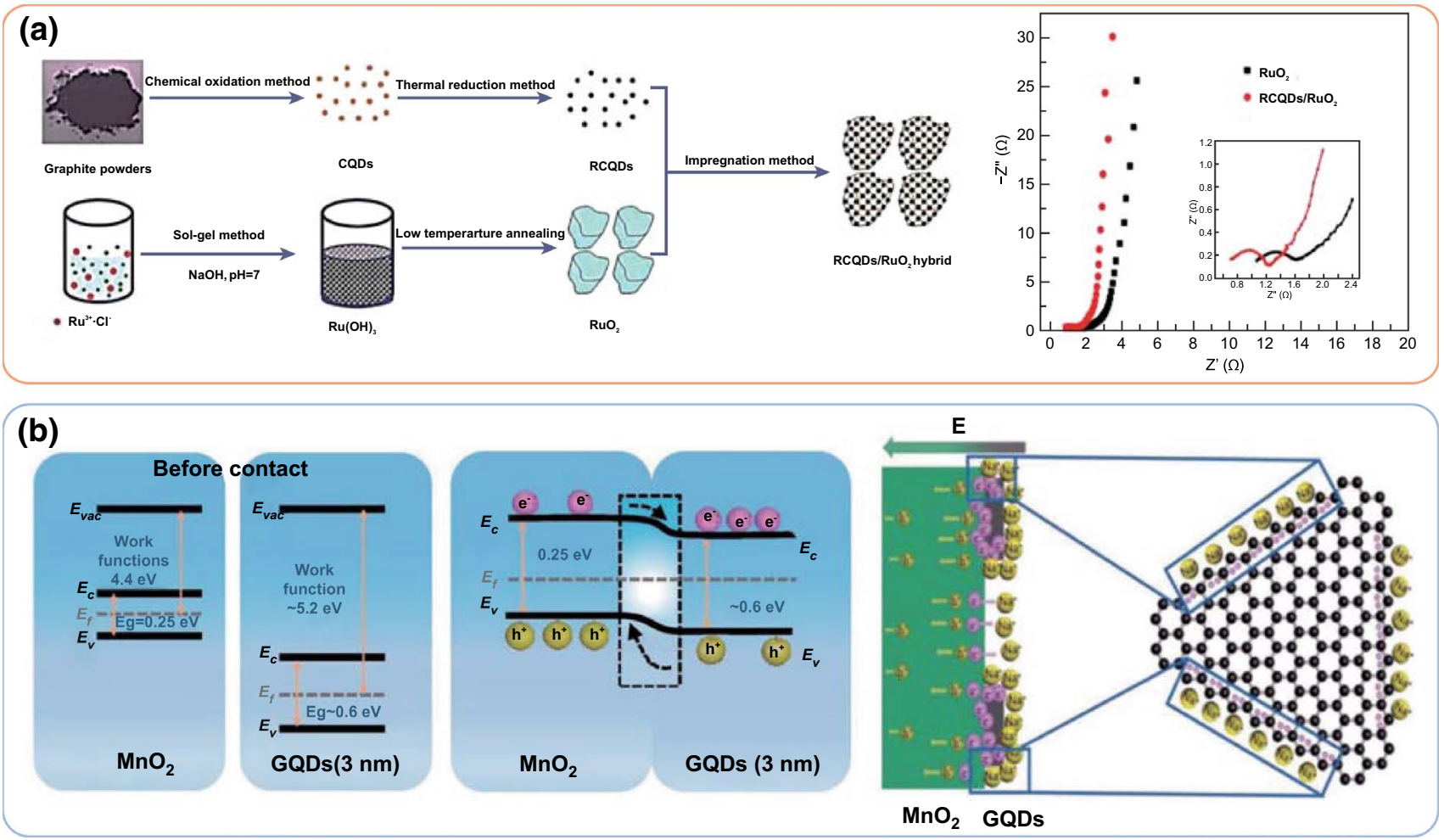

Fig. 3 a Schematic illustration of preparation procedure of the $\mathrm{RCQDs} / \mathrm{RuO}_{2}$ hybrid and comparison of Nyquist impedance plots of $\mathrm{RuO} \mathrm{O}_{2}$ and $\mathrm{RCQDs} / \mathrm{RuO}_{2}$. Adapted with permission from Ref. [48] Copyright 2013 Royal Society of Chemistry. b Energy diagram of $\mathrm{MnO}_{2}$ and GQDs $(\approx 3 \mathrm{~nm})$ before contact and after the formation of a heterojunction, and the schematic diagram of free electrons accumulating near the GQDs surface. Adapted with permission from Ref. [32] Copyright 2018 Wiley-VCH

The greatly improved electrochemical performance of the OD carbons decorated TMCs electrode could be attributed to two reasons: (1) the CQDs or GQDs incorporated in the composite can provide additional capacitance and construct highly conductive networks inside the micro-nano-scaled regions, which promotes the rapid charge transport and ionic diffusion, boosts the fast redox reactions, ensuring the excellent rate performance; (2) a small number of oxygen-containing functional groups (mainly carboxyl) at the edges of CQDs or GQDs can form strong and stable chemical interactions between the OD carbon and TMCs through the formation of $\mathrm{C}-\mathrm{O}-\mathrm{M}$ covalent bonds ( $\mathrm{M}$ represents metal atoms), which is beneficial for improving the rate and cycling performance. However, though the OD carbons generally have been used to enhance some pseudocapacitive materials conductivity, the relative lower specific capacitance and easy agglomeration of such carbons still need to be solved.

\subsection{D Carbons (Nanotubes or Nanofibers)}

Owing to the high conductivity, good flexibility, and superior functionality, 1D carbon materials, such as carbon nanofibers (CNF) and carbon nanotubes (CNTs), have been widely used as individual electrode materials or conductive substrates for supercapacitors $[50,51]$. In the process, the TMCs are commonly in situ introduced into the surface of 1D CNTs through physical or chemical methods. Such a strategy can not only effectively control the morphology of TMCs, but also greatly improve the overall electrical conductivity of 1D TMCs/carbon composites, which is beneficial for the improvement of both power and energy densities. For example, the $\mathrm{Ni}(\mathrm{OH})_{2}$ could be irreversibly transformed into $\mathrm{NiO}_{\mathrm{x}}$ during the energy storage process and commonly resulted in the poor rate capability and cycle stability of such hydroxide. To address the issue, Tang et al. [35] have prepared the $\mathrm{Ni}(\mathrm{OH})_{2} / \mathrm{CNTs} / \mathrm{NF}$ electrode through the CVD and chemical bath deposition (CBD) process. After the introduction of high conductivity CNTs, the intrinsic drawbacks of 
$\mathrm{Ni}(\mathrm{OH})_{2}$ could be effectively exempted. The electrochemical testing showed that the $\mathrm{Ni}(\mathrm{OH})_{2} / \mathrm{CNTs} / \mathrm{NF}$ electrode exhibited both high rate capacity $\left(3300 \mathrm{~F} \mathrm{~g}^{-1}\right.$ at $0.5 \mathrm{~A} \mathrm{~g}^{-1}$, $2211 \mathrm{~F} \mathrm{~g}^{-1}$ at $10 \mathrm{~A} \mathrm{~g}^{-1}$ ) and excellent cycling stability (87\% retention after 3000 cycles). In addition, when assembled as asymmetric supercapacitors using $\mathrm{Ni}(\mathrm{OH})_{2} / \mathrm{CNTs} / \mathrm{NF}$ and $\mathrm{AC}$ as anode and cathode, respectively, the device indicated an ultra-high energy density of $32.5 \mathrm{Wh} \mathrm{kg}^{-1}$ at a power density of $1800 \mathrm{~W} \mathrm{~kg}^{-1}$. Such an obvious improvement can be attributed to the elaborate design of a composite structure, in which the active $\mathrm{Ni}(\mathrm{OH})_{2}$ nanoparticles are effectively anchored on the surface of highly conductive CNTs/ NF current collectors and dramatically impeded the phase transformation of $\mathrm{Ni}(\mathrm{OH})_{2}$.

Besides the 1D carbon skeleton surface, the TMCs can also be confined into the cavities of carbon nanofibers [52]. The interspace provided by the 1D carbon skeleton can effectively prevent the aggregation and phase transformation of TMC-based electrodes. For example, the P-doped $\mathrm{Co}_{3} \mathrm{O}_{4}$ ultrafine nanoparticles have been successfully encapsulated into $\mathrm{P}, \mathrm{N}$ co-doped carbon nanowires
$\left(\mathrm{P}-\mathrm{Co}_{3} \mathrm{O}_{4} @ \mathrm{P}, \mathrm{N}-\mathrm{C}\right)$ by a pyrolysis-oxidation-phosphorization method [53]. Because of the strong fastened effect of electroactive $\mathrm{Co}_{3} \mathrm{O}_{4}$ into the conductive carbon substrate, the agglomeration of active materials was prevented. Moreover, the good keeping of 1D oriented arrangement hybrid composites can provide a huge accessible surface area and hierarchically porous characteristic, which are beneficial for the sufficient permeation and migration of electrolyte ions. When assembled with $\mathrm{Co} @ \mathrm{P} / \mathrm{N}-\mathrm{C}$, the $\mathrm{P}-\mathrm{Co}_{3} \mathrm{O}_{4} @ \mathrm{P} / \mathrm{N}-\mathrm{C} / / \mathrm{Co} @ \mathrm{P} / \mathrm{N}-\mathrm{C}$ asymmetric supercapacitor could achieve an outstanding energy density of $47.6 \mathrm{Wh} \mathrm{kg}^{-1}$ at the high power density of $750 \mathrm{~W} \mathrm{~kg}^{-1}$, indicating the impressive supercapacitor possessing an enormous potential in the practical applications. In addition, a $\mathrm{NiO}$ nanoparticle-dispersed electrospun $\mathrm{N}$-doped porous $\mathrm{CNF}$ (NiO/PCNF) free-standing film electrode was fabricated using dicyandiamide(DCDA) and PAN as CNF precursors and nickel acetylacetone as $\mathrm{Ni}$ sources by $\mathrm{Li}$ et al. (Fig. 4a) [36]. The NiO nanoparticles were uniformly dispersed in the framework of $\mathrm{N}$-doped porous $\mathrm{CNF}$ (Fig. 4b). Such a 1D fibrous feature and the interwoven
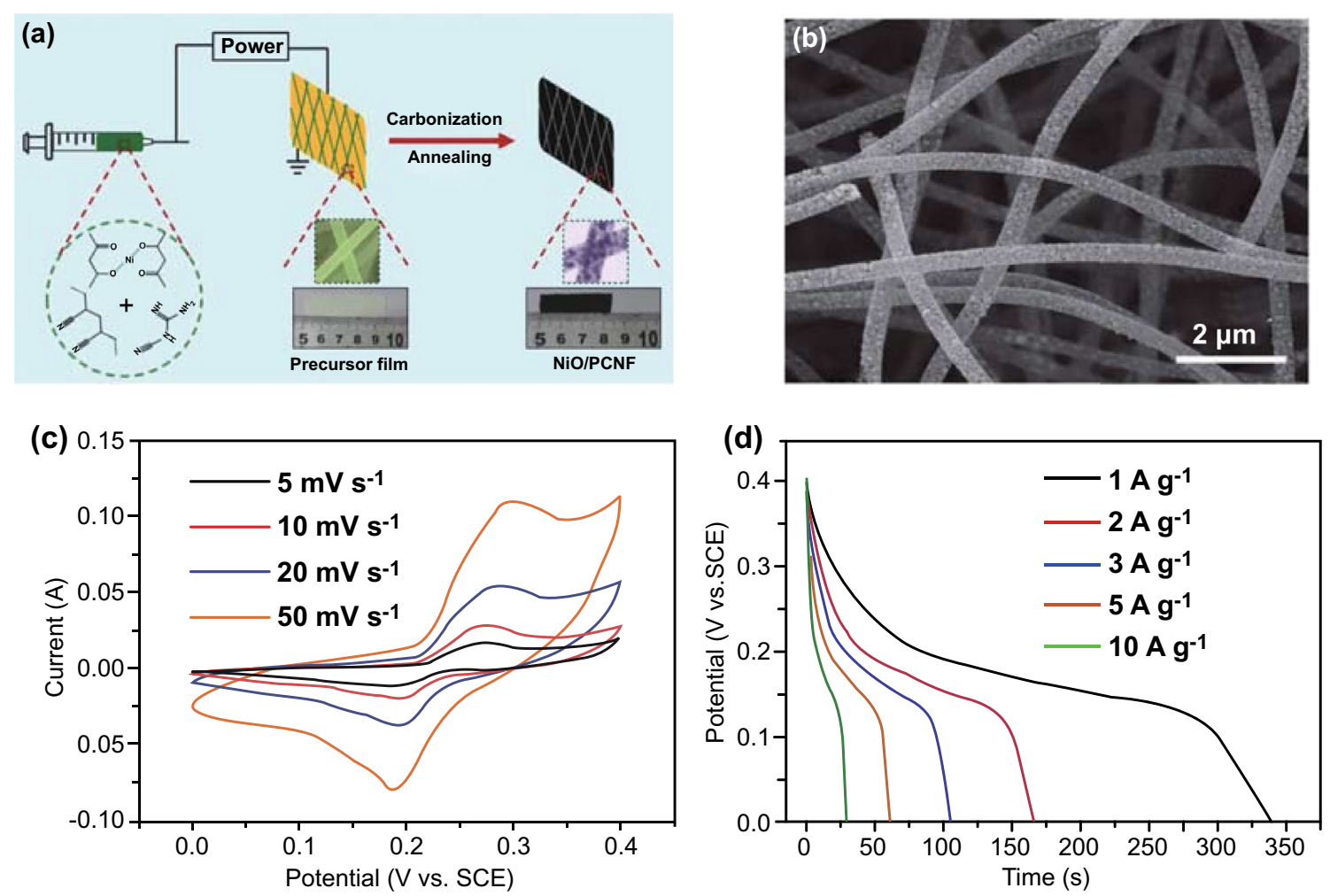

Fig. 4 a Schematic illustration of the synthesis of free-standing NiO/PCNF composite film. b, c and d SEM images, CV curves, and discharge voltage profiles of NiO/PCNF-0.75. Adapted with permission from Ref. [36] Copyright 2018 Wiley-VCH 
conductive skeleton are beneficial for the fast transfer of electrolyte ions/electrons through the in-plane direction. The NiO/PCNF-0.75 (0.75 represents the weight ratio of DCDA and nickel acetylacetone) showed the maximum specific capacitance of $850 \mathrm{~F} \mathrm{~g}^{-1}$ at $1 \mathrm{~A} \mathrm{~g}^{-1}$, and high specific capacitance was retained $748 \mathrm{~F} \mathrm{~g}^{-1}$ even at $10 \mathrm{~A} \mathrm{~g}^{-1}$, meaning outstanding rate capability (Fig. 4c, d).

Owing to the high electrical conductivity, superior mechanical strength, and flexible capability, such 1D TMCs/carbon composites have also been widely researched in wearable device applications [50]. For example, Hu et al. [34] developed a $\mathrm{MnO}_{2}$-CNT-textile electrode through the electrodeposit method of $\mathrm{MnO}_{2}$ onto the highly conductive CNT with polyester coatings, which exhibited a large mass loading $\left(8.3 \mathrm{mg} \mathrm{cm}^{-2}\right)$ and high areal capacitance $\left(2.8 \mathrm{~F} \mathrm{~cm}^{-2}\right)$ in a wearable device. The textile fibers wattled by CNT with high conductivity could largely promote the electrolyte ions/ electrons transfer through the in-plane direction, and the $\mathrm{MnO}_{2}$-CNT-textile electrode exhibited a high energy density of $5-20 \mathrm{Wh} \mathrm{kg}^{-1}$ at the high power density of $13 \mathrm{~kW} \mathrm{~kg}-1$. In another article, Salman and co-workers successfully integrated tungsten nitride (WN) with reduced graphene oxide fibers (rGOF) to obtain a WN-rGOF hybrid by a simple hydrothermal method [54]. Owing to the high tensile strength, excellent flexibility and high electrical conductivity of rGOF, large capacitance and high chemical stability of WN electrode can be obtained. The energy density of WN-rGOFbased hybrid supercapacitors showed a great energy density of $1.448 \mathrm{mWh} \mathrm{cm}^{-3}$. More importantly, the WN-rGOF electrode showed high capacitance retention of $84.7 \%$ after 10,000 cycles even under severe mechanical deformation conditions, exhibiting a fascinating advantage for wearable device applications in the future.

1D carbons showed great potential for supercapacitors application, especially flexible wearable devices. However, higher demands have been made for flexible energy-storage systems along with the rapid development of the society, which needs to improve the areal/volumetric performances of 1D carbon. Notably, the form of free-standing TMCs/carbon films attracted more and more attention owing to no additional binders, conductors, or collectors. Compared with TMCs/carbon powders, it can increase the mass loading of active materials, simplify the electrode preparation process, and avoid uncontrollable side reactions, but it needs more advanced technologies. Therefore, the development and application of free-standing film electrodes may be an important development direction of the energy storage industry.

\subsection{D Carbons}

Due to the ultra-high specific surface area $\left(2630 \mathrm{~m}^{2} \mathrm{~g}^{-1}\right)$ and excellent conductivity, studies about the $2 \mathrm{D}$ graphenebased materials applied in energy storage and conversion have sprung up since its first report in 2004 by Novoselov and Geim [55, 56]. More specially, graphene also has been widely studied as a conductive substrate and flexible host in the synthesis of graphene/TMCs composites $[15,57$, 58]. The continuously conjugated $s p^{2}$-C skeleton of graphene can provide efficient ions/electrons transfer channels, which is not only beneficial for the improvement of rate performance of TMCs, but also significant for the long charge/discharge cycling stability. For example, our group previously prepared $\mathrm{Ni}(\mathrm{OH})_{2}$ /graphene hybrid material via the microwave heating method [38]. Structural characterization demonstrated that the as-prepared $\mathrm{Ni}(\mathrm{OH})_{2}$ with hierarchical flowerlike morphology were homogeneously decorated on the graphene nanosheets. Compared with pure $\mathrm{Ni}(\mathrm{OH})_{2}$, the hybrid material showed higher specific capacitance and more superior rate capability (As shown in Fig. 5a). Moreover, the $\mathrm{Ni}(\mathrm{OH})_{2} /$ graphene//porous graphene-based asymmetric supercapacitor exhibited a high energy density of $77.8 \mathrm{Wh} \mathrm{kg}^{-1}$ at $174.7 \mathrm{~W} \mathrm{~kg}^{-1}$, which could still retain $13.5 \mathrm{Wh} \mathrm{kg}^{-1}$ at an ultrahigh power density of $15.2 \mathrm{~kW} \mathrm{~kg}^{-1}$. The superior performance mainly attributes to high conductivity and specific surface area of graphene-based conductive skeleton and high theoretical specific capacitance of $\mathrm{Ni}(\mathrm{OH})_{2}$.

A class of hybrid $\mathrm{Fe}_{2} \mathrm{O}_{3}$ nanoclusters/rGO papers $\left(\mathrm{Fe}_{2} \mathrm{O}_{3} /\right.$ rGO)-based negative electrodes were also prepared by $\mathrm{Hu}$ and co-workers through a facile hydrothermal method and followed by an electrochemical reduction strategy [39]. When tested in $3 \mathrm{M} \mathrm{KOH}$ aqueous electrolyte, the hybrid $\mathrm{Fe}_{2} \mathrm{O}_{3} / \mathrm{rGO}$ electrode obtained both high volumetric energy and power density $\left(0.056 \mathrm{Wh} \mathrm{cm}^{-3}\right.$ and $\left.6.21 \mathrm{~W} \mathrm{~cm}^{-3}\right)$. Such excellent electrochemical performance can be attributed to the conductive skeleton and flexible host of rGO nanosheets, and the high pseudocapacitance provided by $\mathrm{Fe}_{2} \mathrm{O}_{3}$ nanoparticles. As shown in Fig. 5b, Jiang et al. developed a simple, productive, and economical one-pot ball-milling manner to produce a series of graphene $/ \mathrm{Co}_{3} \mathrm{O}_{4}$ composites [41]. 

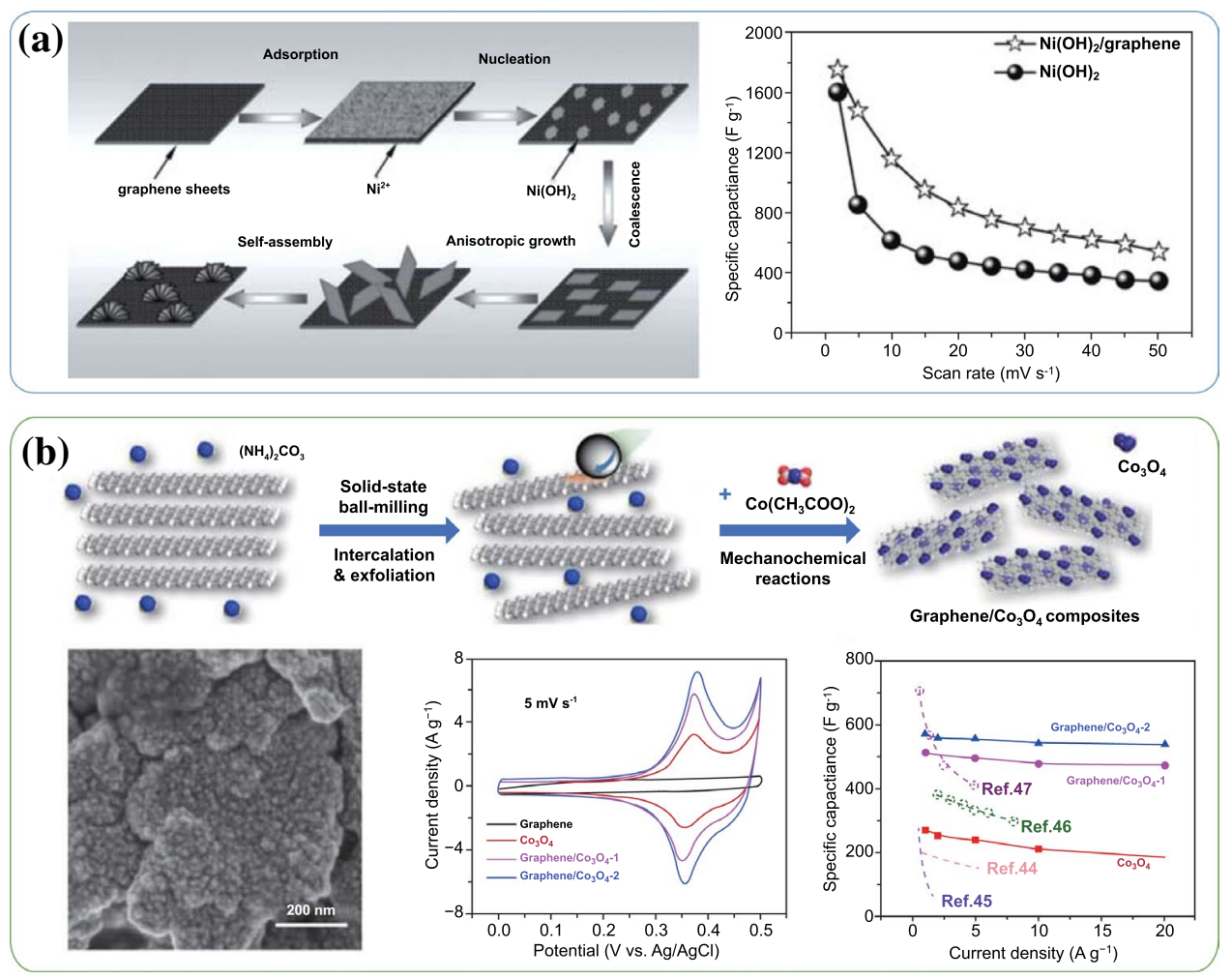

Fig. 5 a Schematic illustration for the possible formation of the $\mathrm{Ni}(\mathrm{OH})_{2} /$ graphene and the specific capacitances of $\mathrm{Ni}(\mathrm{OH})_{2} / \mathrm{graphene}$ and $\mathrm{Ni}(\mathrm{OH})_{2}$ at different scan rates. Adapted with permission from Ref. [38] Copyright 2012 Wiley-VCH. b Schematic illustration for the preparation of graphene/ $\mathrm{Co}_{3} \mathrm{O}_{4}$ composites, SEM images of graphene/ $\mathrm{Co}_{3} \mathrm{O}_{4}-2$, CV curves at $5 \mathrm{mV} \mathrm{s}{ }^{-1}$ of graphene, $\mathrm{Co}_{3} \mathrm{O}_{4}, \mathrm{graphene} / \mathrm{Co}_{3} \mathrm{O}_{4}-1$ and graphene $/ \mathrm{Co}_{3} \mathrm{O}_{4}-2$, and their specific capacitances at various current densities. Adapted with permission from Ref. [41] Copyright 2020 Elsevier

SEM image indicated that the $\mathrm{Co}_{3} \mathrm{O}_{4}$ nanoparticles were uniformly anchored on the graphene surface. Graphene as a conductive skeleton can offer fast ion transport pathway. Compared with other composites, the as-prepared graphene/ $\mathrm{Co}_{3} \mathrm{O}_{4}-2$ (2 represents the graphene content) displayed the most distinguished specific capacitance of $530 \mathrm{~F} \mathrm{~g}^{-1}$ at $20 \mathrm{~A} \mathrm{~g}^{-1}$ (Fig. 5b). When assembled as asymmetric supercapacitors using graphene as anode and graphene $/ \mathrm{Co}_{3} \mathrm{O}_{4}-2$ as a cathode, the energy density of such ASCs could reach $67.5 \mathrm{~W} \mathrm{~h} \mathrm{~kg}^{-1}$ at the high power density of $0.8 \mathrm{~kW} \mathrm{~kg}^{-1}$.

Though the graphene in the construction of TMC-based composite electrodes has been widely employed, the serious agglomeration and restacking issues due to the interplanar $\pi-\pi$ interaction and Van der Waals forces always impede its practical popularization, which is urgent to be solved [59]. Moreover, graphene have outstanding electronic conductivity on the horizontal plane; however, its vertical conductivity is low and usually does not achieve ion cross-layer transmission. To address these problems, some methods have been developed, such as pores-creation using $\mathrm{KOH} / \mathrm{H}_{2} \mathrm{O}_{2}$ treatment, lead-in spacer, and design of ribbons $[60,61]$.

\subsection{D Carbons}

To address the above aggregation issue of graphene, reasonably constructing 3D carbon frameworks, such as 3D porous carbon, 3D graphene building, or 3D cross-linked carbon network, etc., as highly conductive substrates have been raised [62-68]. These carbon skeletons with unique 3D morphology usually exhibit hierarchical porous structure and ultra-high surface area, which can provide abundant electrolyte ions/electrons transfer channels and sufficient growing space for TMCs. In this context, Bao et al. prepared $3 \mathrm{D}$ graphene frameworks $/ \mathrm{Co}_{3} \mathrm{O}_{4}$ composites via a thermal explosion method [42]. As depicted in Fig. 6a, 3D graphene frameworks with macropores acting as the conductive skeleton can facilitate the rapid transfer of electrolyte ions/electrons. In addition, the $\mathrm{Co}_{3} \mathrm{O}_{4}$ nanoparticles with 

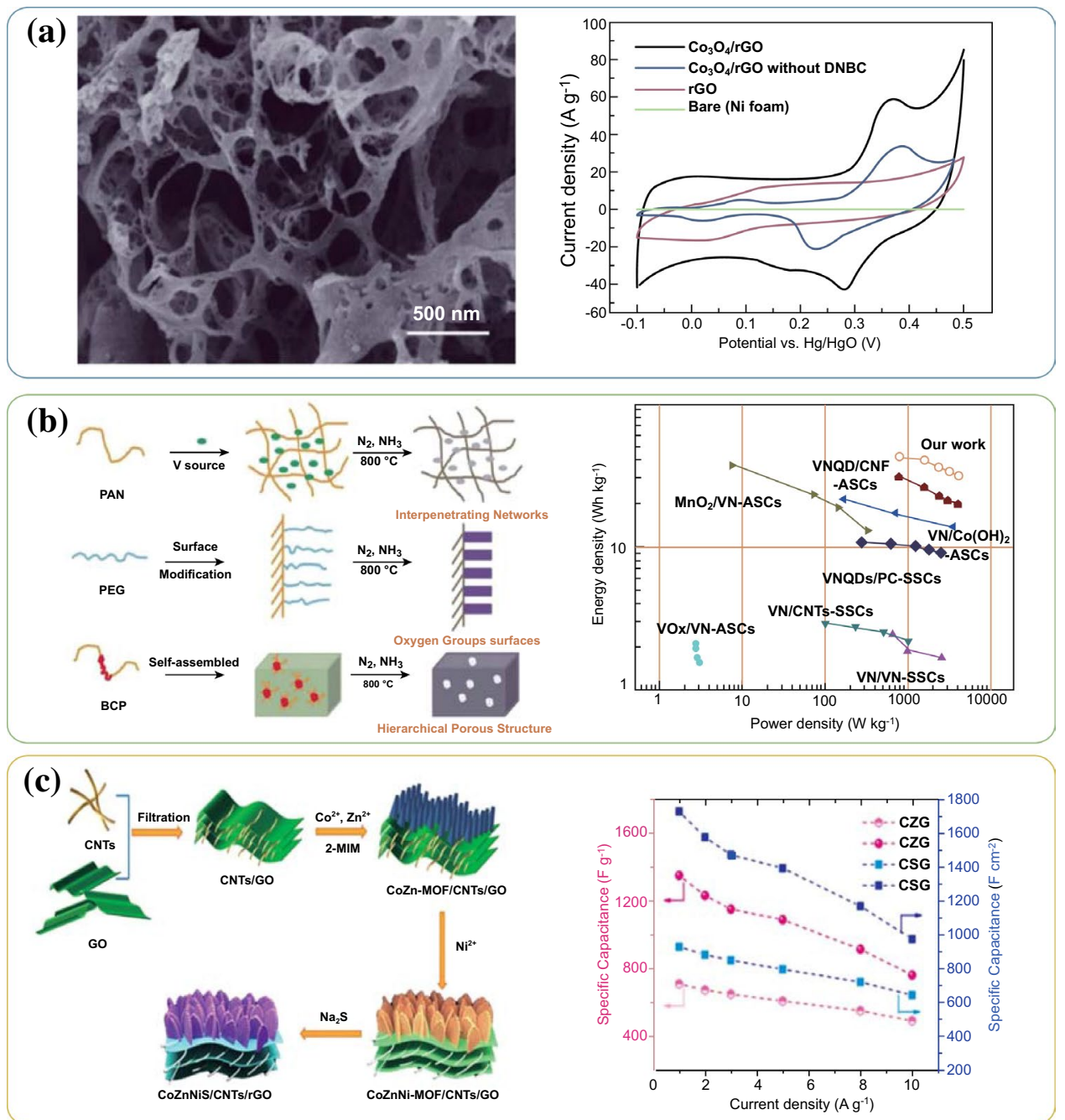

Fig. 6 a SEM image of the 3D graphene frameworks $/ \mathrm{Co}_{3} \mathrm{O}_{4}$ composites and $\mathrm{CV}$ curves at $50 \mathrm{mV} \mathrm{s} \mathrm{s}^{-1}$ of the various sample. Adapted with permission from Ref. [42] Copyright 2017 Wiley-VCH. b Schematic representation of the fabrication strategy and Ragone plots of the VN/C. Adapted with permission from Ref. [43] Copyright 2018 Springer. c Schematic illustration of the preparation of the CoZnNiS/CNTs/rGO composite and their volumetric and gravimetric capacitance at different current densities. Adapted with permission from Ref. [45] Copyright 2020 Elsevier

about 4.6-9.4 nm diameters were uniformly and densely distributed on the 3D carbon frameworks. When 3D graphene $/ \mathrm{Co}_{3} \mathrm{O}_{4}$ composites were used as electrode material for supercapacitors, high specific capacitance $\left(\approx 1765 \mathrm{~F} \mathrm{~g}^{-1}\right.$ at a current density of $1 \mathrm{~A} \mathrm{~g}^{-1}$ ) could be observed, and retention kept $93 \%$ even after 5000 cycles at a highly constant current density of $10 \mathrm{~A} \mathrm{~g}^{-1}$. Moreover, Xu et al. successfully prepared a hybrid material that $\mathrm{VN}$ nanoparticles incorporated into a 3D carbon matrix (3D VN/C) through the multi-phase polymeric strategy (Fig. 6b) [43]. The VN nanoparticles are uniformly distributed among the 3D carbon networks, in which the carbon matrix can not only serve as a $3 \mathrm{D}$ conductive network but also prevent the $\mathrm{VN}$ aggregation. As a result, the 3D VN/C membranes electrode showed excellent electrochemical performance, including high energy density (43.0 $\mathrm{Wh} \mathrm{kg}^{-1}$ at a power density of $800 \mathrm{~W} \mathrm{~kg}^{-1}$ ) and good cycling stability (82.9\% at $1.0 \mathrm{~A} \mathrm{~g}^{-1}$ after 8000 cycles). More importantly, when the power density reached $4 \mathrm{~kW} \mathrm{~kg}^{-1}$, the device still performed a high energy density of $32.3 \mathrm{Wh} \mathrm{kg}^{-1}$.

Apart from the usage of single carbon to build 3D conductive carbon skeletons, the substrates can also be constructed by two or more kinds of carbon units. For example, Qing et al. [69] embedded highly crystallized GQDs 
onto activated carbons (AC) to construct 3D overall conductive networks, which could greatly improve the capacity and rate performances in contrast to pure ACs. The small-sized GQDs are more beneficial to establish evenly distributed conductive networks, which can accelerate the electron/ion transport kinetics in carbon frameworks. Liu et al. [45] designed and prepared MOFs-derived $\mathrm{ZnCoNiS}$ nanosheet arrays based on a 3D rGO/CNTs conductive substrate (CoZnNiS/CNTs/rGO) (As depicted in Fig. 6c). The 3D rGO/CNTs network endowed high conductivity of the whole electrode and greatly promoted the electrons transfer kinetics while shortened the electrolyte ions diffusion paths. Moreover, the rough surface of CoZnNiS nanosheets could provide abundant exposing surfaces and active sites, enhancing the redox reaction rate. As a result, the composite film electrode displayed a maximum specific capacitance and high volumetric specific capacitance (1349.2 $\mathrm{F} \mathrm{g}^{-1}$ and $1727.0 \mathrm{~F} \mathrm{~cm}^{-3}$ at $1 \mathrm{~A} \mathrm{~g}^{-1}$, respectively). When used CoZnNiS/CNTs/rGO and carbon sphere/rGO electrode to assemble hybrid supercapacitor, the device showed a superior energy density of $60.4 \mathrm{Wh} \mathrm{kg}^{-1}$ at an ultrahigh power density of $1200 \mathrm{~W} \mathrm{~kg}^{-1}$.

To sum up, regardless of the $0 \mathrm{D}, 1 \mathrm{D}, 2 \mathrm{D}$, or $3 \mathrm{D}$ carbon skeletons, the reasonable design of carbon structures with high conductivity and large specific surface areas to satisfy the high mass loading of TMCs is quietly important. Moreover, how to design ideal carbon skeletons, which exhibit both high bulk densities and porous structure, seems a big challenge. Particularly, the relationships between the holistic devices' energy density and the ratio of TMCs to carbon-based host have not been reported so far, the content of porous carbon host affects the conductivity and capacitance of the whole electrode that the content of porous carbon host too high to achieve high volume density leading higher electrolyte consumption, too low causing of high charge resistance. In the practical application of TMCs, the fast reaction kinetics of the pseudocapacitive energy storage process commonly need the synergistic effect of conductivity, ions transfer channels, interface stability, etc. Therefore, the systematic design of carbon skeletons for the TMCs/carbon based supercapacitors with high energy/power densities may be the research direction in the future.

\section{Interface Engineering}

Besides the construction of conductive carbon skeletons, the well-designed interface engineering between carbon networks and TMCs is another indispensable role for TMCbased electrodes which exhibit improved energy density and cycle life [70]. Due to the nano-size effect, TMCs nanoparticles with high surface energy are easy to aggregate during the energy storage process, which can directly lead to the capacity fading, resulting in the hindrance of scaled application of TMCs/carbon-based supercapacitors [71, 72]. Moreover, the roughly physical combination of TMCs and carbon skeletons usually causes high interface impedance and cuts off the electron transfer channels across the heterogeneous interfaces. Therefore, the ideal design of carbon/TMCs interfaces is vitally important for the further enhancement of electrochemical performance. In this section, we will summarize the recent progress of the interface engineering between carbon and TMCs from the aspects of heteroatom-doping, functional group modification, organic interlayer, and spatial confinement (Table 2).

Table 2 Comparison of different interfacial strategies

\begin{tabular}{|c|c|c|c|c|}
\hline Types of strategies & TMCs/carbon & Synthetic methods & Rate ability & References \\
\hline \multirow[t]{2}{*}{ Heteroatom-doped carbon skeletons } & $\mathrm{Fe}_{2} \mathrm{O}_{3} \mathrm{ND} @ \mathrm{NG}$ & Solvothermal & 201 at $5 \mathrm{~A} \mathrm{~g}^{-1}, 140$ at $50 \mathrm{~A} \mathrm{~g}^{-1}$ & [73] \\
\hline & $\mathrm{Ni} / \mathrm{Co}-\mathrm{OOH} / \mathrm{NSCF}$ & Electrochemical activation & $853 \mathrm{C} \mathrm{g}^{-1}$ at $5 \mathrm{~A} \mathrm{~g}^{-1}, 518.4$ at $20 \mathrm{~A} \mathrm{~g}^{-1}$ & [17] \\
\hline \multirow[t]{2}{*}{ Covalently heterogeneous interface } & $\mathrm{Ni}(\mathrm{OH})_{2} / \mathrm{af}-\mathrm{GQDs}$ & Impregnation & $2653 \mathrm{~F} \mathrm{~g}^{-1}$ at $1 \mathrm{~A} \mathrm{~g}^{-1}, 1658$ at $20 \mathrm{Ag}^{-1}$ & [96] \\
\hline & $\mathrm{Mn}_{3} \mathrm{O}_{4}-\mathrm{rGO}$ & Thermal treatment & $561.5 \mathrm{C} \mathrm{g}^{-1}$ at $1 \mathrm{~A} \mathrm{~g}^{-1}, 363.8$ at $20 \mathrm{~A} \mathrm{~g}^{-1}$ & [75] \\
\hline \multirow[t]{2}{*}{ Organic interlayer } & CuO-PANI-rGO & hydrothermal & $634.4 \mathrm{~F} \mathrm{~g}^{-1}$ at $0.5 \mathrm{~A} \mathrm{~g}^{-1}, 513.2$ at $20 \mathrm{~A} \mathrm{~g}^{-1}$ & [76] \\
\hline & ACNF/PANI/NiO & Carbonization & $1157 \mathrm{Fg}^{-1}$ at $1 \mathrm{~A} \mathrm{~g}^{-1}, 720$ at $10 \mathrm{~A} \mathrm{~g}^{-1}$ & [77] \\
\hline \multirow[t]{2}{*}{ Spatial confinement } & VNNDs/CNSs & Carbonization & $573 \mathrm{~F} \mathrm{~g}^{-1}$ at $0.5 \mathrm{~A} \mathrm{~g}^{-1}, 334.8$ at $100 \mathrm{~A} \mathrm{~g}^{-1}$ & [78] \\
\hline & NiS-NC HS & Hydrothermal & $1170 \mathrm{~F} \mathrm{~g}^{-1}$ at $0.5 \mathrm{~A} \mathrm{~g}^{-1}, 843.5$ at $10 \mathrm{~A} \mathrm{~g}^{-1}$ & [79] \\
\hline
\end{tabular}




\subsection{Heteroatom-Doped Carbon Skeletons}

Heteroatoms doping (such as B, N, P, and S) of carbon skeleton is an effective way to construct strong TMCs-carbon interfaces [80]. Density functional theory (DFT) calculations verified that the density of states and charge population of carbon materials have been dramatically altered after the heteroatoms doping [81]. Previous works demonstrated that the electrochemical conductivity and wettability of carbon materials were remarkably improved by the heteroatoms doping, which was beneficial for the enhancement of the electrochemical activity of TMCs/carbon-based electrodes (Fig. 7a-c) [82-84]. For example, Dubal and Abdel-Azeim et al. [85] confirmed that the introduction of heteroatoms in carbon matrix could enhance the binding energy between TMCs and carbon (Fig. 7d). In this case, Yang et al. [86] successfully using urea as $\mathrm{N}$ source manufactured ultrasmall $\mathrm{MnO}$ nanoparticles inserted into $\mathrm{N}$-rich carbon nanosheets (MnO@NCs) hybrid by a facile tactic (Fig. 8a). As shown in Fig. 8b, XPS confirmed that $\mathrm{N}$ atoms were successfully
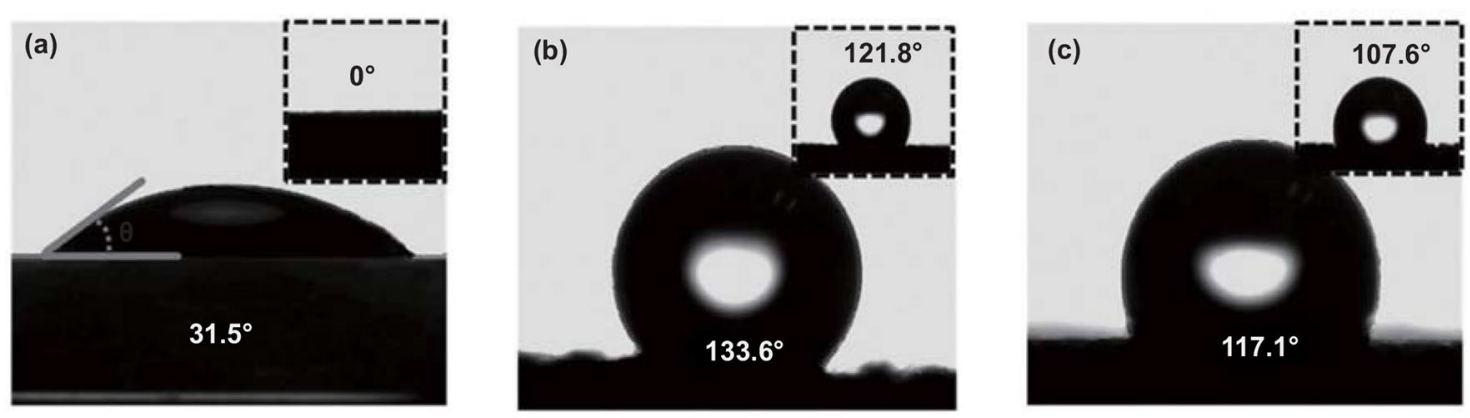

(d)
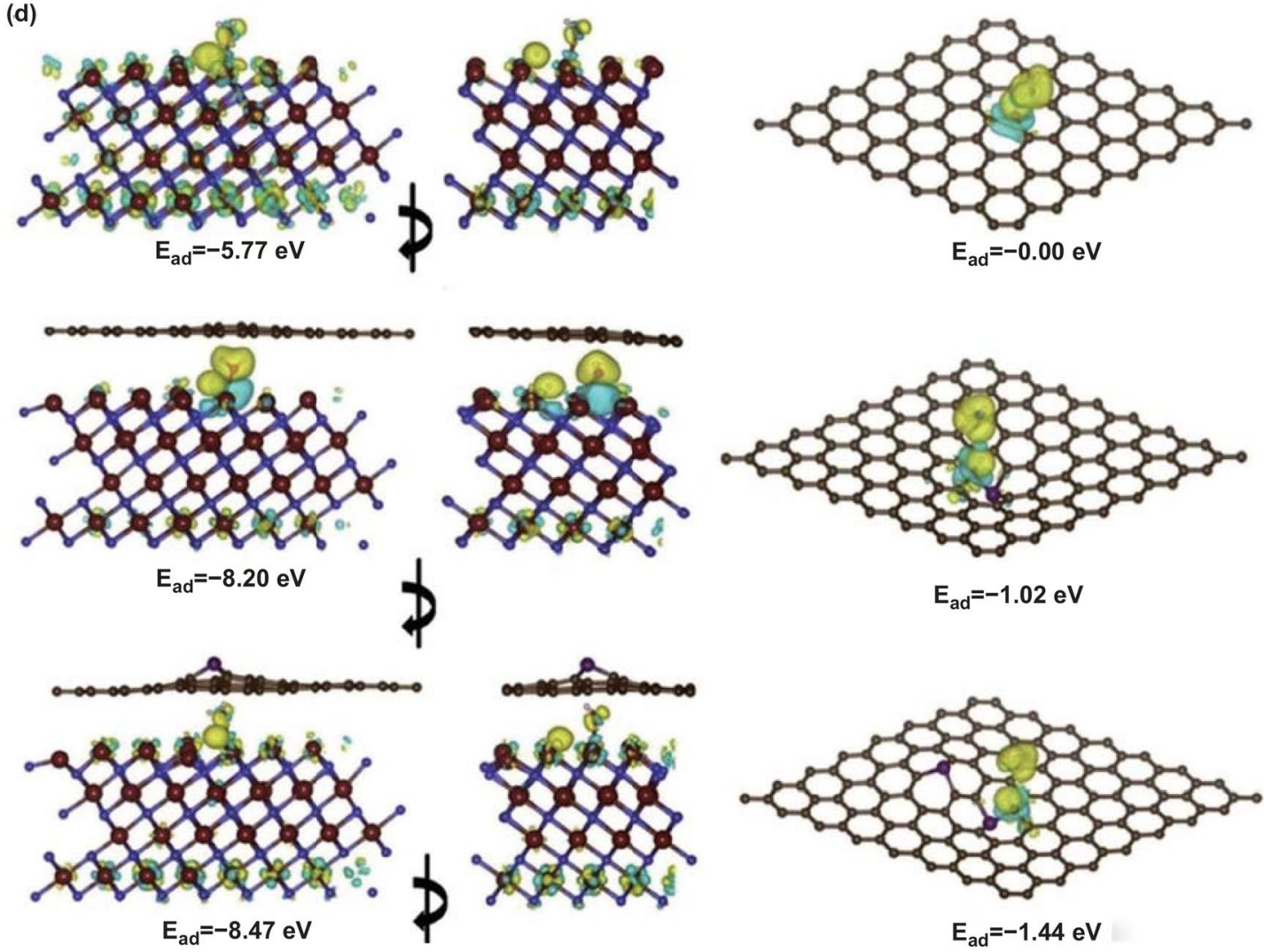

$E_{a d}=-1.44 \mathrm{eV}$

Fig. 7 a-c Comparison of water contact angles of N-carbon foam, carbon foam and carbon cloth. Adapted with permission from Ref [84]. Copyright 2016 Wiley-VCH. d DFT simulations of binding energy between MoN and P-doped carbon. Adapted with permission from Ref. [85] Copyright 2019 Elsevier 

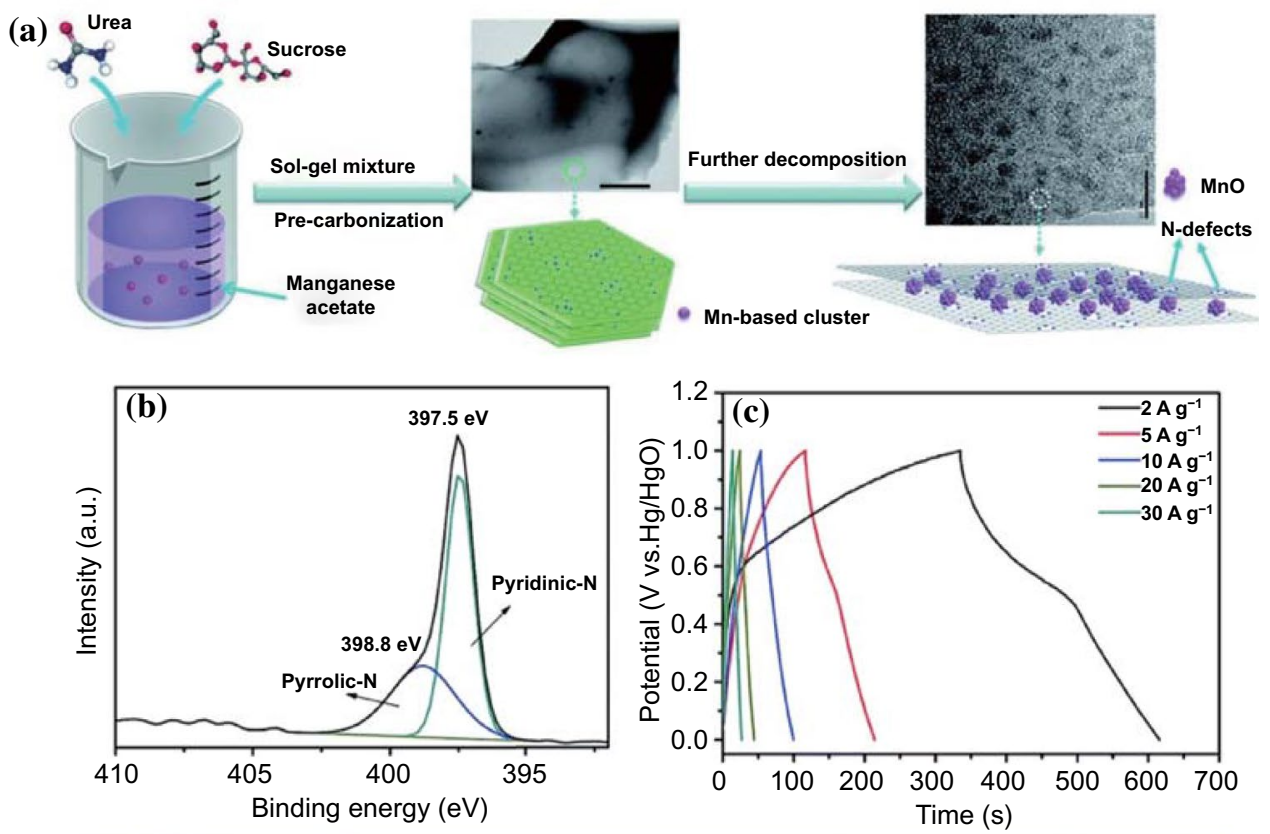

(d)
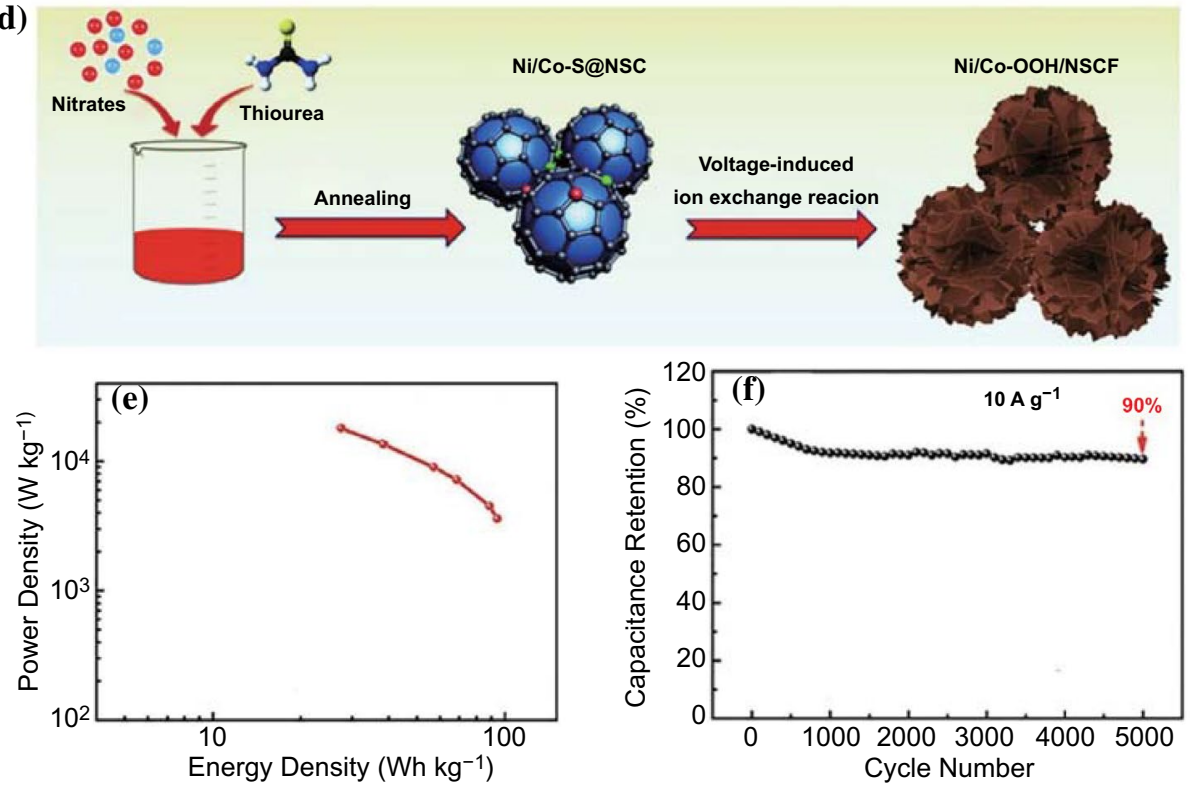

Fig. 8 a Synthetic procedure picture of MnO@NCs. b High-resolution XPS of N $1 s$ peak of MnO@NCs. c Galvanostatic charge-discharge curves MnO@NCs of concerning current densities. Adapted with permission from Ref. [86] Copyright 2014 Royal Society of Chemistry. d-f Schematic illustration for the synthesis and Ragone plots, cycling performance of Ni/Co-OOH/NSCF. Adapted with permission from Ref. [17] Copyright 2020 Elsevier

introduced into the carbon skeleton, and the ultrasmall $\mathrm{MnO}$ nanoparticles (around 2-4 nm) were uniformly anchored on the N-rich carbon nanosheets. Moreover, the copious nitrogen species doped in the carbon skeletons altered the local electron distribution, and the nanoparticles were preferentially in situ nucleated at the N-rich sites, which was beneficial for the uniform dispersion of $\mathrm{MnO}$ nanoparticles and offered powerful support for the large mass loading of $\mathrm{MnO}$ nanoparticles. Consequently, as assembled in an asymmetric device, the $\mathrm{MnO} @ \mathrm{NCs} / / \mathrm{AC}$ demonstrated a striking energy density of $21.6 \mathrm{Wh} \mathrm{kg}^{-1}$ at a high power density of $12.4 \mathrm{~kW} \mathrm{~kg}^{-1}$. 
In another report, the composite electrode of $\mathrm{Fe}_{2} \mathrm{O}_{3}$ nanodots supported by nitrogen-doped graphene sheets $\left(\mathrm{Fe}_{2} \mathrm{O}_{3}\right.$ ND@NG) was prepared through a facile one-pot method [73]. At a current density of $1 \mathrm{~A} \mathrm{~g}^{-1}$, the $\mathrm{Fe}_{2} \mathrm{O}_{3} \mathrm{ND} @$ NG-0.75 (0.75 represents mass ratios of precursor) with the highest $\mathrm{N}$ content electrode exhibited the highest specific capacitance of $274 \mathrm{~F} \mathrm{~g} \mathrm{~g}^{-1}$, which could still arrive to $140 \mathrm{~F} \mathrm{~g}^{-1}$ even at a high current density of $50 \mathrm{~A} \mathrm{~g}^{-1}$, indicating a superior rate performance. The excellent electrochemical performance may be attributed to that the nitrogen doping in graphene not only endows graphene with a high charge mobility rate and extra capacitance, but also increases the binding energy between $\mathrm{Fe}_{2} \mathrm{O}_{3}$ NDs and NG to build a stable heterogeneous interface. In addition, Miao et al. selected MOFs as precursors to obtain a series of $\mathrm{CoSe}_{2} / \mathrm{NC}$ hybrid materials with abundant $\mathrm{N}$ content [87]. $\mathrm{N}$ doping not only enhanced the electric conductivity and wettability of carbon skeletons, but also contributed additional pseudocapacitance. Compared with other hybrids, the $\mathrm{CoSe}_{2} / \mathrm{NC}-400$ electrode presented superior electrochemical performance, including high capacity (120.2 $\mathrm{mAh} \mathrm{g}^{-1}$ at $\left.1 \mathrm{~A} \mathrm{~g}^{-1}\right)$, good rate capability (61.2\% from 1 to $20 \mathrm{~A} \mathrm{~g}^{-1}$ ), and remarkable cyclic ability (retaining $92 \%$ after 10,000 cycles). Furthermore, the $\mathrm{CoSe}_{2} / \mathrm{NC}-400 / / \mathrm{AC}$-based asymmetric device showed an outstanding energy density of $40.9 \mathrm{Wh} \mathrm{kg}^{-1}$ at a high power density of $980 \mathrm{~W} \mathrm{~kg}^{-1}$.

Besides single atom doping, co-doping of multiple atoms is also widely investigated [82]. As reported, various heteroatoms co-dopped in the carbon matrix could play specific roles, such as $\mathrm{N}$ atom boosting capacitance [88], $\mathrm{P}$ atom operating potential window in aqueous electrolyte [89, 90], $\mathrm{O}$ atom promoting the electrode-electrolyte interaction [91, 92], and so on [93]. Moreover, the multiple atoms codoped in the carbon skeleton can play a synergistic coupling effect and effectively improve the electrochemical activities of TMCs/carbon-based electrodes [94]. For example, Hou et al. [17] synthesized $\mathrm{Ni} / \mathrm{Co}-\mathrm{OOH}$ nanosheets decorated with N, S co-doped carbon fragments (NSCF) through an in situ electrochemical self-reconstruction method (Fig. 8d). Even at a high mass loading, the Ni/Co-OOH/NSCF electrode still delivered an ultrahigh capacity and excellent rate capability. Furthermore, as depicted in Fig. 8e, f, an outstanding energy density of $94.3 \mathrm{Wh} \mathrm{kg}^{-1}$ at an ultrahigh power density of $3.6 \mathrm{~kW} \mathrm{~kg}^{-1}$ could be observed based on the assembled asymmetric supercapacitor of $\mathrm{Ni} / \mathrm{Co}-\mathrm{OOH} /$ NSCF//Fe@N-doped carbon. In another article, Zhao and co-workers successfully fabricated $\mathrm{MoS}_{2} /$ nitrogen-phosphorus co-doped graphene composite $\left(\mathrm{MoS}_{2} / \mathrm{NPG}\right)$ via a onepot hydrothermal strategy [95]. The introduction of $\mathrm{N}$ and $\mathrm{P}$ atoms could greatly enhance the conductivity and wettability of graphene. After $\mathrm{N}$ and $\mathrm{P}$ doping, the intimate contact between $\mathrm{MoS}_{2}$ and graphene was largely improved, which could efficiently reduce the electrolyte ions/electrons transfer impedance inside the whole electrode, even across the electrode/electrolyte interfaces. Owing to the synergistic effect of $\mathrm{N}$ and $\mathrm{P}$ doping, the $\mathrm{MoS}_{2} / \mathrm{NPG}$ composite showed an outstanding specific capacitance $\left(588 \mathrm{~F} \mathrm{~g}^{-1}\right)$ in $1 \mathrm{M} \mathrm{Na}_{2} \mathrm{SO}_{4}$ aqueous solution. Moreover, the $\mathrm{MoS}_{2} / \mathrm{NPG}$ electrode-based symmetric supercapacitor device presented a high energy density of $24.34 \mathrm{Wh} \mathrm{kg}^{-1}$ at $300 \mathrm{~W} \mathrm{~kg}^{-1}$. Even at an ultrahigh power density of $5994 \mathrm{~W} \mathrm{~kg}^{-1}$, the energy density still remained $6.66 \mathrm{Wh} \mathrm{kg}^{-1}$.

Despite the heteroatoms-doping carbon displayed improved electrochemical performance in aqueous electrolytes, it may be counterproductive in organic electrolytes. Therefore, systematic study of influence of heteroatom doping on the surface chemistry of carbon materials will be a focus of future research. Moreover, reasonable doping amount and doping type also have a great influence on the electrochemical properties of carbon materials. The amount of dopants in carbon is too low to provide more faradaic pseudocapacitances, too high will sacrifice high conductivity, and different doping types perform various functions such as the forms of nitrogen atoms doped including pyridine $\mathrm{N}$, pyrrolic $\mathrm{N}$, graphitic $\mathrm{N}$, etc.

\subsection{Covalently Heterogeneous Interface}

Be similar to the heteroatoms doping, the introduction of functional groups onto carbon skeleton surface is another necessary strategy to ensure the formation of efficient covalent grafting between TMCs and carbon skeleton through the construction of $\mathrm{M}-\mathrm{O} / \mathrm{N} / \mathrm{P} / \mathrm{S}-\mathrm{C}$ bonds, in which the $\mathrm{M}$ represents TMCs, the $\mathrm{O} / \mathrm{N} / \mathrm{P} / \mathrm{S}$ represents functional groups, and $\mathrm{C}$ represents carbon skeletons. Using strong oxidizing acids (such as nitric and sulfuric acid) to functionalize the carbon surface is the most common method, which can introduce functional groups like amino, carboxyl, hydroxyl, phosphate, or thiol [70]. These superficial functional groups can not only control the loading amount of TMCs but also increase the infiltration of electrode materials in the electrolyte. More 
importantly, the covalent interfaces between TMCs and carbon are beneficial for the improvement of structural stability during the long charge/discharge process.

For example, Ko et al. [74] prepared layer-by-layer assembly films consisting of amine-functionalized carbon nanotubes (CNTs) and oleic acid-stabilized transition metal oxide nanoparticles (OA-TMO NPs) via the direct construction of covalent-bonding interfaces. The covalent interfaces between CNTs and TMO NPs can reduce the internal interfacial resistance and promote fast electron/ions transfer. Therefore, the CNTs/OA-TMO NPs electrode showed excellent electrochemical performance, including high specific capacitance and excellent cycling stability (e.g., the CNTs/ OA-MnO NPs performed the capacity of $305 \mathrm{~F} \mathrm{~cm}^{-3}$ at $5 \mathrm{mV} \mathrm{s}^{-1}$ and capacitance retention of $106 \%$ after 10,000 cycles). In another report, $\mathrm{Ni}(\mathrm{OH})_{2}$ /amino-functionalized graphene quantum dots $\left(\mathrm{Ni}(\mathrm{OH})_{2} / \mathrm{af}-\mathrm{GQDs}\right)$ composite was fabricated by Zheng and his co-workers via a facile mixture stirring method [96]. Obviously, the introduction of amino-groups on graphene surfaces could remarkably promote the ions transport and enhance anchor forces for
$\mathrm{Ni}^{2+}$, which were beneficial for the improvement of electrochemical capacitance. The asymmetric supercapacitor with the $\mathrm{Ni}(\mathrm{OH})_{2} /$ af-GQDs as a positive electrode and electrochemical-exfoliated graphene as negative electrode showed a high energy density of $46.5 \mathrm{Wh} \mathrm{kg}^{-1}$ at $1 \mathrm{~kW} \mathrm{~kg}^{-1}$, which still remained at $16.8 \mathrm{Wh} \mathrm{kg}^{-1}$ even at a high power density of $9 \mathrm{~kW} \mathrm{~kg}^{-1}$.

In addition, Jia et al. [75] encapsulated the $\mathrm{Mn}_{3} \mathrm{O}_{4}$ hollow spheres with modified multi-shell numbers onto the reduced graphene oxide ( $\mathrm{rGO}$ ) surface to obtain the $\mathrm{Mn}_{3} \mathrm{O}_{4}-\mathrm{rGO}$ hybrid materials through oxygen vacancy-assisted hydroxyl modifying method (Fig. 9a). The rGO and multi-shelled $\mathrm{Mn}_{3} \mathrm{O}_{4}$ hollow spheres could form $\mathrm{Mn}-\mathrm{C}-\mathrm{O}$ bond with strong binding forces, which could be identified by the XPS O $1 \mathrm{~s}$ spectrum with the existence of $\mathrm{Mn}-\mathrm{O}-\mathrm{C}$ specific peak (Fig. 9b). As shown in Fig. 9c, d, the $\mathrm{Mn}_{3} \mathrm{O}_{4}-\mathrm{rGO}-2(2$ represents different $\mathrm{rGO}$ weights) with large $\mathrm{Mn}-\mathrm{O}-\mathrm{C}$ content $(42.1 \%)$ exhibited a much higher specific capacitance (561.5 $\mathrm{C} \mathrm{g}^{-1}$ at $1 \mathrm{~A} \mathrm{~g}^{-1}$ ) and more excellent cycling stability (98\% retention after 10,000 cycles). In comparison to the other two hybrid materials, the improved electrochemical
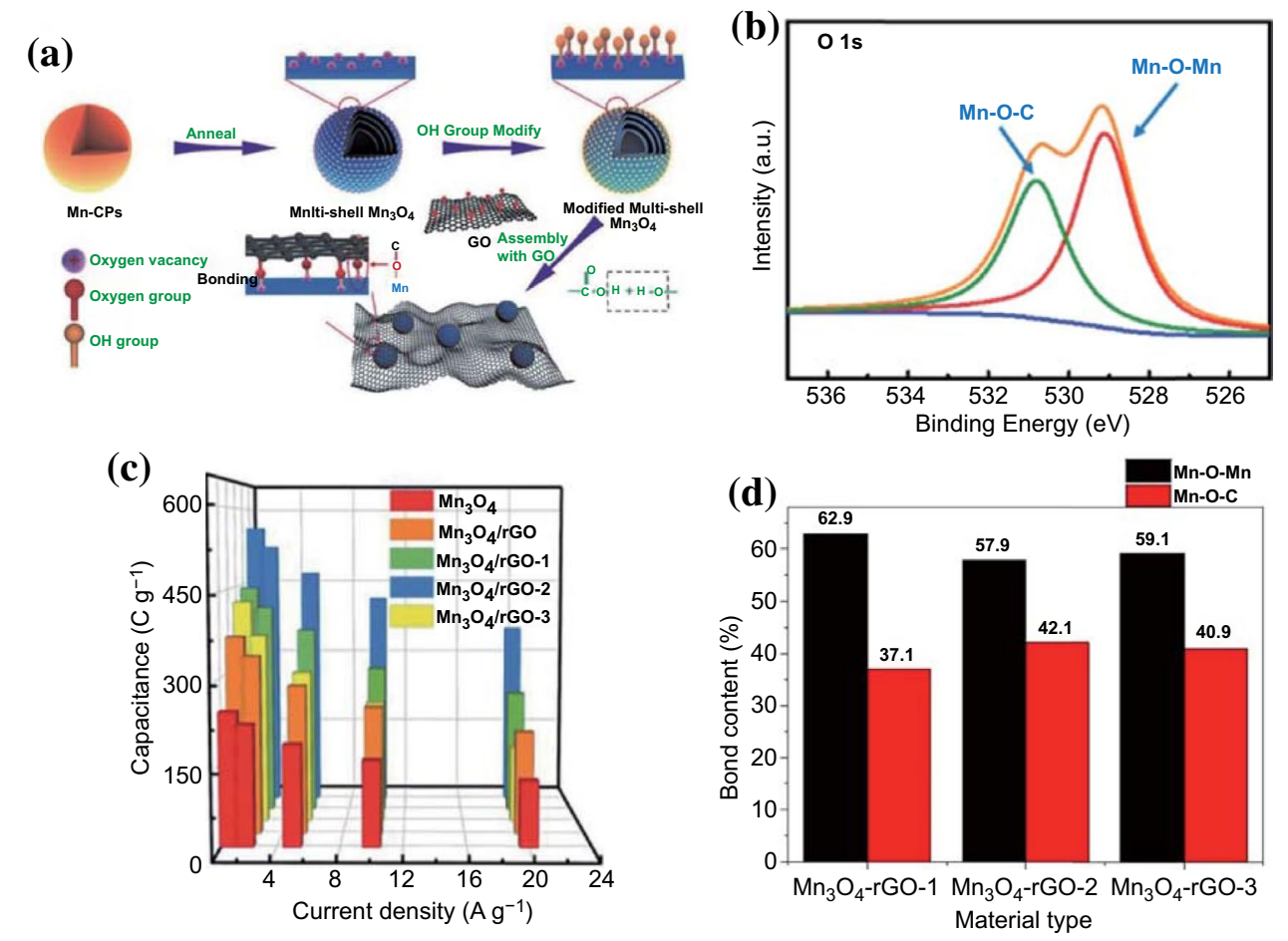

Fig. 9 a Schematic illustration for the fabrication of $\mathrm{Mn}_{3} \mathrm{O}_{4}$-rGO. b O 1s core-level spectra of $\mathrm{Mn}_{3} \mathrm{O}_{4}$-rGO. c The specific capacitance of all samples at different current densities. d Contents of $\mathrm{Mn}-\mathrm{O}-\mathrm{C}$ and $\mathrm{Mn}-\mathrm{O}-\mathrm{Mn}$ in all $\mathrm{Mn}_{3} \mathrm{O}_{4}-\mathrm{rGO}$ samples. Adapted with permission from Ref. [75] Copyright 2019 Royal Society of Chemistry 
performance can be attributed to the construction of covalent heterogeneous interfaces which can ensure the fast charge/ discharge reaction kinetics and ultra-long cycling stabilities [75]. Therefore, to ensure fast and reversible Faradaic redox reactions, the design of strong covalent grafting between carbons and TMCs is a promising strategy that reduces the charge transfer resistance at the interface.

\subsection{Organic Interlayer}

In order to improve the interface stability between TMCs and carbon skeleton, the covalent introduction of organic interlayers onto carbon surface to form the ternary composite is also an efficient method. The organic interlayer between carbon skeleton and TMCs can construct a firm adhesive layer, like glue, connecting the conductive carbon skeleton and pseudocapacitive TMCs. Nowadays, many conductive polymers as carbon coatings have been widely researched, like polyaniline (PANI), polypyrrole (PPy), polythiophene (PTh), etc. [97-99].

Taking polyaniline as an example, Zhu et al. [76] fabricated CuO-PANI-rGO ternary hybrid via an in situ polymerization method followed by hydrothermal treatment (Fig. 10a, b). The introduction of PANI can not only maintain the strong attachment between $\mathrm{CuO}$ nanorods and $\mathrm{rGO}$ surface, but also construct penetrating channels between $\mathrm{CuO}$ and $\mathrm{rGO}$ for rapid charge transfer. As a result, the $\mathrm{CuO}-$ PANI-rGO ternary hybrid displayed a high specific capacitance of $634.4 \mathrm{~F} \mathrm{~g}^{-1}$ at $1 \mathrm{~A} \mathrm{~g}^{-1}$ in an aqueous solution, and the self-assembled typical ternary hybrid device exhibited a high energy density of $126.8 \mathrm{Wh} \mathrm{kg}^{-1}$ at a striking power density of $114.2 \mathrm{~kW} \mathrm{~kg}^{-1}$. Besides, after 10,000 cycles, the specific capacitance lost only remained $2.6 \%$, indicating an outstanding cycle life. In another article, a novel 3D porous graphene/polyaniline $/ \mathrm{Co}_{3} \mathrm{O}_{4}$ ternary hybrid aerogel (3D GPC) was obtained by Lin and co-workers through a similar hydrothermal method [100]. The 3D GPC possessed an excellent electrochemical performance, including high specific capacitance $\left(1247 \mathrm{~F} \mathrm{~g}^{-1}\right.$ at $\left.1 \mathrm{~A} \mathrm{~g}^{-1}\right)$ and superior rate capability $\left(755 \mathrm{~F} \mathrm{~g}^{-1}\right.$ even at a current density of $20 \mathrm{~A} \mathrm{~g}^{-1}$ ). The energy density of $54.5 \mathrm{Wh} \mathrm{kg}^{-1}$ could be achieved at an ultrahigh power density of $3.8 \mathrm{~kW} \mathrm{~kg}^{-1}$ by calculation. The extraordinary capacitive properties of the 3D GPC hybrid can be explained by the following reasons: (a)
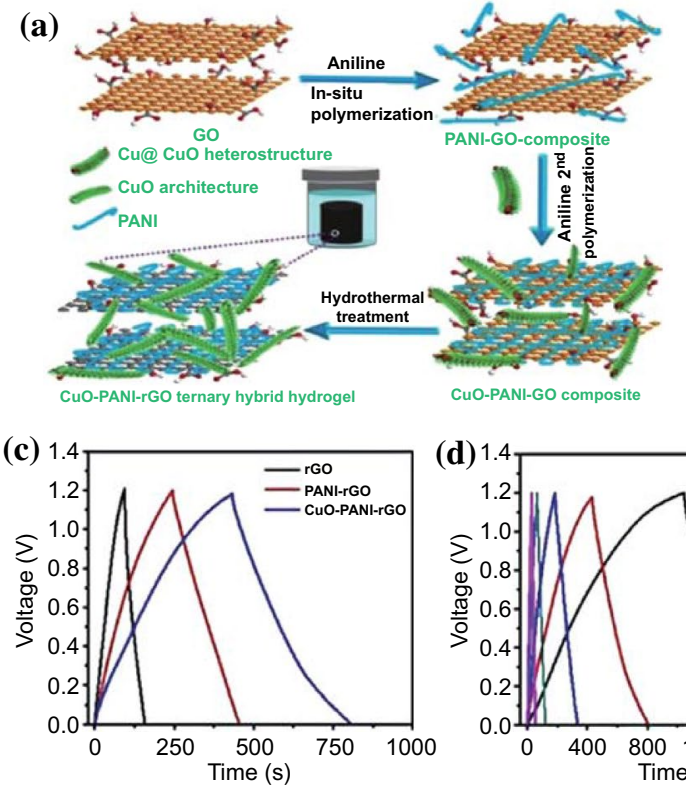

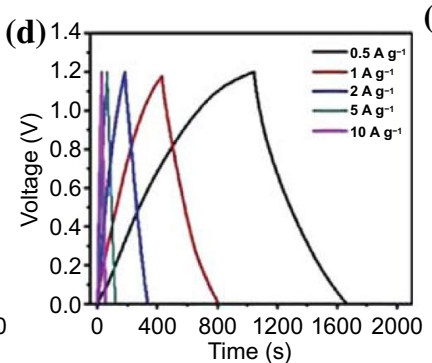

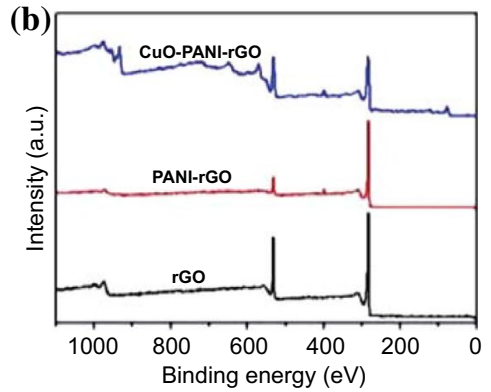

(e)

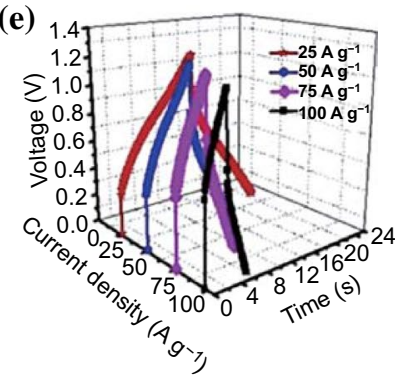

Fig. 10 a Schematic illustration for the self-assembly procedure of the CuO-PANI-rGO ternary hybrid sample. b XPS survey spectra of the typical pure rGO sample, PANI-rGO binary hybrid sample, CuO-PANI-rGO ternary hybrid sample. c GCD curves of the typical CuO-PANI-rGO ternary hybrid sample compared with rGO and PANI-rGO samples at current density of $1.0 \mathrm{~A} \mathrm{~g}^{-1}$. d, e GCD curves of the typical CuO-PANIrGO ternary hybrid sample at different current densities from 0.5 to $10 \mathrm{~A} \mathrm{~g}^{-1}$. Adapted with permission from Ref. [76] Copyright 2016 Elsevier 
(1) the high pseudocapacitance contributed by the PANI and $\mathrm{Co}_{3} \mathrm{O}_{4}$; (2) the synergistic effect provided by the uniformly dispersed PANI/ $\mathrm{Co}_{3} \mathrm{O}_{4}$ NPs onto graphene surface; (3) the effective diffusion paths constructed by the $3 \mathrm{D}$ porous structure. Zhang et al. prepared a series of ternary composites through the incorporation of $\mathrm{NiO}$ nanocrystals into PANbased activated carbon nanofibers (ACNF/PANI/NiO) by the combination of multiple methods [77]. Due to the synergistic effect of NiO nanocrystals and PANI modified carbon substrates, the ACNF/PANI/NiO-0.3 (0.3 represents the mass of $\mathrm{NiO}$ ) composite showed the highest specific capacitance $1157 \mathrm{~F} \mathrm{~g}^{-1}$ at a current density of $1 \mathrm{~A} \mathrm{~g}^{-1}$ in $6 \mathrm{M} \mathrm{KOH}$ electrolyte and still remained $720 \mathrm{~F} \mathrm{~g}^{-1}$ even at a high current density of $10 \mathrm{~A} \mathrm{~g}^{-1}$. Moreover, the ACNF/PANI/NiO-0.3 electrode-based asymmetric supercapacitor exhibited a superior energy density of $14.47 \mathrm{Wh} \mathrm{kg}^{-1}$ at a high power density of $651 \mathrm{~W} \mathrm{~kg}^{-1}$. Organic interlayer introduced between the carbon skeleton and TMCs that not only serves as a "bridge" for accelerating ion transfer in the interface but also provides a high pseudocapacitance, resulting in high capacitance and rate performance.

\subsection{Spatial Confinement}

Besides, in order to construct an efficient binding interface between carbon skeletons and TMCs, the in situ spatial confinement effect also is a useful strategy in the preparation of TMCs/carbon composites [52, 101]. TMCs nanocrystals can be strongly confined in the pore or interlamination of carbon skeletons owing to the physical interaction between TMCs and carbon surface. The spatial confinement effect can not only prevent the emergence of direct detaching of TMCs from carbon surface during the long-term charge/discharge process, but also benefit the fast redox reaction kinetics based on the construction of electron transfer channels. Benefiting from the carbon skeletons with superior conductivity and mechanical strength, the charge transfer properties of TMCs/carbon composites can be largely improved, and the structural stabilities can also be correspondingly preserved, which exhibit great advantageous for the power/energy densities and long cycle life.

For example, Cao et al. fabricated a porous $\mathrm{rGO} / \mathrm{MoO}_{3}$ composite that the $\mathrm{MoO}_{3}$ particles were strongly wrapped by reduced graphene oxide (rGO) nanosheets through a
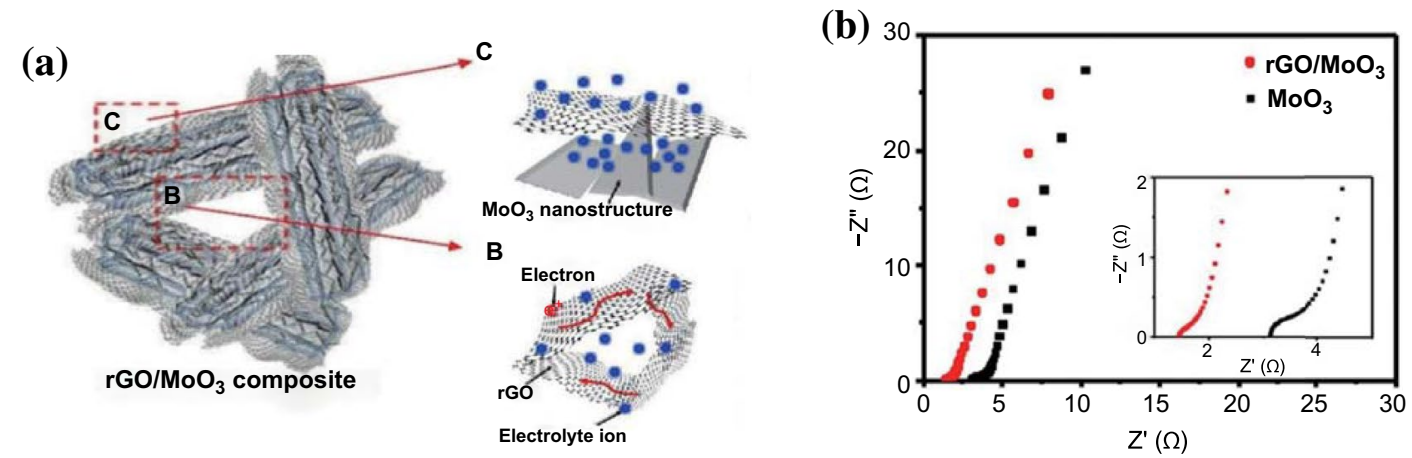

(c)
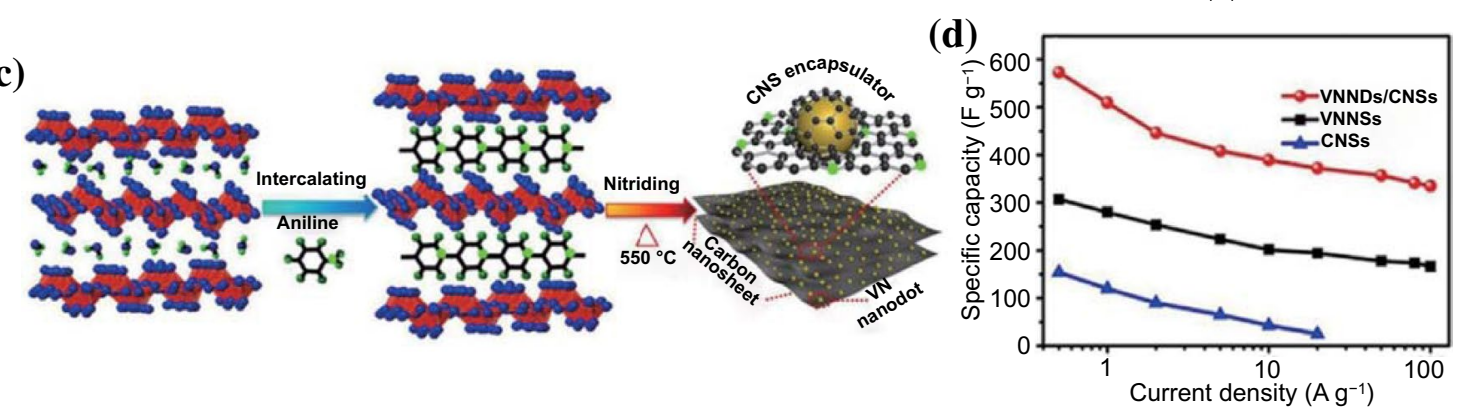

Fig. 11 a Schematic illustration of the unique structure and synergetic effect of $\mathrm{rGO} / \mathrm{MoO}_{3}$ composite. b Nyquist plot of the $\mathrm{rGO} / \mathrm{MoO}{ }_{3}$ composite and $\mathrm{MoO}_{3}$. Adapted with permission from Ref. [102] Copyright 2015 Wiley-VCH. c Schematic illustration of the preparation procedures of the VNNDs/CNSs. d Gravimetric capacitances of VNNDs/CNSs, VNNSs, and CNSs at different current densities. Adapted with permission from Ref. [78] Copyright 2018 Elsevier 
simple mixture of Mo-MOFs and rGO sheets followed by an annealing process (Fig. 11a) [102]. As shown in Fig. $11 \mathrm{~b}$ the conductivity of $\mathrm{rGO} / \mathrm{MoO}_{3}$ composite was greatly improved in comparison to pristine $\mathrm{MoO}_{3}$, which mainly attributed to the unique structure and synergetic effect of $\mathrm{rGO} / \mathrm{MoO}_{3}$ composite. The rGO network greatly reduced the impedance by providing a highly conductive and porous pathway for allowing fast electrons and ions transfer, which was beneficial for the improvement of rate performance. Moreover, the rGO film wrapping around $\mathrm{MoO}_{3}$ prevented the detaching and aggregation of $\mathrm{MoO}_{3}$ nanomaterials, greatly improving the superior cycling capability. Therefore, an all-solid-state flexible supercapacitor device based on $\mathrm{rGO} / \mathrm{MoO}_{3}$ composite delivered a good energy density of $14 \mathrm{Wh} \mathrm{kg}^{-1}$ at a high power density of $500 \mathrm{~W} \mathrm{~kg}^{-1}$ and excellent capacitance retention of $\approx 80 \%$ after 5000 cycles at $2 \mathrm{~A} \mathrm{~g}^{-1}$.

Carbon nanosheets/VN nanodots (VNNDs/CNSs) hybrid electrode material was prepared by $\mathrm{Li}$ and co-workers via a facile spatially confined strategy that the VN nanodots (VNNDs) were intercalated into carbon nanosheets (CNSs) (Fig. 11c) [78]. The strategy can well disperse the VNNDs along with the formation of the pillared lamellar structure of CNSs and provide abundant active sites and enhance fast electrolyte ions/electrons diffusion kinetics. The VNNDs encapsulated in CNSs layers could effectively impede the electrochemical oxidation of $\mathrm{VN}$ and maintain a more stable structure during the longtime charge/discharge process. Compared with VNND or CNSs, the VNNDs/CNSs hybrid electrode exhibited an ultrahigh specific capacitance $\left(573.1 \mathrm{~F} \mathrm{~g}^{-1}\right.$ at $0.5 \mathrm{~A} \mathrm{~g}^{-1}$ ) and an excellent rate capability (the capacity retention of $58.4 \%$ at $100 \mathrm{~A} \mathrm{~g}^{-1}$ compared with that at $0.5 \mathrm{~A} \mathrm{~g}^{-1}$ ) (Fig. 11d). Moreover, the symmetric all solid-state flexible supercapacitors assembled by VNNDs/ CNSs electrodes and KOH/PVA gel electrolyte showed an outstanding volumetric energy density of $16.1 \mathrm{Wh} \mathrm{L}^{-1}$ at an ultrahigh volumetric power density of $64,500 \mathrm{~W} \mathrm{~L}^{-1}$, proving a large potential in the next-generation energy storage devices high energy density.

Yang and his co-works successfully obtained $\mathrm{Co}_{3} \mathrm{O}_{4} / \mathrm{P}$, $\mathrm{N}$ co-doped carbon composites $\left(\mathrm{Co}_{3} \mathrm{O}_{4} @ \mathrm{PNC}\right)$ through confining the growth of $\mathrm{Co}_{3} \mathrm{O}_{4}$ nanoparticles within the nanopores of $\mathrm{P}, \mathrm{N}$ co-doped carbon material [103]. Compared with $\mathrm{Co}_{3} \mathrm{O}_{4}$ (about $320 \mathrm{~F} \mathrm{~g}^{-1}$ ), the $\mathrm{Co}_{3} \mathrm{O}_{4} @ \mathrm{PNC}-2$ ( 2 represents mass loadings of $\mathrm{Co}_{3} \mathrm{O}_{4}$ ) composite showed a higher specific capacitance of $1310 \mathrm{~F} \mathrm{~g}^{-1}$ at $0.5 \mathrm{~A} \mathrm{~g}^{-1}$, which still remained at $655 \mathrm{~F} \mathrm{~g}^{-1}$ even at a high current density of $20 \mathrm{~A} \mathrm{~g}^{-1}$, indicating an excellent rate capability. This obvious improvement was mainly attributed that the introduction of carbon can not only enhance the conductivity of composite but also keep the uniform distribution of $\mathrm{Co}_{3} \mathrm{O}_{4}$ nanoparticles with ultrasmall size $(2-5 \mathrm{~nm})$. As a result, the asymmetric supercapacitor based on $\mathrm{Co}_{3} \mathrm{O}_{4} @$ PNC-2//AC exhibited an ultra-high energy density of $47.18 \mathrm{Wh} \mathrm{kg}^{-1}$ at $375 \mathrm{~W} \mathrm{~kg}^{-1}$ and maintained at $34.22 \mathrm{Wh} \mathrm{kg}^{-1}$ even at an ultra-high power density of $7.5 \mathrm{~kW} \mathrm{~kg}^{-1}$.

As a kind method of spatial constraint, the design of core-shell structure also plays a crucial role in improving the electrochemical performance of TMCs [104]. Carbon shell with high mechanical strength not only could enhance the electrical conductivity of composite, but also protect against the degradation and aggregation of TMCs nanoparticles. In this case, Yoon et al. [79] designed and developed a novel millerite core-nitrogen-doped carbon hollow shell (NiS-NC HS) structure by using PD-derived carbon as coated and $\mathrm{NiS}$ as the core. Compared with pristine $\mathrm{Ni}_{3} \mathrm{~S}_{2}\left(828.21 \mathrm{~F} \mathrm{~g}^{-1}\right)$, the maximum specific capacitance of NiS-NC HS was $1170.72 \mathrm{~F} \mathrm{~g}^{-1}$ at $0.5 \mathrm{~A} \mathrm{~g}^{-1}$, and $90.71 \%$ of its initial capacitance could be maintained at $6 \mathrm{~A} \mathrm{~g}^{-1}$ after 4000 charge-discharge cycles. Moreover, the electrode still could retain $72.1 \%$ of its maximum capacitance even through the current density increasing to $10 \mathrm{~A} \mathrm{~g}^{-1}$, displaying a twofold higher rate capability compared with the pristine $\mathrm{Ni}_{3} \mathrm{~S}_{2}(34.56 \%)$. In another article, a T- $\mathrm{Nb}_{2} \mathrm{O}_{5} @$ carbon hollow core-shell nanostructures are constructed by Zhang et al. via using silica as a template [105]. The T- $-\mathrm{Nb}_{2} \mathrm{O}_{5} @$ carbon hollow core-shell nanostructures showed significant improvement in the rate capability (from 34 to 59\%) compared to the $\mathrm{T}-\mathrm{Nb}_{2} \mathrm{O}_{5}$ nanoparticles. More interestingly, hybrid supercapacitors based on the composite exhibited a stable cycle performance $(85 \%$ capacitance retention after 10,000 cycles) and still processed an energy density of $12 \mathrm{Wh} \mathrm{kg}^{-1}$ at $16 \mathrm{~kW} \mathrm{~kg}$. These results indicated that design of core-shell structure processed great constraining force for TMCs, in which carbon shell could not only enhance the whole conductivity for facilitating the electron transport, but also relieve the volume expansion of TMCs during the charge-discharge process, thereby ensuring the high rate capability and superior cycle stability. 
Till now, despite the interface design of TMCs/carbon has already done a lot of research, achieving both outstanding energy density and superior power density of electrode materials is still a huge challenge, and the crucial challenge is to build up stable interface incorporation between carbon and TMCs. The combination of physical spatial constraints and chemical bonding may be a more efficient manner for achieving rapid electrons transfer at the interface of TMCs/ carbon-based electrodes in the future.

\section{Regulation of TMC's Electronic Structure}

For most of TMCs, the regulation of electronic structure plays a crucial role in enhancing the electrochemical performance of supercapacitors [16, 106, 107]. For example, owing to the different interlink manners, manganese oxides exhibited abundant crystalline structures (including $\alpha, \beta, \gamma, \delta$, and $\lambda$ forms), leading to different electronic structure [108]. Particularly, when the crystal size of TMCs is decreased to nanometer scale or quantum dots, the physical and chemical properties of such materials can make significant changes owing to some special effects such as small size effect, quantum tunneling effect, and surface effect. Moreover, doping heterogeneous atoms to adjust the crystal electronic structure followed by the synergistic effect of multi-metal can also further enhance the electrochemical performance [109, 110]. In recent years, the adjustment of TMC's electronic structure to optimize TMCs/carbon electrodes has been investigated extensively for supercapacitors [16, 111, 112]. In this section, we will summarize the recent progress from the aspects of the effect of nano-crystallization or quantum dots construction, heterogeneous atoms doping, defects, and construction of heterogeneous interfaces in the regulation of TMC's electronic structure for TMCs/carbon-based supercapacitors with both high energy/power densities.

\subsection{Nano-Crystallization or Quantum Dots}

Due to the sluggish reaction kinetics, poor electrical conductivity, and volumetric expansion effect, the high power densities and long cycle lives of TMC-based electrodes are greatly prevented in the practical application of supercapacitors. To solve the above challenges, the design of TMCs with nano-crystallization or quantum dots size is considered as an effective strategy [46]. Specifically, nano-structured TMCs can provide larger electrochemical active surfaces owing to surface effect, which shortens the ion diffusion distances and increases the contact areas with electrolytes $[113,114]$. For example, Wang et al. [115] synthesized sub-nanometer, ultrafine a- $\mathrm{Fe}_{2} \mathrm{O}_{3}$ sheets loading on graphene $\left(\mathrm{SU}-\mathrm{Fe}_{2} \mathrm{O}_{3}-\right.$ rGO) by controlling the crystallization kinetics (As shown in Fig. 11a). Compared with the $\mathrm{NP}-\mathrm{Fe}_{2} \mathrm{O}_{3}-\mathrm{rGO}$ microparticles, the $\mathrm{SU}-\mathrm{Fe}_{2} \mathrm{O}_{3}-\mathrm{rGO}$ with the ultrathin thickness (only about $0.9 \mathrm{~nm}$ ) and smaller lateral size (about $14.5 \mathrm{~nm}$ ) can avoid the slow ion diffusion kinetics in the bulk phase of $\mathrm{Fe}_{2} \mathrm{O}_{3}$ and greatly facilitate the ion/electron transport during electrochemical reactions (Fig. 12b). As a result, the $\mathrm{SU}-\mathrm{Fe}_{2} \mathrm{O}_{3}$ rGO electrode exhibited a superior specific capacitance of $1575 \mathrm{~F} \mathrm{~g}^{-1}$ at $1.25 \mathrm{~A} \mathrm{~g}^{-1}$ and remained at $955 \mathrm{~F} \mathrm{~g}^{-1}$ even at a high current density of $25 \mathrm{~A} \mathrm{~g}^{-1}$, indicating a superior rate performance. When assembled as asymmetric supercapacitor using $\mathrm{SU}-\mathrm{Fe}_{2} \mathrm{O}_{3}-\mathrm{rGO}$ as anode and $\mathrm{NiCo}_{2} \mathrm{O}_{4}$ hybrid as cathode, a high energy density of $43.6 \mathrm{Wh} \mathrm{kg}^{-1}$ could be achieved at a power density $844 \mathrm{~W} \mathrm{~kg}^{-1}$ (Fig. 12c) and the device possessed excellent cycle life with a capacitance retention of $106.4 \%$ after 30,000 cycles at $5 \mathrm{~A} \mathrm{~g}^{-1}$.

In a similar case, the GCFS- 0.33 electrode with high specific capacitance $\left(310.2 \mathrm{C} \mathrm{g}^{-1}\right.$ at $2 \mathrm{mV} \mathrm{s}^{-1}$ ) was obtained in which the ternary $\mathrm{Co}_{0.33} \mathrm{Fe}_{0.67} \mathrm{~S}_{2}$ nanoparticles (10-60 nm) were embedded between the graphene nanosheets through a facile one-step hydrothermal method [116]. When the GCFS- 0.33 composites and sulfurized graphene/CoNiAllayered double hydroxides were used as the negative and positive electrode, respectively, the as-fabricated ASCs exhibited a high energy density of $66.8 \mathrm{Wh} \mathrm{kg}^{-1}$ at a power density of $300.5 \mathrm{~W} \mathrm{~kg}^{-1}$ and still retained a high energy density of $13.1 \mathrm{Wh} \mathrm{kg}^{-1}$ even at an ultrahigh power density of $29.4 \mathrm{~kW} \mathrm{~kg}^{-1}$. Such a robust sandwich-like structure with superior mechanical integration and high electrical conductivity can provide unobstructed pathways for the fast diffusion/transportation of electrolyte ions/electrons during rapid charge/discharge processes, which is beneficial to improve the rate capability. Wang et al. [117] have synthesized a $\mathrm{Ni}_{3} \mathrm{~S}_{2} @ \mathrm{Co}_{9} \mathrm{~S}_{8} / \mathrm{N}-\mathrm{HPC}$ composite in which the $\mathrm{Ni}_{3} \mathrm{~S}_{2}$ attaching $\mathrm{Co}_{9} \mathrm{~S}_{8}$ nanocrystal was encapsulated into a $3 \mathrm{D} \mathrm{N}$-doped hierarchical porous carbon (N-HPC). The strawberry-like $\mathrm{Ni}_{3} \mathrm{~S}_{2} @ \mathrm{Co}_{9} \mathrm{~S}_{8}$ nanoparticles (average diameter of $900 \mathrm{~nm}$ ) confined in the carbon skeleton can provide high theoretical specific capacitance, and 3D interconnected hierarchical porous carbon framework can construct fast electrolyte ions/ 


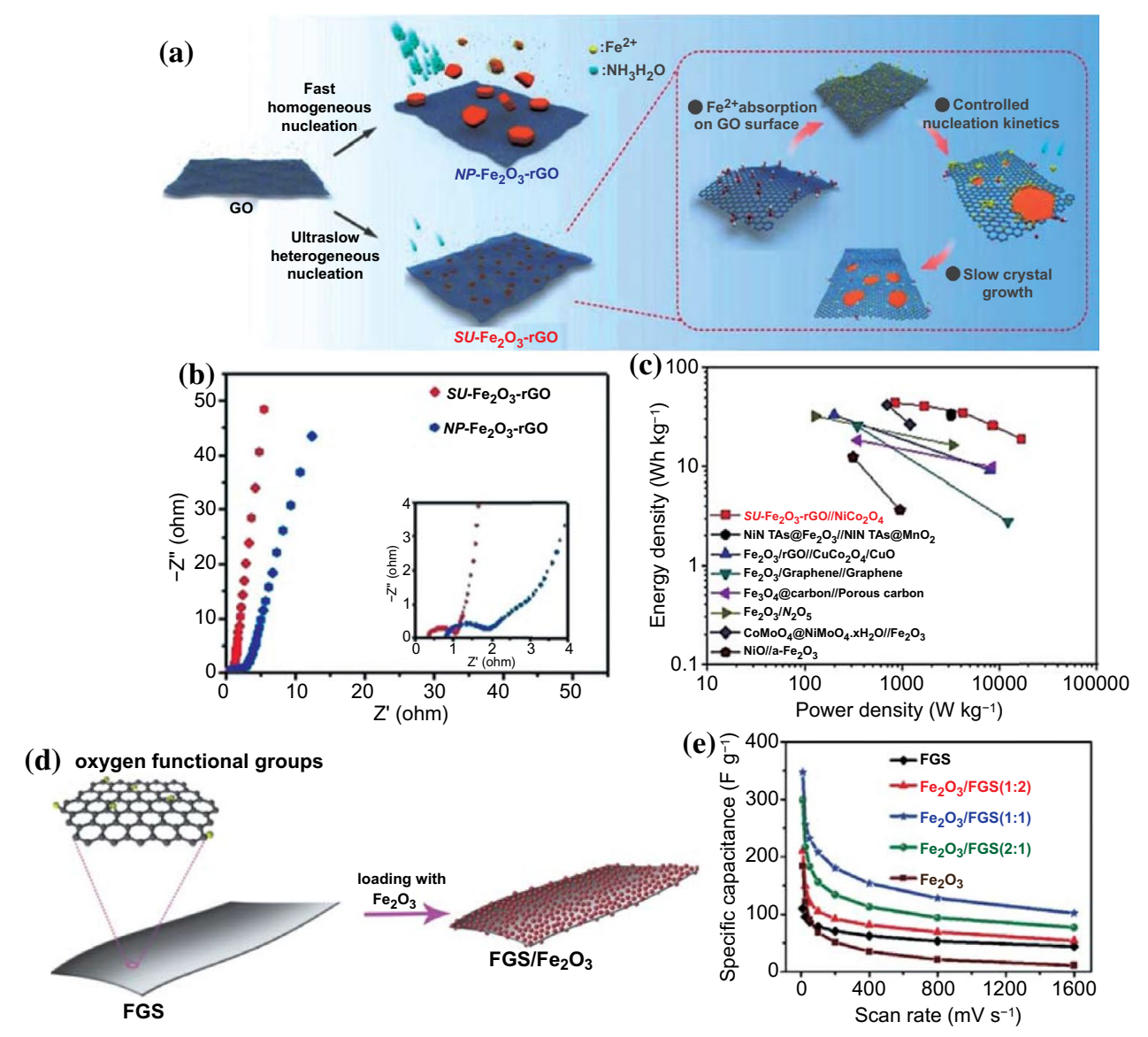

Fig. 12 a Schematic illustration of the growth of $\mathrm{SU}-\mathrm{Fe}_{2} \mathrm{O}_{3}$ sheets on graphene by means of controlled crystallization kinetics. b Comparison of electrochemical impedance of different size of $\mathrm{Fe}_{2} \mathrm{O}_{3}-\mathrm{rGO}$. $\mathbf{c}$ Ragone plot related to the energy and power densities of $\mathrm{SU}-\mathrm{Fe}_{2} \mathrm{O}_{3}-\mathrm{rGO}_{/} / \mathrm{NiCo}_{2} \mathrm{O}_{4}$. Adapted with permission from Ref. [115] Copyright 2019 Wiley-VCH. d Schematic illustration of $\mathrm{Fe}_{2} \mathrm{O}_{3} / \mathrm{FGS}$ composite. e Specific capacitances of the pristine FGS, $\mathrm{Fe}_{2} \mathrm{O}_{3}$, and $\mathrm{Fe}_{2} \mathrm{O}_{3} / \mathrm{FGS}$ composite electrodes at different scan rate. Adapted with permission from Ref. [24] Copyright 2015 Wiley-VCH

electrons transfer channels. Benefiting from the synergistic effect, the $\mathrm{Ni}_{3} \mathrm{~S}_{2} @ \mathrm{Co}_{9} \mathrm{~S}_{8} / \mathrm{N}-\mathrm{HPC}$ composite showed an ultrahigh specific capacitance and excellent cycling stability. In addition, the $\mathrm{Ni}_{3} \mathrm{~S}_{2} @ \mathrm{Co}_{9} \mathrm{~S}_{8} / \mathrm{N}-\mathrm{HPC} / / \mathrm{HPC}$ was assembled into an ASCs in a $6 \mathrm{M} \mathrm{KOH}$ electrolyte. The ASCs delivered a high energy density of $77.1 \mathrm{~W} \mathrm{~h} \mathrm{~kg}^{-1}$ at $263.3 \mathrm{~W} \mathrm{~kg}^{-1}$ and still remained as high as $36.1 \mathrm{Wh} \mathrm{kg}^{-1}$ even at an ultrahigh power density of $25.9 \mathrm{~kW} \mathrm{~kg}^{-1}$.

Quantum dots (QDs) have presented an exponential growth of research in various potential applications in the last decades, especially in supercapacitors [118-121]. Due to the quantum effect, TMCs-QDs as electrode materials for supercapacitors have received extensive attention [122]. For example, Xia et al. synthesized $\mathrm{Fe}_{2} \mathrm{O}_{3} / \mathrm{FGS}$ hybrid materials that $\mathrm{Fe}_{2} \mathrm{O}_{3}$ quantum dots (QDs) (about $2 \mathrm{~nm}$ ) were uniformly decorated on the functionalized graphene sheets (FGS) through a thermal decomposition method (Fig. 12d) [24]. The $\mathrm{Fe}_{2} \mathrm{O}_{3}$ QDs can be evenly dispersed on the surface of FGS with a proper mass ratio of $\mathrm{Fe}_{2} \mathrm{O}_{3} / \mathrm{FGS}$ (2:1), and the high conductivity and large surface area of FGS efficiently suppress the agglomeration of $\mathrm{Fe}_{2} \mathrm{O}_{3}$ QDs. As a result, the asymmetrical supercapacitor based on $\mathrm{Fe}_{2} \mathrm{O}_{3} /$ FGS exhibited a high energy density of $50.7 \mathrm{Wh} \mathrm{kg}^{-1}$ at a power density of $100 \mathrm{~W} \mathrm{~kg}^{-1}$ and cycling stability of $95 \%$ after 5000 cycles in a voltage window of $2 \mathrm{~V}$. Moreover, a $\mathrm{Nb}_{2} \mathrm{O}_{5}$ QD-NC hybrid material was prepared by Liu et al. that $\mathrm{Nb}_{2} \mathrm{O}_{5}$ quantum dots (about $5 \mathrm{~nm}$ ) were successfully embedded into the nitrogen-doped porous carbon (NC) derived from ZIF-8 dodecahedrons [123]. When assembled with commercial activated carbon cathode, the hybrid supercapacitors (HSCs) 
showed a high energy density of $76.9 \mathrm{Wh} \mathrm{kg}^{-1}$ at an ultrahigh power density of $11,250 \mathrm{~W} \mathrm{~kg}^{-1}$ and superior cycling stability (about capacity retention of $85 \%$ ) in an organic condition. The excellent performance of $\mathrm{Nb}_{2} \mathrm{O}_{5}$ QD-NC can be ascribed to the following reasons: (1) the high surface area and highly porous structure of $\mathrm{NC}$ can provide more ion attachment site which is beneficial for the fast electrolyte ions/electrons transfer; (2) ultrasmall size (ca. $5 \mathrm{~nm}$ ) may shorten the ion diffusion and electron transportation distance; (3) the uniform distribution of $\mathrm{Nb}_{2} \mathrm{O}_{5}$ QDs and strongly interfacial binding between $\mathrm{Nb}_{2} \mathrm{O}_{5}$ QDs and $\mathrm{NC}$ can prevent the volume change upon cycling; (4) N doping may boost the electronic properties and provide additional charge-storage sites.

In contrast to conventional bulk materials, TMCs with nanoscale size can greatly improve ionic and electronic transport, which may be a promising solution for the achievement of both high energy and power densities for TMCs/carbon-based supercapacitors [124]. Consequently, nanoscale TMCs crystals supported by the conductive carbon skeletons can not only avoid the deficiency of single material, but also greatly boost the practical application of $\mathrm{TMCs} /$ carbon electrodes in energy storage devices.

\subsection{Heterogeneous Atoms Doping}

Heterogeneous atoms doping is another effective strategy, which can fundamentally regulate the electronic structure and alter the electron distribution to further improve the reaction activity and the electrochemical performance of TMCs/carbon based supercapacitors [125, 126]. According to the doping type, heterogeneous atoms doping can be divided into cation doping (heterogeneous metal atoms, e.g., $\mathrm{Ni}$ and $\mathrm{Co}$, $\mathrm{Co}$ and $\mathrm{W}, \mathrm{Mn}$ and $\mathrm{Fe}$, even more, metal atoms, etc.) and anion doping (e.g., N, P, or F). Owing to the synergistic effect of the multiple transition metal atoms, combination of various TMCs can provide highly electrochemical conductivity and abundant redox activity, which is beneficial for the electrochemical performance [127, $128,129]$. For example, Liu's group systematically studied the influence of cobalt and manganese atoms ( $\mathrm{Co}, \mathrm{Mn}$ ) on the single doping or co-doping of $\mathrm{Ni}(\mathrm{OH})_{2}$ crystals by DFT calculations [130]. The Mn doping could increase the capacity owing to the lower deprotonation energy and facile electron transfer path, while the Co doping could improve the structural stability of the entire electrode (Fig. 13e-g) [130]. As shown in Fig. 13b-d, the Ni-Co-Mn-OH/rGO// $\mathrm{PPD} / \mathrm{rGO}$ hybrid capacitor demonstrated remarkable energy densities of 74.7 and $49.9 \mathrm{~W} \mathrm{~kg}^{-1}$ at the power densities of 1.68 and $18.5 \mathrm{~kW} \mathrm{~kg}^{-1}$, respectively. Moreover, $91 \%$ of its initial capacity could be retained after 10,000 cycles at $20 \mathrm{~A} \mathrm{~g}^{-1}$, showing super-fast energy storage capacity and long cycle life. In another article, Mohamed et al. [131] fabricated Co-W-S composites in an N, S co-doped porous carbon matrix (Co-W-S@N, S-PC) using PTA@ZIF-67 as a precursor via a simple carbonization method. Compared with the $\mathrm{Co}_{1-x} \mathrm{~S} @ \mathrm{~N}, \mathrm{~S}-\mathrm{PC}$, the introduction of $\mathrm{W}$ atom could not only increase the redox activity of transition metal redox centers, but also provide additional faradaic pseudocapacitance. As a result, the Co-W-S@N, S-PC electrode demonstrated an ultrahigh specific capacitance $\left(1929 \mathrm{~F} \mathrm{~g}^{-1}\right.$ at $5 \mathrm{mV} \mathrm{s}^{-1}$ ). Furthermore, the asymmetric supercapacitor device based on Co-W-S@N, S-PC//AC delivered a superior energy density of $32.9 \mathrm{Wh} \mathrm{kg}^{-1}$ at the high power density of $700.2 \mathrm{~W} \mathrm{~kg}^{-1}$ and good cyclic stability with capacitance retention of $77 \%$ after 5000 cycles at $10 \mathrm{~A} \mathrm{~g}^{-1}$.

In contrast to cation doping, the anion doping of TMCs based electrodes is rarely reported. The experimental results and DFT calculations have confirmed that the anion-doping in TMCs could act as an effective approach to enhance the electrochemical conductivity and improve the reaction kinetics [53, 132]. For example, Liu et al. developed a $\mathrm{P}-\mathrm{CoS}_{2} @ \mathrm{P}, \mathrm{S}, \mathrm{N}-\mathrm{C}$ hybrid of P-doped $\mathrm{CoS}_{2}\left(\mathrm{P}-\mathrm{CoS}_{2}\right)$ nanoparticles confined in highly conductive $\mathrm{P}, \mathrm{S}, \mathrm{N}$ tri-doped carbon skeleton (P, S, N-C) [133]. The P-CoS $2 @ \mathrm{P}, \mathrm{S}, \mathrm{N}-\mathrm{C}$ hybrid delivered a high specific capacity of $689 \mathrm{C} \mathrm{g}^{-1}$ at $2 \mathrm{~A} \mathrm{~g}^{-1}$, and still possessed capacitance retention of $77.5 \%$ even at a high current density of $30 \mathrm{~A} \mathrm{~g}^{-1}$. This was mainly because the introduction of $\mathrm{P}$ atom could enhance the covalency and decrease the migration energy of electrons, which largely boosted the electrochemical conductivity. In addition, ultrafine $\mathrm{P}_{-}-\mathrm{Co}_{3} \mathrm{O}_{4}$ nanoparticles embedded into $\mathrm{P}, \mathrm{N}-\mathrm{C}$ nanowires $\left(\mathrm{P}-\mathrm{Co}_{3} \mathrm{O}_{4} @ \mathrm{P}, \mathrm{N}-\mathrm{C}\right)$ were also prepared via an in situ structural reconstruction strategy [53]. The theoretical calculation and experimental results showed that $\mathrm{P}$ doping could improve the electrochemical reactivity and facilitate the electrons/ions transport. Therefore, the appropriate incorporation of a small number of heterogeneous atoms into TMCs can not only provide additional capacity but also improve its electrical conductivity, which provides a helpful way to regulate the electronic structure of the TMCs. 
(a)

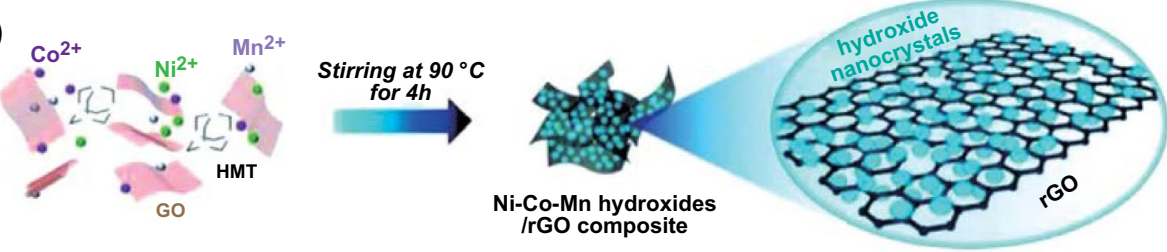

(b)

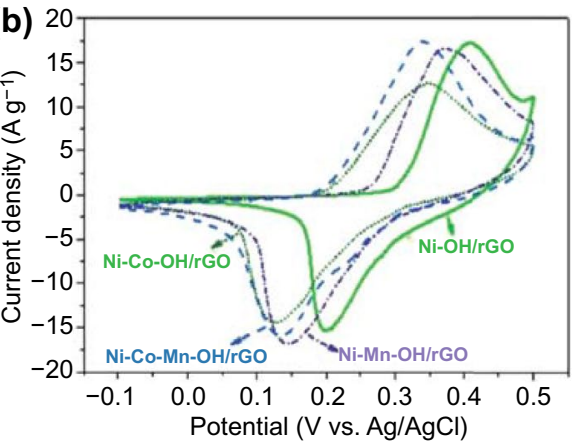

(c)

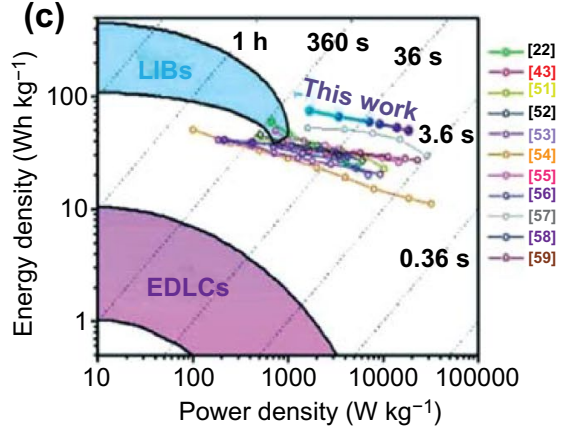

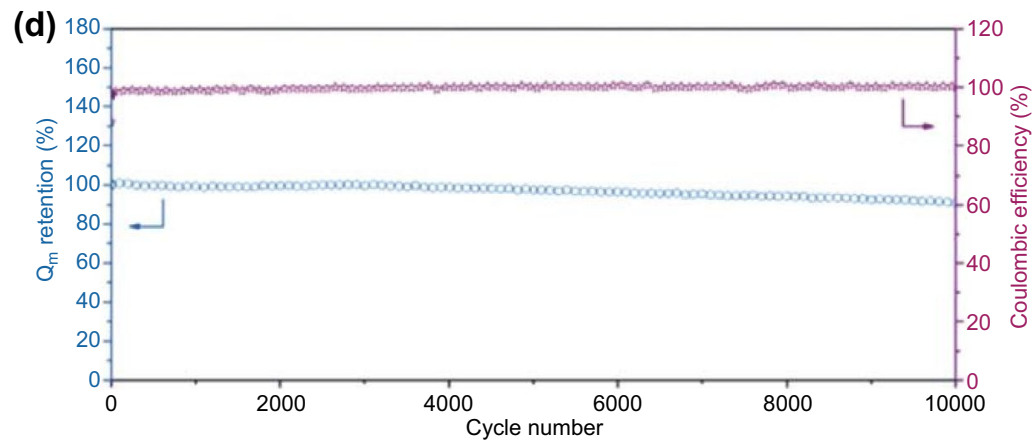
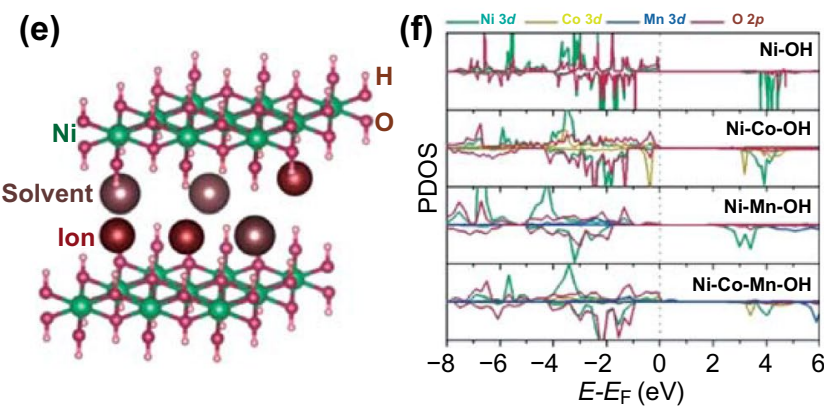

(g)
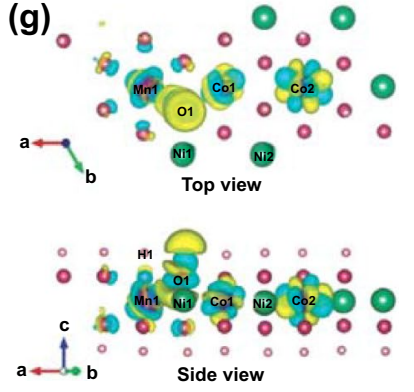

Fig. 13 a Schematic illustration of the preparation of $\mathrm{Ni}-\mathrm{Co}-\mathrm{Mn}-\mathrm{OH} / \mathrm{rGO}$. b CV curves at $5 \mathrm{mV} \mathrm{s}{ }^{-1}$. c Ragone plot of the Ni-Co-Mn-OH/ $\mathrm{rGO} / / \mathrm{PPD} / \mathrm{rGO}$ hybrid supercapacitor device. $\mathbf{d}$ Cycling performance of the hybrid supercapacitor device at $20 \mathrm{~A} \mathrm{~g}^{-1}$. e-g Schematic illustration of nickel hydroxide-layered structure with interlayer species and two possible mechanisms to store charge and density of state (PDOS) diagrams. Adapted with permission from Ref. [130] Copyright 2018 Wiley-VCH

\subsection{Defects}

Defects, such as vacancies, edges, grain boundaries, substitutional impurities, and so on, always play significant roles in improving geometric and electronic structures of TMCs [134]. Different defects often play different functions in improving the electrochemical performance of TMCs, such as vacancies increasing more active sites and enhancing conductivity $[135,136]$, substitutional impurities providing additional capacitances and so on [131, 137]. Specifically, the vacancies including metal vacancies and nonmetallic vacancies have been extensively explored to accelerate the intrinsic conductivity and redox activity of TMCs for supercapacitors [136, 138, 139]. In this part, taking oxygen 
vacancies, for example, we will mainly discuss the effect of oxygen vacancies on the electrochemical performance of transition metal oxides (TMOs) based supercapacitors.

Kim et al. have confirmed that the presence of oxygen vacancies in $\alpha-\mathrm{MoO}_{3}$ can greatly improve the electrical conductivity (electrical conductivity from $10^{-5} \mathrm{~S} \mathrm{~cm}^{-1}$ increasing to $10^{-4} \mathrm{~S} \mathrm{~cm}^{-1}$ ) and broaden the interlayer spacing. The experimental results showed that $\mathrm{MoO}_{3-x}$ had higher capacity $\left(\sim 550 \mathrm{C} \mathrm{g}^{-1}\right)$ and better cycling stability $(76 \%$ after $10,000$ cycles $)$ compared with $\mathrm{MoO}_{3}\left(<400 \mathrm{C} \mathrm{g}^{-1}, 50 \%\right.$ after 50 cycles) at a sweep rate of $100 \mathrm{mV} \mathrm{s}^{-1}$ [140]. The incorporation of oxygen vacancies could act as electron donors and consequently increase the free carrier concentration as well as provide more exposed electrochemical active sites, resulting in improved electrochemical properties [141]. To gain abundant oxygen vacancies, Yang and co-workers firstly prepared ultrafine $\mathrm{Co}_{3} \mathrm{O}_{4}$ nanoparticles/graphene (UCNG) composites with abundant oxygen-vacancy via a new-type one-step laser irradiation strategy [142]. The theoretical calculations demonstrated that the surface oxygen vacancies could promote the electrons transfer by creating midgap electronic states. As a result, the UCNG electrode achieved a high specific capacitance of $978.1 \mathrm{~F} \mathrm{~g}^{-1}$ at $1 \mathrm{~A} \mathrm{~g}^{-1}$ and more than capacitance retention of $93.7 \%$ even at a high current density of $10 \mathrm{~A} \mathrm{~g}^{-1}$. Moreover, based on the fluorinedoped, Liu et al. [125] successfully fabricated $\mathrm{F}_{-} \mathrm{Co}_{2} \mathrm{MnO}_{4}$ $\mathrm{x} / \mathrm{CF}$ composite by introducing oxygen vacancies into $\mathrm{Co}_{2} \mathrm{MnO}_{4}$ (Fig. 14a). As advanced electrode materials for supercapacitor, the $\mathrm{F}-\mathrm{Co}_{2} \mathrm{MnO}_{4-x} / \mathrm{CF}$ exhibited a higher specific capacity of $269 \mathrm{mAh} \mathrm{g}^{-1}$ and more superior cyclic stability $(93.3 \%$ of the initial specific capacity after 5000 cycles) in comparison to the $\mathrm{F}-\mathrm{Co}_{2} \mathrm{MnO}_{4} / \mathrm{CF}\left(204 \mathrm{mAh} \mathrm{g}^{-1}\right.$, 90.9\%) and $\mathrm{Co}_{2} \mathrm{MnO}_{4} / \mathrm{CF}\left(165 \mathrm{mAh} \mathrm{g}^{-1}, 85.8 \%\right)$, principally demonstrating that the introduction of $\mathrm{F}$ dopants and
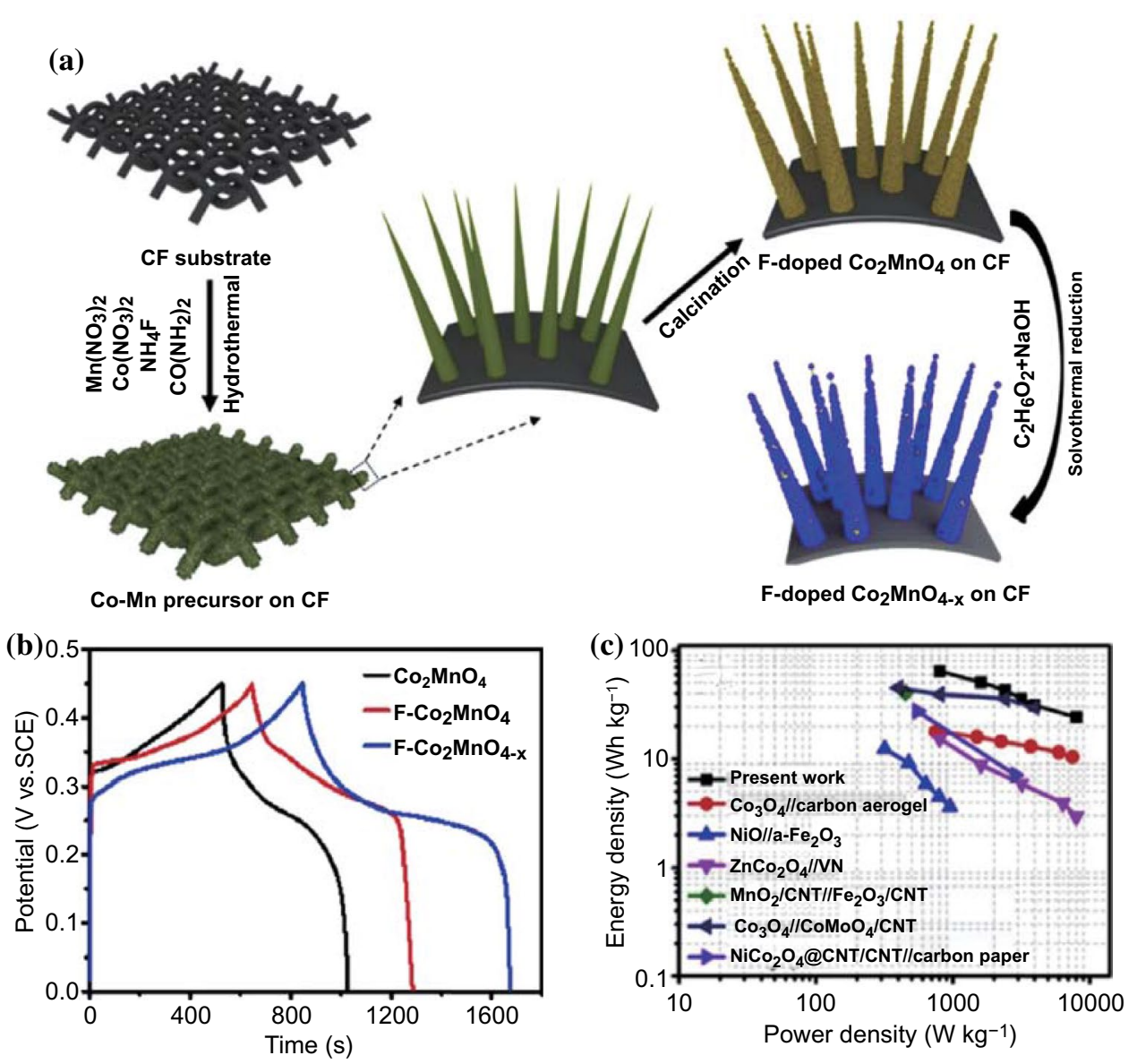

Fig. 14 a Schematic of the synthesis of $\mathrm{F}-\mathrm{Co}_{2} \mathrm{MnO}_{4-\mathrm{x}}$ nanowires on CF substrate. b GCD curves of $\mathrm{Co}_{2} \mathrm{MnO}_{4}, \mathrm{~F}_{-} \mathrm{Co}_{2} \mathrm{MnO}_{4}$, and F-Co $\mathrm{MnO}_{4-x}$ electrodes at $1 \mathrm{~A} \mathrm{~g}^{-1}$. c Ragone plot of $\mathrm{F}_{-} \mathrm{Co}_{2} \mathrm{MnO}_{4-x} / \mathrm{CF} / / \mathrm{Fe}_{2} \mathrm{O}_{3} / \mathrm{CF}$ device. Adapted with permission from Ref. [125] Copyright 2019 Elsevier 
oxygen vacancies could synergistically increase the electrical conductivity and reactivity of electrochemically active sites (Fig. 14b). Moreover, the ASCs of $\mathrm{F}-\mathrm{Co}_{2} \mathrm{MnO}_{4-x} / \mathrm{CF} / /$ $\mathrm{Fe}_{2} \mathrm{O}_{3} / \mathrm{CF}$ exhibited high energy density of $64.4 \mathrm{Wh} \mathrm{kg}^{-1}$ at a power density of $800 \mathrm{~W} \mathrm{~kg}^{-1}$ (Fig. 14c).

In short, the introduction of oxygen vacancies into TMOs can tremendously improve the electrochemical performance for supercapacitors, e g., greater electrical conductivity, more prominent specific capacitance, rate performance, and cyclic stability. Besides, the distribution of the defects is also a critical factor of the electrochemical performance enhancement, oxygen vacancies with uniform distribution in TMCs are beneficial to improve the cycle stability [143]. Therefore, defects reasonably introduced into electrode materials can not only contribute to improving the physicochemical properties but also adjust the performance of materials.

\subsection{Heterogeneous Interface}

In the past few years, the construction of heterogeneous interfaces during the synthesis of TMCs crystals has aroused extensive research interests due to its improved high ion carrier mobility and broad electrode potential, mainly because the unique structure can decrease the activity of hydrogen evolution reaction (HER) and oxygen evolution reaction (OER) at high voltage window [144-147]. For example, the NiFeP@ $\mathrm{NiCo}_{2} \mathrm{~S}_{4} /$ carbon cloth $\left(\mathrm{NiFeP} @ \mathrm{NiCo}_{2} \mathrm{~S}_{4} / \mathrm{CC}\right)$ hybrid electrode with $\mathrm{NiFeP} @ \mathrm{NiCo}_{2} \mathrm{~S}_{4}$ heterostructure was successfully manufactured by using a novel combination of hydrothermal reaction, phosphorization treatment, and electrodeposition technique strategy (Fig. 15a) [148]. Compared with $\mathrm{NiFeP} / \mathrm{CC}$ and $\mathrm{NiCo}_{2} \mathrm{~S}_{4} / \mathrm{CC}$, the NiFeP@ $\mathrm{NiCo}_{2} \mathrm{~S}_{4} / \mathrm{CC}$ hybrid electrode demonstrated higher specific capacitance (Fig. 15c), better rate capability, and more excellent cycling stability. In an asymmetric supercapacitor of

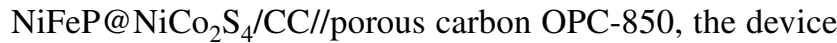
obtained a superior energy density of $32.1 \mathrm{Wh} \mathrm{kg}^{-1}$ at an ultrahigh power density of $18,034.2 \mathrm{~W} \mathrm{~kg}^{-1}$ (Fig. 15d). The distinguished electrochemical performance can be attributed that the unique heterostructure not only provides abundant open channels to achieve rapid electronic transport, but also enlarge accessible 2D surface to offer more active sites for absorbing electrolyte ions (Fig. 15b).

In addition, bimetallic MOF-derived $\mathrm{NiCo}_{2} \mathrm{~S}_{4}-\mathrm{Ni}_{9} \mathrm{~S}_{8}-\mathrm{C}$ double-layered yolk-shell microspheres were synthesized by Yan et al. [149]. Owing to the existence of $\mathrm{NiCo}_{2} \mathrm{~S}_{4}-\mathrm{Ni}_{9} \mathrm{~S}_{8}$ hetero-interface, the composite materials exhibited superior specific capacity (293.6 $\mathrm{mAh} \mathrm{g}^{-1}$ at $1 \mathrm{~A} \mathrm{~g}^{-1}$ ) and good rate ability (capacitance retained $81.1 \%$ as current densities increased from 1 to $20 \mathrm{~A} \mathrm{~g}^{-1}$ ). Based on DFT calculations, the authors also confirmed that the hetero-interfaces of $\mathrm{NiCo}_{2} \mathrm{~S}_{4}-\mathrm{Ni}_{9} \mathrm{~S}_{8}$ changed the electronic distribution, thus
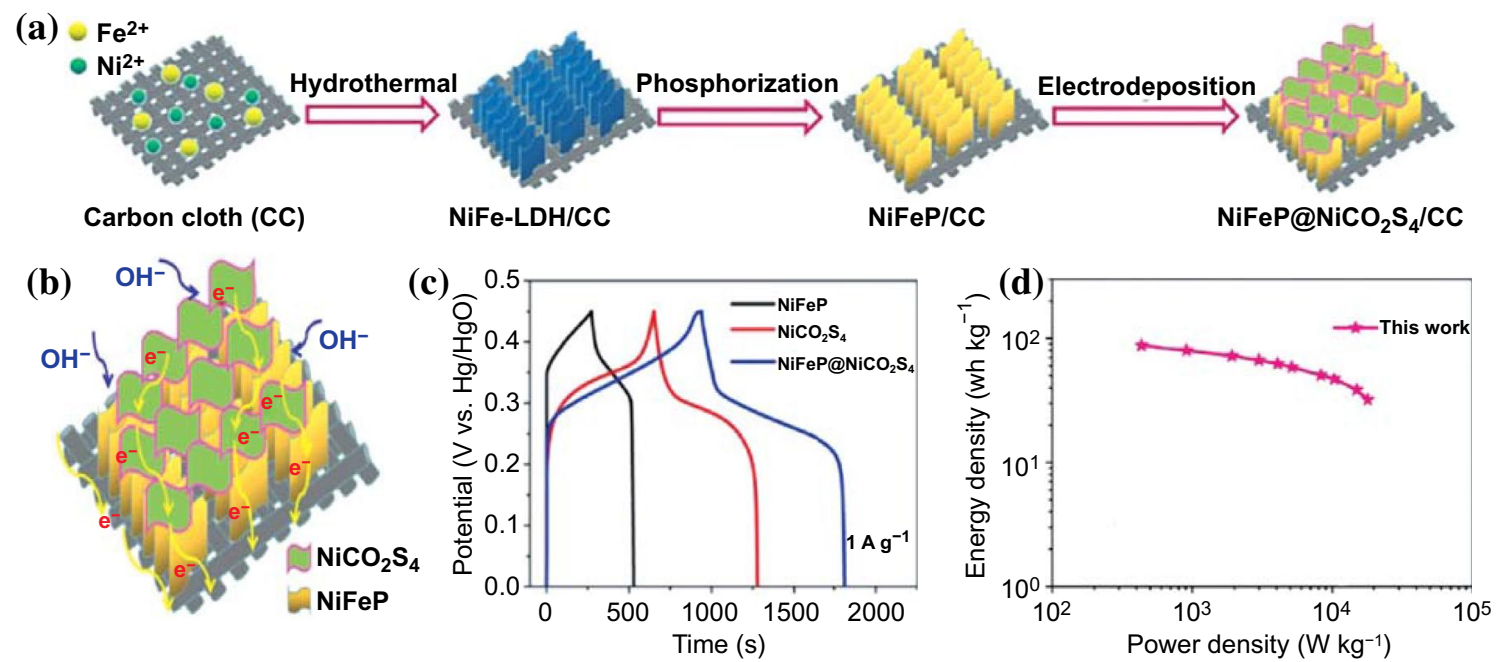

Fig. 15 a Schematic of the $\mathrm{NiFeP} @ \mathrm{NiCo}_{2} \mathrm{~S}_{4}$ hybrid nanosheets synthesis process. b Schematic description of charge storage and transfer advantages of $\mathrm{NiFeP@NiCo} \mathrm{S}_{4} / \mathrm{CC}$ electrode. c GCD of $\mathrm{NiFeP} / \mathrm{CC}, \mathrm{NiCo}_{2} \mathrm{~S}_{4} / \mathrm{CC}$, and $\mathrm{NiFeP@} \mathrm{NiCo}_{2} \mathrm{~S}_{4} / \mathrm{CC}$ electrodes at $1 \mathrm{~A} \mathrm{~g}-1$. d Ragone plot of the e NiFeP@ $\mathrm{NiCo}_{2} \mathrm{~S}_{4} / \mathrm{CC} / / \mathrm{OPC}-850$ ASCs and a comparison with previous works. Adapted with permission from Ref. [149] Copyright 2020 Elsevier 
strengthening the electrochemical conductivity of the entire electrode. Moreover, the hybrid supercapacitors assembled by $\mathrm{NiCo}_{2} \mathrm{~S}_{4}-\mathrm{Ni}_{9} \mathrm{~S}_{8}-\mathrm{C}$ DYMs and graphene hydrogel showed an excellent energy density of $51 \mathrm{Wh} \mathrm{kg}^{-1}$ at a superhigh power density of $1399.4 \mathrm{~W} \mathrm{~kg}^{-1}$. In another article, Dang and his co-workers fabricated a 3D NiCoP/CoP hetero-nanosheets network supported by N-CNTs (N-CTs@ $\mathrm{NiCoP} / \mathrm{CoP}$ ) via one-step phosphorization of nickel/cobalt hydroxide [150]. The hybrid supercapacitor of N-CNTs@ $\mathrm{NiCoP} / \mathrm{CoP} / / \mathrm{ZIF}-67-$ derived porous carbon demonstrated an outstanding energy density of $45.5 \mathrm{Wh} \mathrm{kg}^{-1}$ at $784 \mathrm{~W} \mathrm{~kg}^{-1}$ and great stability of $87 \%$ retention (after 10,000 cycles at $12 \mathrm{~A} \mathrm{~g}^{-1}$ ). The superior electrochemical performance can be mainly ascribed to the strong synergistic effect of $\mathrm{NiCoP} /$ $\mathrm{CoP}$ heterojunctions, the large surface area of N-CNTs skeletons, and 3D conductive networks.

In conclusion, a heterogeneous interface consisting of two or more types of TMCs materials not only enhances the structural stability, but also provides fast pathways for electrolyte ion/electrons transfer, leading to the improved electrochemical performance of the whole electrode, which could offer a good thought of a structural design for TMCs/ carbon based supercapacitors.

\section{Summary and Outlook}

TMCs/carbon-based supercapacitors with the potential high energy densities represent the application tendency of nextgeneration energy storage systems. However, as for the practical and large-scale applications, the poor power density and inferior cycle stability derived from the low intrinsic conductivity and structural instability of TMCs are critical constraints. In this review, focusing on the current fundamental understanding, challenges, and opportunities, we systematically discuss the possible design strategies for the TMCs/ carbon-based supercapacitors from the aspects of conductive carbon substrates, interface engineering, and modification of electronic structures for the first time. Firstly, we present the structural design strategies for the carbon skeletons with different dimensions. As the electrode supports and conductive skeletons, carbon substrates with high electron conductivities to guarantee the rapid charge transfer, abundant pore channels to promote the electrolyte ions migration, large specific surface area to load more amounts of TMCs, even superior mechanical stability/flexibility to support long cycle life, etc., are greatly needed. Secondly, we point out that the strong interfaces between carbon skeletons and TMCs play a crucial role in achieving high power density and long cycle stability of TMCs/carbon-based supercapacitors. Specifically, we describe four feasible manners for the construction of steady interfaces between carbon skeletons and TMCs by the modification of carbon surface or physical interaction, including heteroatom-doping, functional groups modification, organic interlayer introduction, and spatial confinement. Lastly, the modification of TMCs (including TMCs-QDs) crystals with nanoscale dimensions can reduce the electron/ion diffusion distance, increase the electrode/ electrolyte contact surface, improve the intrinsic conductivity/redox activity, etc., and also have been presented as one guarantee role to realize both high power/energy densities of TMCs/carbon based supercapacitors.

Despite large amounts of research that have been done to study the assemble strategies, electrochemical performance, and energy storage mechanism of TMCs/carbon based supercapacitors, some critical challenges still need to be considered: (1) How to achieve the high-efficiency utilization of carbon as conductive support plays a pretty important role. Although large specific surface area and porous structure of carbon substrate can provide high conductivity and abundant electrons/electrolyte ions transfer channels, carbon materials with low specific capacitance restrict its development. Therefore, the high-efficiency utilization of carbon as conductive substrate needs to be considered on basis of appropriate mass ratio between carbon and TMCs, achieving high energy density as well as high power density. (2) The trade-off between high mass loading and agglomeration of nanoscale TMCs crystals also is a challenge. TMCs with nanostructure can achieve high mass loading and efficient utilization ratio, which possess much higher faradaic pseudocapacitive reaction kinetics. However, in a real scenario, the high surface energy of TMCs with ultrasmall sizes is easy to be agglomerated, resulting in sluggish reaction kinetics as same as bulk materials. (3) New techniques and methods are urgently needed to construct steady composite interfaces. For composite materials, the fast transfer of electrolyte ions/electrons across the heterogeneous interfaces plays an important role in achieving ultrahigh charge/discharge rates. However, how to build a steady composite interface is still a problem that needs deep thinking. (4) Besides, the choices of electrolyte, current collector, separator, and other components are also equally important. 
Notably, the form of free-standing film electrodes attracted more and more attention owing to no additional binders, conductors, or collectors. Compared with powder electrodes, it can increase mass loading of active materials, simplify the electrode preparation process, and avoid uncontrollable side reactions, which may be an important development direction of energy storage industry in the future.

This review provides a comprehensive and in-depth discussion about the structural design strategies for the high power TMCs/carbon-based supercapacitors. We try to present the classic and latest research findings and propose progressive perspectives towards the critical challenges that are relevant to the practical and large-scale application of TMCs/carbon-based supercapacitors. Overall, it is highly expected that more novel design strategies and efficient TMCs/carbon-based supercapacitors could come into the picture and further revolutionize the way we live in the future.

Acknowledgements This work was supported by the National Natural Science Foundation of China (Nos. 51972342, and 51872056), Taishan Scholar Project of Shandong Province (ts20190922), Key Basic Research Project of Natural Science Foundation of Shandong Province (ZR2019ZD51), Project funded by China Postdoctoral Science Foundation (2019TQ0353 and 2020M672165), Fundamental Research Funds for the Central Universities (20CX06024A), Shandong Provincial Natural Science Foundation, China (ZR201911040344).

Open Access This article is licensed under a Creative Commons Attribution 4.0 International License, which permits use, sharing, adaptation, distribution and reproduction in any medium or format, as long as you give appropriate credit to the original author(s) and the source, provide a link to the Creative Commons licence, and indicate if changes were made. The images or other third party material in this article are included in the article's Creative Commons licence, unless indicated otherwise in a credit line to the material. If material is not included in the article's Creative Commons licence and your intended use is not permitted by statutory regulation or exceeds the permitted use, you will need to obtain permission directly from the copyright holder. To view a copy of this licence, visit http://creativecommons.org/licenses/by/4.0/.

\section{References}

1. P. Simon, Y. Gogotsi, Materials for electrochemical capacitors. Nat. Mater. 7(11), 845-854 (2008). https://doi.org/10. 1038/nmat2297

2. Y. Wang, L. Zhang, H. Hou, W. Xu, G. Duan et al., Recent progress in carbon-based materials for supercapacitor electrodes: a review. J. Mater. Sci. 56(1), 173-200 (2021). https://doi.org/10.1007/s10853-020-05157-6

3. Y. Shao, M.F. El-Kady, J. Sun, Y. Li, Q. Zhang et al., Design and mechanisms of asymmetric supercapacitors. Chem. Rev. 118(18), 9233-9280 (2018). https://doi.org/10.1021/acs. chemrev.8b00252

4. H. Wang, H. Dai, Strongly coupled inorganic-nano-carbon hybrid materials for energy storage. Chem. Soc. Rev. 42(7), 3088-3113 (2013). https://doi.org/10.1039/c2cs35307e

5. Z. Yang, J. Zhang, M.C.W. Kintner-Meyer, X. Lu, D. Choi et al., Electrochemical energy storage for green grid. Chem. Rev. 111(5), 3577-3613 (2011). https://doi.org/10.1021/ cr100290v

6. J.R. Miller, P. Simon, Materials science-electrochemical capacitors for energy management. Science 321(5889), 651-652 (2008). https://doi.org/10.1126/science.1158736

7. F. Beguin, V. Presser, A. Balducci, E. Frackowiak, Carbons and electrolytes for advanced supercapacitors. Adv. Mater. 26(14), 2219-2251 (2014). https://doi.org/10.1002/adma. 201304137

8. A. Berrueta, A. Ursua, I. San Martin, A. Eftekhari, P. Sanchis, Supercapacitors: electrical characteristics, modeling, applications, and future trends. IEEE Access 7, 50869-50896 (2019). https://doi.org/10.1109/access.2019.2908558

9. X. Zhao, B.M. Sanchez, P.J. Dobson, P.S. Grant, The role of nanomaterials in redox-based supercapacitors for next generation energy storage devices. Nanoscale 3(3), 839-855 (2011). https://doi.org/10.1039/c0nr00594k

10. Y. Wang, Y. Xia, Recent progress in supercapacitors: from materials design to system construction. Adv. Mater. 25(37), 5336-5342 (2013). https://doi.org/10.1002/adma.201301932

11. J. Yan, Q. Wang, T. Wei, Z. Fan, Recent advances in design and fabrication of electrochemical supercapacitors with high energy densities. Adv. Energy Mater. 4(4), 14264 (2014). https://doi.org/10.1002/aenm.201300816

12. P. Veerakumar, A. Sangili, S. Manavalan, P. Thanasekaran, K.-C. Lin, Research progress on porous carbon supported metal/metal oxide nanomaterials for supercapacitor electrode applications. Ind. Eng. Chem. Res. 59(14), 6347-6374 (2020). https://doi.org/10.1021/acs.iecr.9b06010

13. K.A. Owusu, L. Qu, J. Li, Z. Wang, K. Zhao et al., Lowcrystalline iron oxide hydroxide nanoparticle anode for high-performance supercapacitors. Nat. Commun. 8, 14264 (2017). https://doi.org/10.1038/ncomms14264

14. L. Zheng, J. Song, X. Ye, Y. Wang, X. Shi et al., Construction of self-supported hierarchical nico-s nanosheet arrays for supercapacitors with ultrahigh specific capacitance. Nanoscale 12(25), 13811-13821 (2020). https://doi.org/10. 1039/d0nr02976a

15. P. Geng, S. Zheng, H. Tang, R. Zhu, L. Zhang et al., Transition metal sulfides based on graphene for electrochemical energy storage. Adv. Energy Mater. 8(15), 1703259 (2018). https://doi.org/10.1002/aenm.201703259

16. T. Wang, H.C. Chen, F. Yu, X.S. Zhao, H. Wang, Boosting the cycling stability of transition metal compounds-based 
supercapacitors. Energy Storage Mater. 16, 545-573 (2019). https://doi.org/10.1016/j.ensm.2018.09.007

17. L. Hou, W. Yang, R. Li, X. Xu, P. Wang et al., Self-reconstruction strategy to synthesis of $\mathrm{Ni} / \mathrm{Co}-\mathrm{OOH}$ nanoflowers decorated with $\mathrm{N}, \mathrm{S}$ co-doped carbon for high-performance energy storage. Chem. Eng. J. 396, 125323 (2020). https:// doi.org/10.1016/j.cej.2020.125323

18. Y. Jiang, J. Liu, Definitions of pseudocapacitive materials: a brief review. Energy Environ. Mater. 2(1), 30-37 (2019). https://doi.org/10.1002/eem2.12028

19. Z. Qiu, Y. Wang, X. Bi, T. Zhou, J. Zhou et al., Biocharbased carbons with hierarchical micro-meso-macro porosity for high rate and long cycle life supercapacitors. J. Power Sources 376, 82-90 (2018). https://doi.org/10.1016/j.jpows our.2017.11.077

20. S. Kumar, G. Saeed, L. Zhu, K.N. Hui, N.H. Kim et al., Od to $3 \mathrm{~d}$ carbon-based networks combined with pseudocapacitive electrode material for high energy density supercapacitor: a review. Chem. Eng. J. 403, 126352 (2021). https://doi.org/10. 1016/j.cej.2020.126352

21. P. Balaya, Size effects and nanostructured materials for energy applications. Energy Environ. Sci. 1(6), 645-654 (2008). https://doi.org/10.1039/b809078p

22. Y. Son, M. Park, Y. Son, J.-S. Lee, J.-H. Jang et al., Quantum confinement and its related effects on the critical size of $\mathrm{GeO}_{2}$ nanoparticles anodes for lithium batteries. Nano Lett. 14(2), 1005-1010 (2014). https://doi.org/10.1021/nl404466v

23. R.W. Mo, Z.Y. Lei, K.N. Sun, D. Rooney, Facile synthesis of anatase tio2 quantum-dot/graphenenanosheet composites with enhanced electrochemical performance for lithium-ion batteries. Adv. Mater. 26(13), 2084-2088 (2014). https://doi. org/10.1002/adma.201304338

24. H. Xia, C. Hong, B. Li, B. Zhao, Z. Lin et al., Facile synthesis of hematite quantum-dot/functionalized graphene-sheet composites as advanced anode materials for asymmetric supercapacitors. Adv. Funct. Mater. 25(4), 627-635 (2015). https:// doi.org/10.1002/adfm.201403554

25. H.M. Jeong, K.M. Choi, T. Cheng, D.K. Lee, R. Zhou et al., Rescaling of metal oxide nanocrystals for energy storage having high capacitance and energy density with robust cycle life. Proc. Natl. Acad. Sci. USA 112(26), 7914-7919 (2015). https://doi.org/10.1073/pnas.1503546112

26. V.C. Hoang, K. Dave, V.G. Gomes, Carbon quantum dotbased composites for energy storage and electrocatalysis: mechanism, applications and future prospects. Nano Energy 66, 104093 (2019). https://doi.org/10.1016/j.nanoen.2019. 104093

27. X. Yang, C. Cai, Y. Zou, C. Xiang, H. Chu et al., $\mathrm{Co}_{3} \mathrm{O}_{4}$-doped two-dimensional carbon nanosheet as an electrode material for high-performance asymmetric supercapacitors. Electrochim. Acta 335, 135611 (2020). https://doi.org/10.1016/j. electacta.2020.135611

28. X.-M. Han, Y.-B. Wu, H.-Y. Zhao, J. Bi, B.-B. Wei, Preparation and supercapacitor properties of carbon-coated $\mathrm{SnO}_{2}$ hollow fibers. Acta Phys. Chim. Sin. 31(11), 2220-2228 (2015). https://doi.org/10.3866/pku.whxb201510131
29. Y. Zhu, Z. Wu, M. Jing, H. Hou, Y. Yang et al., Porous $\mathrm{NiCo}_{2} \mathrm{O}_{4}$ spheres tuned through carbon quantum dots utilised as advanced materials for an asymmetric supercapacitor. J. Mater. Chem. A 3(2), 866-877 (2015). https://doi.org/10. 1039/c4ta05507a

30. H. Lv, X. Gao, Q. Xu, H. Liu, Y.-G. Wang et al., Carbon quantum dot-induced $\mathrm{MnO}_{2}$ nanowire formation and construction of a binder-free flexible membrane with excellent superhydrophilicity and enhanced supercapacitor performance. ACS Appl. Mater. Interfaces 9(46), 40394-40403 (2017). https://doi.org/10.1021/acsami.7b14761

31. G. Wei, X. Xu, J. Liu, K. Du, J. Du et al., Carbon quantum dots decorated hierarchical $\mathrm{Ni}(\mathrm{OH})(2)$ with lamellar structure for outstanding supercapacitor. Mater. Lett. 186, 131-134 (2017). https://doi.org/10.1016/j.matlet.2016.09.126

32. H. Jia, Y. Cai, J. Lin, H. Liang, J. Qi et al., Heterostructural graphene quantum dot/ $\mathrm{MnO}_{2}$ nanosheets toward high-potential window electrodes for high-performance supercapacitors. Adv. Sci. 5(5), 1700887 (2018). https://doi.org/10.1002/advs. 201700887

33. A.B. Ganganboina, E.Y. Park, R.-A. Doong, Boosting the energy storage performance of $\mathrm{V}(2) \mathrm{O}(5)$ nanosheets by intercalating conductive graphene quantum dots. Nanoscale 12(32), 16944-16955 (2020). https://doi.org/10.1039/d0nr0 $4362 \mathrm{a}$

34. L. Hu, W. Chen, X. Xie, N. Liu, Y. Yang et al., Symmetrical $\mathrm{MnO}_{2}$-carbon nanotube-textile nanostructures for wearable pseudocapacitors with high mass loading. ACS Nano 5(11), 8904-8913 (2011). https://doi.org/10.1021/nn203085j

35. Z. Tang, C.-H. Tang, H. Gong, A high energy density asymmetric supercapacitor from nano-architectured $\mathrm{Ni}(\mathrm{OH})_{2} /$ carbon nanotube electrodes. Adv. Funct. Mater. 22(6), 12721278 (2012). https://doi.org/10.1002/adfm.201102796

36. Q. Li, J. Guo, D. Xu, J. Guo, X. Ou et al., Electrospun $\mathrm{N}$-doped porous carbon nanofibers incorporated with nio nanoparticles as free-standing film electrodes for high-performance supercapacitors and $\mathrm{CO}_{2}$ capture. Small 14(15), 1704203 (2018). https://doi.org/10.1002/smll.201704203

37. A. Meng, X. Yuan, T. Shen, J. Zhao, G. Song et al., Amorphous nickel sulfide nanoparticles anchored on N-doped graphene nanotubes with superior properties for high-performance supercapacitors and efficient oxygen evolution reaction. Nanoscale 12(7), 4655-4666 (2020). https://doi.org/10. 1039/c9nr09654j

38. J. Yan, Z. Fan, W. Sun, G. Ning, T. Wei et al., Advanced asymmetric supercapacitors based on $\mathrm{Ni}(\mathrm{OH})_{2} /$ graphene and porous graphene electrodes with high energy density. Adv. Funct. Mater. 22(12), 2632-2641 (2012). https://doi.org/10. 1002/adfm.201102839

39. Y. Hu, C. Guan, Q. Ke, Z.F. Yow, C. Cheng et al., Hybrid $\mathrm{Fe}_{2} \mathrm{O}_{3}$ nanoparticle clusters/RGO paper as an effective negative electrode for flexible supercapacitors. Chem. Mater. 28(20), 7296-7303 (2016). https://doi.org/10.1021/acs. chemmater.6b02585

40. T. Xiong, W.S.V. Lee, X. Huang, J.M. Xue, $\mathrm{Mn}_{3} \mathrm{O}_{4} /$ reduced graphene oxide based supercapacitor with ultra-long cycling 
performance. J. Mater. Chem. A 5(25), 12762-12768 (2017). https://doi.org/10.1039/c7ta03319b

41. Y. Jiang, C. He, S. Qiu, J. Zhang, X. Wang et al., Scalable mechanochemical coupling of homogeneous $\mathrm{Co}_{3} \mathrm{O}_{4}$ nanocrystals onto in -situ exfoliated graphene sheets for asymmetric supercapacitors. Chem. Eng. J. 397, 125503 (2020). https://doi.org/10.1016/j.cej.2020.125503

42. L. Bao, T. Li, S. Chen, C. Peng, L. Li et al., $3 \mathrm{~d}$ graphene frameworks $/ \mathrm{Co}_{3} \mathrm{O}_{4}$ composites electrode for high-performance supercapacitor and enzymeless glucose detection. Small 13(5), 1602077 (2017). https://doi.org/10.1002/smll. 201602077

43. Y. Wu, Y. Yang, X. Zhao, Y. Tan, Y. Liu et al., A novel hierarchical porous $3 \mathrm{~d}$ structured vanadium nitride/carbon membranes for high-performance supercapacitor negative electrodes. Nano-Micro Lett. 10(4), 63 (2018). https://doi. org/10.1007/s40820-018-0217-1

44. S. Li, K. Yang, P. Ya, K. Ma, Z. Zhang et al., Three-dimensional porous carbon $/ \mathrm{Co}_{3} \mathrm{O}_{4}$ composites derived from graphene/Co-MOF for high performance supercapacitor electrodes. Appl. Surf. Sci. 503, 144090 (2020). https://doi.org/ 10.1016/j.apsusc.2019.144090

45. Y. Liu, N. Xin, Q. Yang, W. Shi, 3d cnts/graphene network conductive substrate supported mofs-derived CoZnNiS nanosheet arrays for ultra-high volumetric/gravimetric energy density hybrid supercapacitor. J. Colloid Interface Sci. 583, 288-298 (2020). https://doi.org/10.1016/j.jcis.2020.08.128

46. T. Shen, L. Yang, M.E. Pam, Y. Shi, H.Y. Yang, Quantum dot-carbonaceous nanohybrid composites: preparation and application in electrochemical energy storage. J. Mater. Chem. A 8(43), 22488-22506 (2020). https://doi.org/10. 1039/d0ta07674k

47. Z. Zhang, J. Zhang, N. Chen, L. Qu, Graphene quantum dots: An emerging material for energy-related applications and beyond. Energy Environ. Sci. 5(10), 8869-8890 (2012). https://doi.org/10.1039/c2ee22982j

48. Y. Zhu, X. Ji, C. Pan, Q. Sun, W. Song et al., A carbon quantum dot decorated $\mathrm{RuO}_{2}$ network: outstanding supercapacitances under ultrafast charge and discharge. Energy Environ. Sci. 6(12), 3665-3675 (2013). https://doi.org/10. $1039 / \mathrm{c} 3 \mathrm{ee} 41776 \mathrm{j}$

49. Y. Huang, T. Shi, Y. Zhong, S. Cheng, S. Jiang et al., Graphene-quantum-dots induced $\mathrm{NiCo}_{2} \mathrm{~S}_{4}$ with hierarchical-like hollow nanostructure for supercapacitors with enhanced electrochemical performance. Electrochim. Acta 269, 45-54 (2018). https://doi.org/10.1016/j.electacta. 2018.02.145

50. L. Liu, Z. Niu, J. Chen, Flexible supercapacitors based on carbon nanotubes. Chin. Chem. Lett. 29(4), 571-581 (2018). https://doi.org/10.1016/j.cclet.2018.01.013

51. G. Nie, X. Zhao, Y. Luan, J. Jiang, Z. Kou et al., Key issues facing electrospun carbon nanofibers in energy applications: On-going approaches and challenges. Nanoscale 12(25), 13225-13248 (2020). https://doi.org/10.1039/d0nr03425h

52. L. Jiang, Y. Qiu, P. Luo, Y. Yu, Nickel hydroxide-impregnated and -coated carbon nanotubes using an easily manipulated solvothermal route for supercapacitors. Ceram. Int. 42(10), 11634-11639 (2016). https://doi.org/10.1016/j.ceramint. 2016.04.064

53. S. Liu, Y. Yin, Y. Shen, K.S. Hui, Y.T. Chun et al., Phosphorus regulated cobalt oxide@ nitrogen-doped carbon nanowires for flexible quasi-solid-state supercapacitors. Small 16(4), 1906458 (2020). https://doi.org/10.1002/smll.201906458

54. A. Salman, S. Padmajan Sasikala, I.H. Kim, J.T. Kim, G.S. Lee et al., Tungsten nitride-coated graphene fibers for highperformance wearable supercapacitors. Nanoscale 12(39), 20239-20249 (2020). https://doi.org/10.1039/d0nr06636b

55. B. Wang, T. Ruan, Y. Chen, F. Jin, L. Peng et al., Graphenebased composites for electrochemical energy storage. Energy Storage Mater. 24, 22-51 (2020). https://doi.org/10.1016/j. ensm.2019.08.004

56. S. Korkmaz, I.A. Kariper, Graphene and graphene oxide based aerogels: synthesis, characteristics and supercapacitor applications. J. Energy Storage 27, 101038 (2020). https:// doi.org/10.1016/j.est.2019.101038

57. T. Palaniselvam, J.-B. Baek, Graphene based 2d-materials for supercapacitors. 2d Mater 2(3), 032002 (2015). https://doi. org/10.1088/2053-1583/2/3/032002

58. M.S. Rahmanifar, M. Hemmati, A. Noori, M.F. El-Kady, M.F. Mousavi et al., Asymmetric supercapacitors: an alternative to activated carbon negative electrodes based on earth abundant elements. Mater. Today Energy 12, 26-36 (2019). https://doi.org/10.1016/j.mtener.2018.12.006

59. X. Yang, C. Cheng, Y. Wang, L. Qiu, D. Li, Liquid-mediated dense integration of graphene materials for compact capacitive energy storage. Science 341(6145), 534-537 (2013). https://doi.org/10.1126/science.1239089

60. Z. Tang, X. Li, T. Sun, S. Shen, H. Xiu et al., Porous crumpled graphene with hierarchical pore structure and high surface utilization efficiency for supercapacitor. Microporous Mesoporous Mat. 272, 40-43 (2018). https://doi.org/ 10.1016/j.micromeso.2018.06.020

61. Y. Xu, Z. Lin, X. Zhong, X. Huang, N.O. Weiss et al., Holey graphene frameworks for highly efficient capacitive energy storage. Nat. Commun. 5, 4554 (2014). https://doi. org/10.1038/ncomms5554

62. A.R. Thiruppathi, B. Sidhureddy, E. Boateng, D.V. Soldatov, A. Chen, Synthesis and electrochemical study of threedimensional graphene-based nanomaterials for energy applications. Nanomaterials 10(7), 1295 (2020). https:// doi.org/10.3390/nano10071295

63. R.R. Salunkhe, Y.V. Kaneti, J. Kim, J.H. Kim, Y. Yamauchi, Nanoarchitectures for metal-organic framework-derived nanoporous carbons toward supercapacitor applications. Acc. Chem. Res. 49(12), 2796-2806 (2016). https://doi. org/10.1021/acs.accounts.6b00460

64. H. Jiang, P.S. Lee, C. Li, 3d carbon based nanostructures for advanced supercapacitors. Energy Environ. Sci. 6(1), 41-53 (2013). https://doi.org/10.1039/c2ee23284g

65. J. Xu, Z. Tan, W. Zeng, G. Chen, S. Wu et al., A hierarchical carbon derived from sponge-templated activation of graphene oxide for high-performance supercapacitor 
electrodes. Adv. Mater. 28(26), 5222 (2016). https://doi. org/10.1002/adma.201600586

66. J. Chen, J. Xu, S. Zhou, N. Zhao, C.-P. Wong, Nitrogendoped hierarchically porous carbon foam: a free-standing electrode and mechanical support for high-performance supercapacitors. Nano Energy 25, 193-202 (2016). https:// doi.org/10.1016/j.nanoen.2016.04.037

67. J. Luo, H. Zhang, Z. Zhang, J. Yu, Z. Yang, In-built template synthesis of hierarchical porous carbon microcubes from biomass toward electrochemical energy storage. Carbon 155, 1-8 (2019). https://doi.org/10.1016/j.carbon.2019. 08.044

68. C. Leng, Z. Zhao, Y. Song, L. Sun, Z. Fan et al., 3D carbon frameworks for ultrafast charge/discharge rate supercapacitors with high energy-power density. Nano-Micro Lett. 13, 8 (2021). https://doi.org/10.1007/s40820-020-00535-w

69. Y. Qing, Y. Jiang, H. Lin, L. Wang, A. Liu et al., Boosting the supercapacitor performance of activated carbon by constructing overall conductive networks using graphene quantum dots. J. Mater. Chem. A 7(11), 6021-6027 (2019). https://doi.org/10.1039/c8ta11620b

70. G.M. Tomboc, B. Tesfaye Gadisa, M. Jun, N.K. Chaudhari, H. Kim et al., Carbon transition-metal oxide electrodes: understanding the role of surface engineering for high energy density supercapacitors. Chem. Asian J. 15(11), 1628-1647 (2020). https://doi.org/10.1002/asia.202000324

71. B. Qu, C. Ma, G. Ji, C. Xu, J. Xu et al., Layered $\mathrm{SnS}_{2}$-reduced graphene oxide composite-a high-capacity, high-rate, and long-cycle life sodium-ion battery anode material. Adv. Mater. 26(23), 3854-3859 (2014). https:// doi.org/10.1002/adma.201306314

72. X. Zhou, Z. Zhang, X. Lu, X. Lv, G. Ma et al., $\mathrm{Sb}_{2} \mathrm{O}_{3}$ nanoparticles anchored on graphene sheets via alcohol dissolution-reprecipitation method for excellent lithiumstorage properties. ACS Appl. Mater. Interfaces 9(40), 34927-34936 (2017). https://doi.org/10.1021/acsami.7b101 07

73. L. Liu, J. Lang, P. Zhang, B. Hu, X. Yan, Facile synthesis of $\mathrm{Fe}_{2} \mathrm{O}_{3}$ nano-dots@ nitrogen-doped graphene for supercapacitor electrode with ultralong cycle life in koh electrolyte. ACS Appl. Mater. Interfaces 8(14), 9335-9344 (2016). https://doi.org/10.1021/acsami.6b00225

74. Y. Ko, D. Shin, B. Koo, S.W. Lee, W.-S. Yoon et al., Ultrathin supercapacitor electrodes with high volumetric capacitance and stability using direct covalent-bonding between pseudocapacitive nanoparticles and conducting materials. Nano Energy 12, 612-625 (2015). https://doi. org/10.1016/j.nanoen.2015.01.002

75. H. Jia, Z. Wang, C. Li, X. Si, X. Zheng et al., Designing oxygen bonding between reduced graphene oxide and multishelled $\mathrm{Mn}_{3} \mathrm{O}_{4}$ hollow spheres for enhanced performance of supercapacitors. J. Mater. Chem. A 7(12), 6686-6694 (2019). https://doi.org/10.1039/c8ta11482j

76. S. Zhu, M. Wu, M.-H. Ge, H. Zhang, S.-K. Li et al., Design and construction of three-dimensional $\mathrm{CuO} /$ polyaniline/RGO ternary hierarchical architectures for high performance supercapacitors. J. Power Sources 306, 593601 (2016). https://doi.org/10.1016/j.jpowsour.2015.12.059

77. J. Zhang, L. Su, L. Ma, D. Zhao, C. Qin et al., Preparation of inflorescence-like acnf/pani/nio composite with three-dimension nanostructure for high performance supercapacitors. J. Electroanal. Chem. 790, 40-49 (2017). https://doi.org/10. 1016/j.jelechem.2017.02.047

78. Q. Li, Y. Chen, J. Zhang, W. Tian, L. Wang et al., Spatially confined synthesis of vanadium nitride nanodots intercalated carbon nanosheets with ultrahigh volumetric capacitance and long life for flexible supercapacitors. Nano Energy 51, 128-136 (2018). https://doi.org/10.1016/j. nanoen.2018.06.053

79. S.N. Tiruneh, B.K. Kang, H.W. Choi, S.B. Kwon, M.S. Kim et al., Millerite core-nitrogen-doped carbon hollow shell structure for electrochemical energy storage. Small 14(41), 1802933 (2018). https://doi.org/10.1002/smll.201802933

80. F. Lai, J. Feng, R. Yan, G.-C. Wang, M. Antonietti et al., Breaking the limits of ionic liquid-based supercapacitors: mesoporous carbon electrodes functionalized with manganese oxide nanosplotches for dense, stable, and widetemperature energy storage. Adv. Funct. Mater. 28(36), 1801298 (2018). https://doi.org/10.1002/adfm.201801298

81. R. Paul, F. Du, L. Dai, Y. Ding, Z.L. Wang et al., 3d heteroatom-doped carbon nanomaterials as multifunctional metal-free catalysts for integrated energy devices. Adv. Mater. 31(13), 1805598 (2019). https://doi.org/10.1002/ adma.201805598

82. A. Gopalakrishnan, S. Badhulika, Effect of self-doped heteroatoms on the performance of biomass-derived carbon for supercapacitor applications. J. Power Sources 480, 228830 (2020). https://doi.org/10.1016/j.jpowsour.2020.228830

83. X. Wang, C. Yang, J. Li, X.A. Chen, K. Yang et al., Insights of heteroatoms doping-enhanced bifunctionalities on carbon based energy storage and conversion. Adv. Funct. Mater. 31(11), 2009109 (2020). https://doi.org/10.1002/adfm.20200 9109

84. K. Xiao, L.-X. Ding, G. Liu, H. Chen, S. Wang et al., Freestanding, hydrophilic nitrogen-doped carbon foams for highly compressible all solid-state supercapacitors. Adv. Mater. 28(28), 5997 (2016). https://doi.org/10.1002/adma.20160 1125

85. D.P. Dubal, S. Abdel-Azeim, N.R. Chodankar, Y.-K. Han, Molybdenum nitride nanocrystals anchored on phosphorusincorporated carbon fabric as a negative electrode for highperformance asymmetric pseudocapacitor. Iscience 16, 50 (2019). https://doi.org/10.1016/j.isci.2019.05.018

86. M. Yang, Y. Zhong, X. Zhou, J. Ren, L. Su et al., Ultrasmall $\mathrm{MnO} @ \mathrm{~N}$-rich carbon nanosheets for high-power asymmetric supercapacitors. J. Mater. Chem. A 2(31), 12519-12525 (2014). https://doi.org/10.1039/c4ta02055c

87. C. Miao, X. Xiao, Y. Gong, K. Zhu, K. Cheng et al., Facile synthesis of metal-organic framework-derived $\mathrm{CoSe}_{2}$ nanoparticles embedded in the $\mathrm{N}$-doped carbon nanosheet array and application for supercapacitors. ACS Appl. Mater. 
Interfaces 12(8), 9365-9375 (2020). https://doi.org/10.1021/ acsami.9b22606

88. H.M. Jeong, J.W. Lee, W.H. Shin, Y.J. Choi, H.J. Shin et al., Nitrogen-doped graphene for high-performance ultracapacitors and the importance of nitrogen-doped sites at basal planes. Nano Lett. 11(6), 2472-2477 (2011). https://doi.org/ $10.1021 / \mathrm{nl} 2009058$

89. Y. Wen, B. Wang, C. Huang, L. Wang, D. Hulicova-Jurcakova, Synthesis of phosphorus-doped graphene and its wide potential window in aqueous supercapacitors. Chem. Eur. J. 21(1), 80-85 (2015). https://doi.org/10.1002/chem.20140 4779

90. J. Zhang, S. Ali, F. Liu, A. Ali, K. Wang et al., Phosphorus-doped carbon composites with rich graphene derived from phenol resin as supercapacitor electrode materials with high window potential and energy density. J. Electron. Mater. 48(7), 4196-4206 (2019). https://doi.org/10.1007/ s11664-019-07188-5

91. J. Li, W. Liu, D. Xiao, X. Wang, Oxygen-rich hierarchical porous carbon made from pomelo peel fiber as electrode material for supercapacitor. Appl. Surface Sci. 416, 918-924 (2017). https://doi.org/10.1016/j.apsusc.2017.04.162

92. M. Krishnamoorthy, N. Jha, Oxygen-rich hierarchical porous graphene as an excellent electrode for supercapacitors, aqueous Al-ion battery, and capacitive deionization. ACS Sustain. Chem. Eng. 7(9), 8475-8489 (2019). https://doi.org/10.1021/ acssuschemeng.9b00233

93. S. Ghosh, S. Barg, S.M. Jeong, K. Ostrikov, Heteroatomdoped and oxygen-functionalized nanocarbons for highperformance supercapacitors. Adv. Energy Mater. 10(32), 2001239 (2020). https://doi.org/10.1002/aenm.202001239

94. Z. Liu, S. Zhang, L. Wang, T. Wei, Z. Qiu et al., High-efficiency utilization of carbon materials for supercapacitors. Nano Select. 1(2), 244-262 (2020). https://doi.org/10.1002/ nano. 202000011

95. S. Zhao, W. Xu, Z. Yang, X. Zhang, Q. Zhang, One-pot hydrothermal synthesis of nitrogen and phosphorus co-doped graphene decorated with flower-like molybdenum sulfide for enhanced supercapacitor performance. Electrochim. Acta 331, 135265 (2020). https://doi.org/10.1016/j.electacta.2019. 135265

96. L. Zheng, L. Guan, J. Song, H. Zheng, Rational design of a sandwiched structure $\mathrm{Ni}(\mathrm{OH})(2)$ nanohybrid sustained by amino-functionalized graphene quantum dots for outstanding capacitance. Appl. Surface Sci. 480, 727-737 (2019). https:// doi.org/10.1016/j.apsusc.2019.02.243

97. L.-L. Jiang, X. Lu, C.-M. Xie, G.-J. Wan, H.-P. Zhang et al., Flexible, free-standing $\mathrm{TiO}_{2}$-graphene-polypyrrole composite films as electrodes for supercapacitors. J. Phys. Chem. C 119(8), 3903-3910 (2015). https://doi.org/10.1021/jp511 $022 \mathrm{z}$

98. A. Ehsani, A.A. Heidari, H.M. Shiri, Electrochemical pseudocapacitors based on ternary nanocomposite of conductive polymer/graphene/metal oxide: an introduction and review to it in recent studies. Chem. Record 19(5), 908-926 (2019). https://doi.org/10.1002/tcr.201800112
99. Z. Xu, Z. Zhang, H. Yin, S. Hou, H. Lin et al., Investigation on the role of different conductive polymers in supercapacitors based on a zinc sulfide/reduced graphene oxide/conductive polymer ternary composite electrode. RSC Adv. 10(6), 3122-3129 (2020). https://doi.org/10.1039/c9ra07842h

100. H. Lin, Q. Huang, J. Wang, J. Jiang, F. Liu et al., Self-assembled graphene/polyaniline/ $\mathrm{Co}_{3} \mathrm{O}_{4}$ ternary hybrid aerogels for supercapacitors. Electrochim. Acta 191, 444-451 (2016). https://doi.org/10.1016/j.electacta.2015.12.143

101. S.M. Zhu, H.A. Zhou, M. Hibino, I. Honma, M. Ichihara, Synthesis of $\mathrm{MnO}_{2}$ nanoparticles confined in ordered mesoporous carbon using a sonochemical method. Adv. Funct. Mater. 15(3), 381-386 (2005). https://doi.org/10.1002/ adfm.200400222

102. X. Cao, B. Zheng, W. Shi, J. Yang, Z. Fan et al., Reduced graphene oxide-wrapped $\mathrm{MoO}_{3}$ composites prepared by using metal-organic frameworks as precursor for all-solid-state flexible supercapacitors. Adv. Mater. 27(32), 4695-4701 (2015). https://doi.org/10.1002/adma.201501310

103. J. Yang, X. Xu, X. Zhou, S. Jiang, W. Chen et al., Ultrasmall $\mathrm{Co}_{3} \mathrm{O}_{4}$ nanoparticles confined in $\mathrm{P}, \mathrm{N}$-doped carbon matrices for high-performance supercapacitors. J. Phys. Chem. C 124(17), 9225-9232 (2020). https://doi.org/10.1021/acs.jpcc. 0c01539

104. X. Lu, T. Liu, T. Zhai, G. Wang, M. Yu et al., Improving the cycling stability of metal-nitride supercapacitor electrodes with a thin carbon shell. Adv. Energy Mater. 4(4), 1300994 (2014). https://doi.org/10.1002/aenm.201300994

105. S. Zhang, J. Wu, J. Wang, W. Qiao, D. Long et al., Constructing t- $\mathrm{Nb}_{2} \mathrm{O}_{5} @$ carbon hollow core-shell nanostructures for high-rate hybrid supercapacitor. J. Power Sources 396, 88-94 (2018). https://doi.org/10.1016/j.jpowsour.2018.06. 007

106. M. Pan, W. Zeng, H. Quan, J. Cui, Y. Guo et al., Low-crystalline Ni/Co-oxyhydroxides nanoarrays on carbon cloth with high mass loading and hierarchical structure as cathode for supercapacitors. Electrochim. Acta 357, 136886 (2020). https://doi.org/10.1016/j.electacta.2020.136886

107. J. Theerthagiri, R.A. Senthil, P. Nithyadharseni, S.J. Lee, G. Durai et al., Recent progress and emerging challenges of transition metal sulfides based composite electrodes for electrochemical supercapacitive energy storage. Ceram. Int. 46(10), 14317-14345 (2020). https://doi.org/10.1016/j.ceram int.2020.02.270

108. M. Sun, B. Lan, L. Yu, F. Ye, W. Song et al., Manganese oxides with different crystalline structures: Facile hydrothermal synthesis and catalytic activities. Mater. Lett. 86, 18-20 (2012). https://doi.org/10.1016/j.matlet.2012.07.011

109. X. Ma, P. Zhang, Y. Zhao, Y. Liu, J. Li et al., Role of n doping on the electrochemical performances of $\mathrm{ZnCo}_{2} \mathrm{O}_{4}$ quantum dots/reduced graphene oxide composite nanosheets. Chem. Eng. J. 327, 1000-1010 (2017). https://doi.org/10.1016/j.cej. 2017.06.084

110. I. Shakir, A. Rasheed, S. Haider, M.F.A. Aboud, The impact of $\mathrm{Cu}^{2+}$ and $\mathrm{Mg}^{2+}$ onto the electrochemical energy storage properties of nanocrystalline $\mathrm{Co}_{0.8} \mathrm{Ni}_{0.2} \mathrm{Fe}_{2} \mathrm{O}_{4}$ particles and 
their hybrids with graphene. Ceram. Int. 45(14), 1809918105 (2019). https://doi.org/10.1016/j.ceramint.2019.05.066

111. D. Majumdar, Review on current progress of $\mathrm{MnO}_{2}$-based ternary nanocomposites for supercapacitor applications. ChemElectroChem 8(2), 291-336 (2020). https://doi.org/ 10.1002/celc. 202001371

112. J.H. Zhong, A.L. Wang, G.R. Li, J.W. Wang, Y.N. Ou et al., $\mathrm{Co}_{3} \mathrm{O}_{4} / \mathrm{Ni}(\mathrm{OH})(2)$ composite mesoporous nanosheet networks as a promising electrode for supercapacitor applications. J. Mater. Chem. 22(12), 5656-5665 (2012). https://doi.org/10. 1039/c2jm15863a

113. C. Xu, Z. Li, C. Yang, P. Zou, B. Xie et al., An ultralong, highly oriented nickel-nanowire-array electrode scaffold for high-performance compressible pseudocapacitors. Adv. Mater. 28(21), 4105-4110 (2016). https://doi.org/10.1002/ adma.201505644

114. X. Zang, C. Shen, E. Kao, R. Warren, R. Zhang et al., Titanium disulfide coated carbon nanotube hybrid electrodes enable high energy density symmetric pseudocapacitors. Adv. Mater. 30(5), 1704754 (2018). https://doi.org/10.1002/adma. 201704754

115. C. Wang, L. Zhang, M. Li, J. Zhang, Y. Chen et al., Subnanometer, ultrafine alpha- $\mathrm{Fe}_{2} \mathrm{O}_{3}$ sheets realized by controlled crystallization kinetics for stable, high-performance energy storage. Chem. Eur. J. 25(19), 5005-5013 (2019). https://doi.org/10.1002/chem.201805593

116. W. Liu, H. Niu, J. Yang, K. Cheng, K. Ye et al., Ternary transition metal sulfides embedded in graphene nanosheets as both the anode and cathode for high-performance asymmetric supercapacitors. Chem. Mater. 30(3), 1055-1068 (2018). https://doi.org/10.1021/acs.chemmater.7b04976

117. S. Wang, Z. Xiao, S. Zhai, H. Wang, W. Cai et al., Construction of strawberry-like $\mathrm{Ni}_{3} \mathrm{~S}_{2} @ \mathrm{Co}_{9} \mathrm{~S}_{8}$ heteronanoparticle-embedded biomass-derived $3 \mathrm{~d}$ n-doped hierarchical porous carbon for ultrahigh energy density supercapacitors. J. Mater. Chem. A 7(29), 17345-17356 (2019). https://doi. org/10.1039/c9ta05145g

118. Y. Yang, Y. Zheng, W. Cao, A. Titov, J. Hyvonen et al., High-efficiency light-emitting devices based on quantum dots with tailored nanostructures. Nat. Photonics 9(4), 259-266 (2015). https://doi.org/10.1038/nphoton.2015.36

119. T. Shen, J. Yuan, X. Zhong, J. Tian, Dip-coated colloidal quantum-dot films for high-performance broadband photodetectors. J. Mater. Chem. C 7(21), 6266-6272 (2019). https://doi.org/10.1039/c9tc00079h

120. H. Moon, C. Lee, W. Lee, J. Kim, H. Chae, Stability of quantum dots, quantum dot films, and quantum dot light-emitting diodes for display applications. Adv. Mater. 31(34), 1804294 (2019). https://doi.org/10.1002/adma.201804294

121. J. Zhou, Y. Yang, C.-Y. Zhang, Toward biocompatible semiconductor quantum dots: from biosynthesis and bioconjugation to biomedical application. Chem. Rev. 115(21), 1166911717 (2015). https://doi.org/10.1021/acs.chemrev.5b00049

122. P. Wu, Y. Xu, J. Zhan, Y. Li, H. Xue et al., The research development of quantum dots in electrochemical energy storage. Small 14(42), 1801479 (2018). https://doi.org/10. 1002/smll.201801479

123. S. Liu, J. Zhou, Z. Cai, G. Fang, Y. Cai et al., $\mathrm{Nb}_{2} \mathrm{O}_{5}$ quantum dots embedded in mof derived nitrogen-doped porous carbon for advanced hybrid supercapacitor applications. J. Mater. Chem. A 4(45), 17838-17847 (2016). https://doi.org/ $10.1039 / \mathrm{c} 6 \mathrm{ta} 07856 \mathrm{~g}$

124. E. Pomerantseva, F. Bonaccorso, X. Feng, Y. Cui, Y. Gogotsi, Energy storage: The future enabled by nanomaterials. Science 366(6468), 969 (2019). https://doi.org/10.1126/science.aan82 85

125. S. Liu, Y. Yin, D. Ni, K.S. Hui, M. Ma et al., New insight into the effect of fluorine doping and oxygen vacancies on electrochemical performance of $\mathrm{Co}_{2} \mathrm{MnO}_{4}$ for flexible quasi-solidstate asymmetric supercapacitors. Energy Storage Mater. 22, 384-396 (2019). https://doi.org/10.1016/j.ensm.2019.02.014

126. Q. Chen, J. Jin, Z. Kou, J. Jiang, Y. Fu et al., Cobalt-doping in hierarchical $\mathrm{Ni}(3) \mathrm{S}(2)$ nanorod arrays enables high areal capacitance. J. Mater. Chem. A 8(26), 13114-13120 (2020). https://doi.org/10.1039/d0ta04483k

127. J. Zhang, Y. Wang, H.-J. Liao, T.-Y. Yang, Z. Chen et al., Hierarchical mn-doped $\mathrm{Fe}_{2} \mathrm{O}_{3} @$ RGO hollow core-shell spheres for high-performance hybrid capacitor. Mater. Today Energy 17, 100388 (2020). https://doi.org/10.1016/j.mtener. 2020.100388

128. S. Pang, L. Gong, N. Du, H. Luo, K. Yu et al., Formation of high-performance Cu-WOx@C tribasic composite electrode for aqueous symmetric supercapacitor. Mater. Today Energy 13, 239-248 (2019). https://doi.org/10.1016/j. mtener.2019.05.016

129. W. Liu, Z. Zhang, Y. Zhang, Y. Zheng, N. Liu et al., Interior and exterior decoration of transition metal oxide through $\mathrm{Cu}^{0} / \mathrm{Cu}^{+} \mathrm{Co}$-doping strategy for high-performance supercapacitor. Nano-Micro Lett. 13, 61 (2021). https://doi.org/ 10.1007/s40820-021-00590-x

130. B. Zhao, L. Zhang, Q. Zhang, D. Chen, Y. Cheng et al., Rational design of nickel hydroxide-based nanocrystals on graphene for ultrafast energy storage. Adv. Energy Mater. 8(9), 1702247 (2018). https://doi.org/10.1002/aenm.20170 2247

131. A.M. Mohamed, A.O.A. El Naga, T. Zaki, H.B. Hassan, N.K. Allam, Bimetallic co-w-s chalcogenides confined in $\mathrm{n}, \mathrm{s}$-codoped porous carbon matrix derived from metalorganic frameworks for highly stable electrochemical supercapacitors. ACS Appl. Energy Mater. 3(8), 8064-8074 (2020). https://doi.org/10.1021/acsaem.0c01513

132. M. Yu, Z. Wang, C. Hou, Z. Wang, C. Liang et al., Nitrogen-doped $\mathrm{Co}_{3} \mathrm{O}_{4}$ mesoporous nanowire arrays as an additive-free air-cathode for flexible solid-state zinc-air batteries. Adv. Mater. 29(15), 1602868 (2017). https://doi.org/ 10.1002/adma.201602868

133. S. Liu, D. Gao, J. Li, K. San Hui, Y. Yin et al., Phosphorus dual-site driven $\mathrm{Cos}_{2} @ \mathrm{~S}, \mathrm{~N}$ co-doped porous carbon nanosheets for flexible quasi-solid-state supercapacitors. J. Mater. Chem. A 7(46), 26618-26630 (2019). https://doi. org/10.1039/c9ta09646a 
134. Z. Hu, Z. Wu, C. Han, J. He, Z. Ni et al., Two-dimensional transition metal dichalcogenides: Interface and defect engineering. Chem. Soc. Rev. 47(9), 3100-3128 (2018). https:// doi.org/10.1039/c8cs00024g

135. X. Zhang, X. Liu, Y. Zeng, Y. Tong, X. Lu, Oxygen defects in promoting the electrochemical performance of metal oxides for supercapacitors: Recent advances and challenges. Small Methods 4(6), 1900823 (2020). https://doi. org/10.1002/smtd.201900823

136. D. Yao, F. Wang, W. Lei, Y. Hua, X. Xia et al., Oxygen vacancies boosting ultra-stability of mesoporous $\mathrm{ZnO}$ $\mathrm{CoO} @$ n-doped carbon microspheres for asymmetric supercapacitors. Sci. China Mater. 63(10), 2013-2027 (2020). https://doi.org/10.1007/s40843-020-1357-9

137. L. Su, S. Lei, L. Liu, L. Liu, Y. Zhang et al., Sprinkling $\mathrm{MnFe}_{2} \mathrm{O}_{4}$ quantum dots on nitrogen-doped graphene sheets: The formation mechanism and application for high-performance supercapacitor electrodes. J. Mater. Chem. A 6(21), 9997-10007 (2018). https://doi.org/10.1039/c8ta02982b

138. H. Zeng, M.H. Oubla, X. Zhong, N. Alonso-Vante, F. Du et al., Rational defect and anion chemistries in $\mathrm{Co}_{3} \mathrm{O}_{4}$ for enhanced oxygen evolution reaction. Appl. Catal. B-Environ. 281, 119535 (2021). https://doi.org/10.1016/j.apcatb. 2020.119535

139. C. Ren, X. Jia, W. Zhang, D. Hou, Z. Xia et al., Hierarchical porous integrated $\mathrm{Co}_{1-\mathrm{x}} \mathrm{S} / \mathrm{CoFe}_{2} \mathrm{O}_{4} @ \mathrm{RGO}$ nanoflowers fabricated via temperature-controlled in situ calcining sulfurization of multivariate CoFe-MOF-74@RGO for highperformance supercapacitor. Adv. Funct. Mater. 30(45), 2004519 (2020). https://doi.org/10.1002/adfm.202004519

140. H.-S. Kim, J.B. Cook, H. Lin, J.S. Ko, S.H. Tolbert et al., Oxygen vacancies enhance pseudocapacitive charge storage properties of $\mathrm{MoO}_{3-\mathrm{x}}$. Nat. Mater. 16(4), 454 (2017). https:// doi.org/10.1038/nmat4810

141. J. Yang, X. Xiao, P. Chen, K. Zhu, K. Cheng et al., Creating oxygen-vacancies in $\mathrm{MoO}_{3-\mathrm{x}}$ nanobelts toward high volumetric energy-density asymmetric supercapacitors with long lifespan. Nano Energy 58, 455-465 (2019). https://doi.org/ 10.1016/j.nanoen.2019.01.071

142. S. Yang, Y. Liu, Y. Hao, X. Yang, W.A. Goddard et al., Oxygen-vacancy abundant ultrafine $\mathrm{Co}_{3} \mathrm{O}_{4}$ /graphene composites for high-rate supercapacitor electrodes. Adv. Sci. 5(4), 1700659 (2018). https://doi.org/10.1002/advs.201700659

143. Q.-L. Wu, S.-X. Zhao, L. Yu, X.-X. Zheng, Y.-F. Wang et al., Oxygen vacancy-enriched $\mathrm{MoO}_{3-\mathrm{x}}$ nanobelts for asymmetric supercapacitors with excellent room/low temperature performance. J. Mater. Chem. A 7(21), 13205-13214 (2019). https://doi.org/10.1039/c9ta03471d

144. X. Zheng, G. Wang, F. Huang, H. Liu, C. Gong et al., Liquid phase exfoliated hexagonal boron nitride/graphene heterostructure based electrode toward asymmetric supercapacitor application. Front. Chem. 7, 00544 (2019). https://doi.org/10. 3389/fchem.2019.00544

145. Z. Gao, C. Chen, J. Chang, L. Chen, P. Wang et al., Porous $\mathrm{Co}_{3} \mathrm{~S}_{4} @ \mathrm{Ni}_{3} \mathrm{~S}_{4}$ heterostructure arrays electrode with vertical electrons and ions channels for efficient hybrid supercapacitor. Chem. Eng. J. 343, 572-582 (2018). https://doi.org/10. 1016/j.cej.2018.03.042

146. S. Saha, P. Samanta, N.C. Murmu, T. Kuila, A review on the heterostructure nanomaterials for supercapacitor application. J. Energy Storage 17, 181-202 (2018). https://doi.org/ 10.1016/j.est.2018.03.006

147. J.-C. Liu, Z.-H. Huang, T.-Y. Ma, Aqueous supercapacitor with ultrahigh voltage window beyond 2.0 volt. Small Struct. 1(1), 2000020 (2020). https://doi.org/10.1002/sstr.202000020

148. L. Wan, C. He, D. Chen, J. Liu, Y. Zhang et al., In situ grown

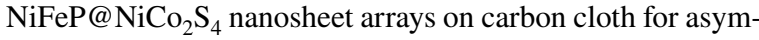
metric supercapacitors. Chem. Eng. J. 399, 125778 (2020). https://doi.org/10.1016/j.cej.2020.125778

149. Y. Yan, A. Li, C. Lu, T. Zhai, S. Lu et al., Double-layered yolk-shell microspheres with $\mathrm{NiCo}_{2} \mathrm{~S}_{4}-\mathrm{Ni}_{9} \mathrm{~S}_{8}$-C hetero-interfaces as advanced battery-type electrode for hybrid supercapacitors. Chem. Eng. J. 396, 125316 (2020). https://doi.org/ 10.1016/j.cej.2020.125316

150. T. Dang, D. Wei, G. Zhang, L. Wang, Q. Li et al., Homologous NiCoP/CoP hetero-nanosheets supported on $\mathrm{N}$-doped carbon nanotubes for high-rate hybrid supercapacitors. Electrochim. Acta 341, 135988 (2020). https://doi.org/10.1016/j. electacta.2020.135988 